\title{
LOW-COST IGNITION DEMONSTRATION REACTOR (IDR) SCOPING STUDY
}

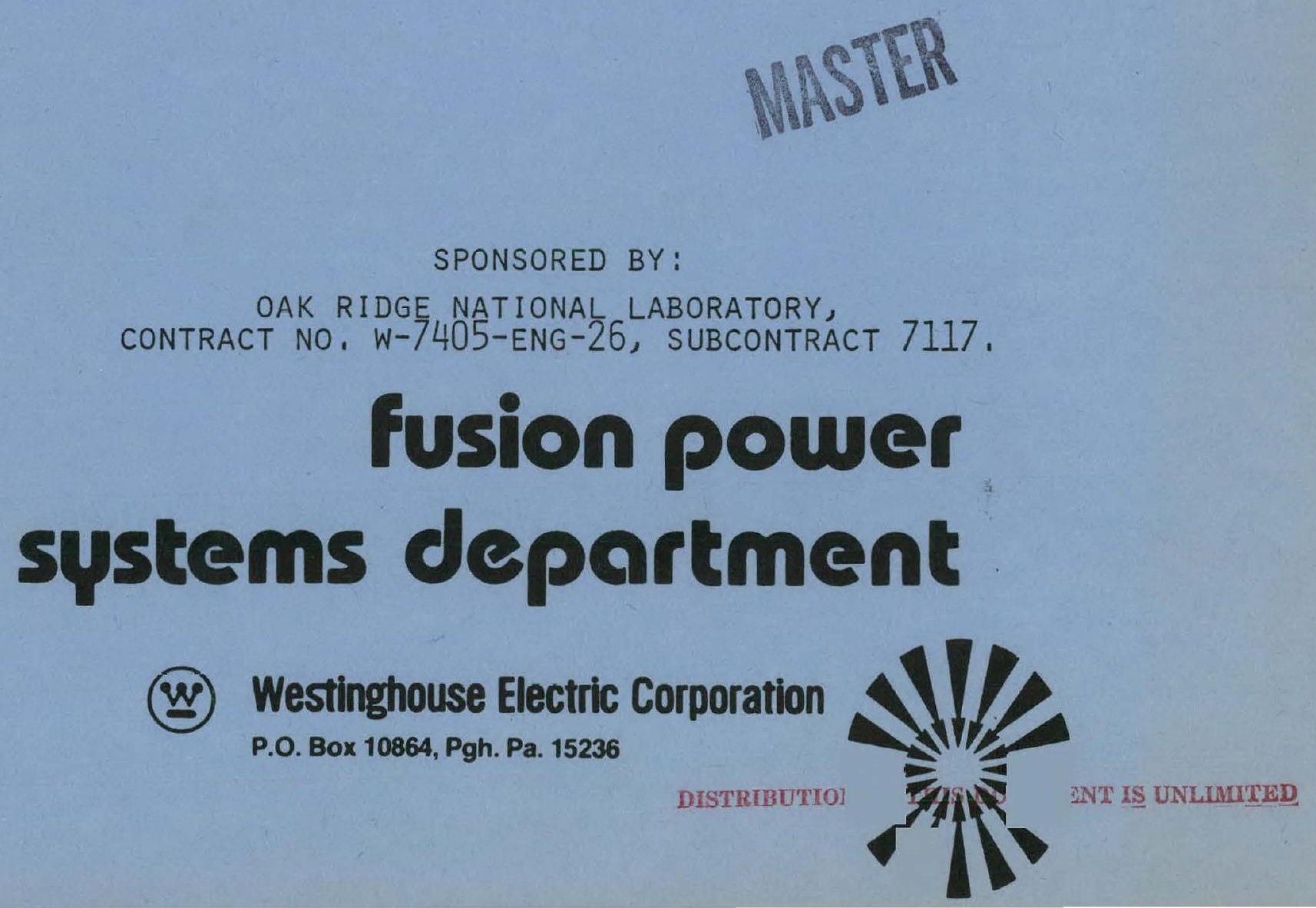




\section{DISCLAIMER}

This report was prepared as an account of work sponsored by an agency of the United States Government. Neither the United States Government nor any agency Thereof, nor any of their employees, makes any warranty, express or implied, or assumes any legal liability or responsibility for the accuracy, completeness, or usefulness of any information, apparatus, product, or process disclosed, or represents that its use would not infringe privately owned rights. Reference herein to any specific commercial product, process, or service by trade name, trademark, manufacturer, or otherwise does not necessarily constitute or imply its endorsement, recommendation, or favoring by the United States Government or any agency thereof. The views and opinions of authors expressed herein do not necessarily state or reflect those of the United States Government or any agency thereof. 


\section{DISCLAIMER}

Portions of this document may be illegible in electronic image products. Images are produced from the best available original document. 
DATE: SEPT, 30, 1977

H. R. HOWLAND

J. H. SCHULTZ

T. C. Varluen

F. H. HECK

A. Y, LEE

R. A. SMITH

\section{SPONSORED BY: \\ OAK RIDGE NATIONAL LABORATORY, CONTRACT NO. W-7405-ENG-26, SUBCONTRACT 7117. \\ fusion power \\ systems department}

(vi) Westinghouse Electric Corporation P.O. Box 10864, Pgh. Pa. 15236

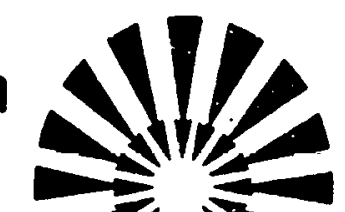


WFPS-TME- 081

SEPT, 30, 1977

\section{LOW-COST IGNITION DEMONSTRATION REACTOR (IDR) SCOPING STUDY}

PRepared by: 14, R, Howland

$H, \mathrm{R}$, HOWLAND

REVIEWED BY: OM Heck

F. M. HECK, MANAGER

ELECTRICAL SYSTEMS ENGINEERING
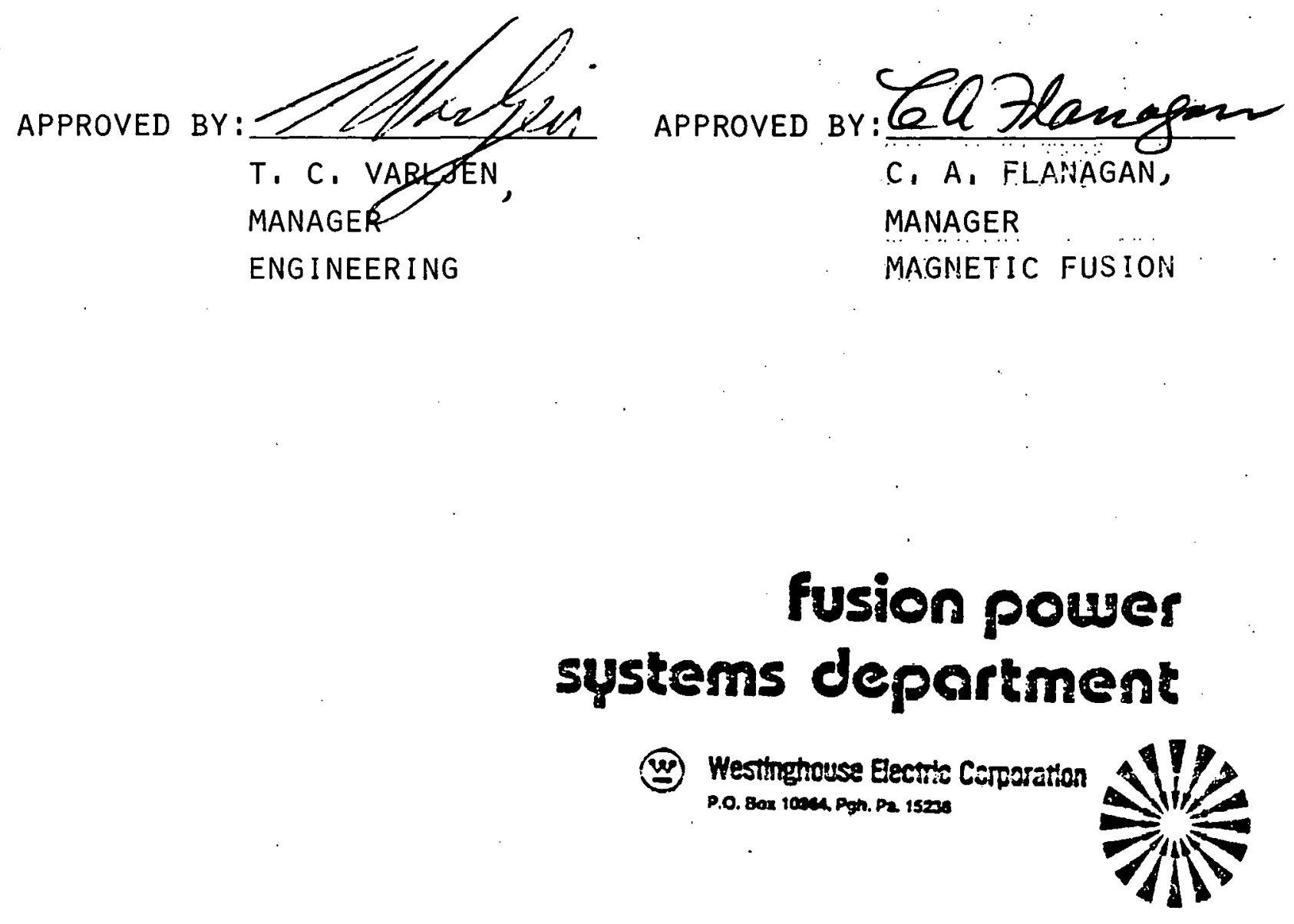


\section{ACKNOWLEDGEMENT}

This work was performed for the Oak Ridge National Laboratory Fusion Energy Division, under U.S. Energy Research and Development Administration Contract W-7405-ENG-26, Subcontract 7117. Reproduction, translation, publication, use and disposal, in whole or in part, by or for the United States Government is permitted.

\section{LEGAL NOTICE}

This report was prepared as an account of Government sponsored work. Neither the United States, nor the Administration, nor any person acting on behalf of the Administration:

A. Makes any warranty or representation, expressed or implied, with respect to the accuracy, completeness, or usefulness of the information contained in this report, or that the use of any information, apparatus, method or process disclosed in this report may not infringe privately owned rights; or

B. Assumes any liabilities with respect to the use of, or for damages resulting from the use of any information, apparatus, method, or process disclosed in this report.

This decument copy, since it is transmitted in made avdiable in confidence solely for tracts whth the United States Energy Reseanch and Development Administration. This document is not to be published nor its contents otherwise documented or used for puxposes than that specified, before patent approval for such release or us\& has been secured. 
TABLE OF CONTENTS

PAGE NO.

1.0 INTRODUCTION AND SUMMARY

$1-1$

2.0 DESIGN OPTIONS FOR AN IGNITION DEMONSTRATION REACTOR

2-1

3.0 SELECTION OF REFERENCE PLASMA PARAMETERS

3.1 INTRODUCTION

3.2 SCOPING RANGES FOR PLASMA PARAMETERS

3.3 SELECTION OF REFERENCE PLASMA PARAMETERS

3-3

3.4 IDR OPERATING SCENARIO

$3-6$

4.0 IDR SYSTEM DESIGN CONCEPTS

5.0 BALANCE OF SYSTEMS DEFINITION AND COST ESTIMATES

APPENDIX A - COOLING DESIGN CONSIDERATIONS

$A A-1$

A.1 COOLING REGIME AND BASIC DATA

$A A-3$

A.2 PULSED HEATING AND COOLDOWN ANALYSIS

$A A-9$

A.3 STEADY STATE TF COIL OPERATION

APPENDIX B - POWER SUPPLY DESIGN CONSIDERATIONS

$A B-1$

APPENDIX C - TF COIL DESIGN AND SUPPORT STRUCTURE CONSIDERATIONS

$A C-1$

6.0 REFERENCES

$6-1$ 
2-1 Ignition Demonstration Reactor Concept IDR I

2-2 Ignition Demonstration Reactor Concept. IDR II

2-3 Ignition Demonstration Reactor Concept IDR III

4-1 Conceptual Arrangement of IDR III Components 4-5

4-2 Plan View of the IDR III Concept 4-6

4-3 Conceptual Arrangement of IDR II Components 4-7

A-1 Pool Boiling Heat Transfer Data for $L_{2} \quad A A-4$

A-2 Resistivity of Copper and Aluminum as a Function of Temperature

A-3 Specific Heat of Copper and Aluminum as a Function of Temperature

A-4 Thermal Conductivity of Copper and Aluminum as a Function of Temperature

A-5 Cooldown of Copper Plate Edge Cooled by $\mathrm{LN}_{2}$ AA-13

A-6 Wall and Bath Temperature Difference During Cooldown of Copper Plate

A-7 Idealized Current Waveform in TF Coil AA-16

A-8 Temperature vs. $J^{2} t$ of Copper at $B=0$ and $B=10 \mathrm{~T}$

$A A-18$

A-9 Coolant Flow and Channel Orientation for Steady State Operation

A-10 Reference Coolant Channel Geometry AA-32

B-1 Poloidal Field Coil Circuit Concepts AB-3

B-2 TF Coil Direct Drive Circuit AB-3 


\section{LIST OF FIGURES (CONTINUED)}

FIGURE

C-1 Doublet III Finger Joint Configuration

C-2 Joint Concept with Laminar TF Coil Plate Construction

C-3 Alternate Finger Joint Concept with Laminar TF Coil Plate Construction

TF Coil Joint Concept with Removable Keys

TF Coil Joint Concept with Alternating Key Location
PAGE NO.

$A C-1$

$A C-2$

$A C-3$

AC -4

AC -5 
2-1 IDR DESIGN CONSIDERATIONS

3-3 INITIAL IDR OPERATING SCENARIO

4-1 PARAMETER SUMMARY FOR THE IDR III CONCEPT

5- 7 COMPARISON OF THE KEY FEATURES OF TFTR, IDR II, IDR III, AND TNS-1

5-2 COMPARISON OF COST ESTIMATES FOR TFTR, IDR II, IDR III, AND TNS-1

A-1 PARAMETER SUMMARY FOR PULSED HEATING AND COOLDOWN

A-2 PEAK RESISTIVE AND CHARGING POWERS FOR MATERIAL LIMITED FINAL TEMPERATURE, $B=0 \mathrm{~T}$

A-3 PEAK RESISTIVE AND CHARGING POWERS FOR MATERIAL LIMITED FINAL TEMPERATURE, $B=10 \mathrm{~T}$

A-4 POWER SUPPLY REQUIREMENTS WITH FINAL HOT-SPOT TEMPERATURE OF $150 \mathrm{~K}, \mathrm{~B}=10 \mathrm{~T}$

AA-25

A-5 PARAMETER SUMMARY FOR STEADY-STATE TF COIL OPERAIION

AA-29

A-6 REFERENCE CONFIGURATIONAL PARAMETERS FOR THERMAL HYDRAULIC DESIGN

A-7 REFERENCE CONSTANTS AND CONVERSION FACTORS FOR THERMAL HYDRAULIC DESIGN

A-8 CHANNEL GEOMETRY PARAMETERS

A-9 PARAMETERS FOR SINGLE PHASE COOLING

A-10 TF COIL SET POWER SUPPLY REQUIREMENTS WITH STEADY STA 


\subsection{INTRODUCTION AND SUMMARY}

An ORNL/Westinghouse design team has been studying alternative design strategies for a near-term tokamak ignition device to follow TFTR, which has been designated in this work as The Next Step (TNS). The impetus for this effort stemmed from the judgment that it would not be practical or prudent to proceed directly from the first sub-ignition D-T burning system (TFTR) to a full-fledged Experimental Power Reactor (EPR) without an intermediate step or steps.

The most desirable version of TNS, as envisioned by the design team, would address the most critical physics and engineering questions associated with the EPR, without the requirement for high duty cycle operation, tritium breeding or electrical power generation. Specific objectives for TNS which were formulated include:

- Achieve ignition and demonstrate burning dynamics.

- Provide for potential design solutions for long pulse operation.

- Extrapolate to a viable power reactor.

- Be available in the mid-1980's.

- Be a technology forcing function.

For the most part these objectives and the design criteria which have been derived from them emphasize reactor technology as well as the achievement of ignition. A series of parametric trade studies ${ }^{1}$ was performed to evaluate consistently the relative costs and performance parameters of D-T burning tokamaks over a range of plasma sizes and toroidal field coil technologies. Four different types of TF coil technology were investigated: water-cooled copper coils, superconducting $\mathrm{NbTi}$ and $\mathrm{Nb}_{3} \mathrm{Sn}$ coils, and a "hybrid" coil arrangement consisting of a normal conducting copper coil nested within a superconducting NbTi coil. 
Point designs ${ }^{3}$ resulting from the trade studies resulted in devices with major plasma radii in the range $4.0-5.7 \mathrm{~m}$, minor radi $i$ in the range $1.0-1.2 \mathrm{~m}$ and building and equipment costs in the range 290-440 M\$. A decision modeling. process $^{4}$ showed that the selection of a TF coil technology type depends heavily on the relative importance given reactor technology compared to that given near-term engineering achievability. Systems employing moderately high field $\mathrm{Nb}_{3} \mathrm{Sn}$ TF coils are preferred when reactor technology is emphasized. On the other hand, if an early demonstration of ignition is desired, with an emphasis on margin for achievability, the selection of water-cooled copper TF coils is indicated.

An alternative mission for TNS is the earliest possible, and least costly, demonstration of ignition. This approach would provide a relatively near-term stimulus for the program and provide confidence for the planning and implementation of future large scale ignition devices. On the other hand, if now unknown physics problems were to be encountered and identified, the approach would permit early redirection prior to the commitment of a large scale system. A recognized difficulty with this early emphasis on ignition is that many of the long range technology R\&D programs will lose their focus and one or more additional devices may be required in the TNS-EPR-DEMO sequence.

The work described in this document was undertaken to examine the implications of the alternative ignition-oriented TNS mission and complements the main-line TNS trade studies. Prior work shows that much of the expense, direct and indirect, and lead time of tokamaks considered in the trade studies results from satisfying objectives related to power reactor technology. As a consequence, the following set of less ambitious objectives was formulated for this alternative ignitionoriented TNS:

- Achieve ignition

- Be available as early as possible

- Minimum total cost

The device which satisfies these objectives is called an Ignition Demonstration Reactior (IDR) in this evaluation. 
The approach taken in the evaluation was to consider a limited number of specific point designs and to determine their cost using the same basic costing metholology applied to the main-line TNS study.

Two tokamaks, which differ in certain configurational details have been evaluated. Their building and equipment costs fall in the range 130-145 M\$. A free-standing facility has been assumed; that is, no credit has been assumed for existing site development or facilities. Copper toroidal field coils are assumed. In order to minimize machine size and reduce the cost of power supplies, the TF coils are cooled by cryogenic liquid nitrogen. The burn time is sufficient to demonstrate ignition, but does not require agressive impurity control. Capital equipment cost has been reduced by omitting on-site processing of tritium and liquid nitrogen. These simplifications lead to major capital cost reductions relative to the more ambitious TNS designs and enhance the engineering achievability of the device. At the same time the plasma parameters have been specified conservatively to ensure that ignition is achieved. The following paragraphs describe the highlights of the conceptual approach.

The two tokamaks examined differ in the plasma elongation and associated consequences. One plasma is circular; the configuration has the poloidal field coils outside the TF coils. The other plasma is elongated moderately to $\delta=1.3$; the poloidal field coils are within the TF coils for this system. This relatively moderate value of elongation has been chosen in order to hold down the cost of the poloidal field power supplies. The elongated plasma has higher density, lower temperature for ignition, longer confinement time, and lower neutral beam power requirements than the circular plasma.

The dominant transport loss mechanisms are assumed to be empirical (electrons) and neoclassical (ions), at moderate collisionalities. Ignition criteria are met both for these assumed mechanisms and for the more pessimistic trapped particle mode scaling on the basis of flat density and temperature profiles. With plasma current $\geqslant 4 M A$, alpha confinement is expected to be good. Toroidal field ripple has been held to $\leqslant 1 \%$ peak-to-average to avoid excessive alpha loss in ripple wells. 
The neutral beam particle energy specified ( $\leq 150 \mathrm{keV})$ is near the state-of-the-art to be demonstrated on TFTR. In addition, reduced density startup, heating during particle buildup, and profile effects are assumed. The neutral beam power required has been estimated conservatively as $40-60 \mathrm{MW}$.

The TF coils are discrete coil units of washer-type construction, with alternating plates of copper, stainless steel and insulator. The Lorentz forces are shared between the hardened copper and stainless steel. The peak stress in the copper is $30 \mathrm{kpsi}$, in the stainless steel, $50 \mathrm{kpsi}$. In order to avoid annealing the hardened copper, the peak temperature allowed in the copper is $300 \mathrm{~K}$. The centering forces are absorbed by wedging of the TF coil noses. In the case of the configuration with the PF coils inside the TF coils, the design concept includes two joints in each TF coil. for access to the PF coils. The outer joint is a lap joint; the inner joint may be made with shear pins or keys. These joint concepts need further study to establish engineering feasibility definitively, though they appear to be feasible from the preliminary scoping investigation.

The TF coils are immersed in a pool of liquid nitrogen; the shield and vacuum vessel are enclosed in a dewar. Cooling takes place primarily at the exposed edges of the copper plates. For cooldown times within the ground rule of 20 minutes (to reach $\simeq 80 \mathrm{~K}$ ), a current density in copper of $6 \mathrm{kA} / \mathrm{cm}^{2}$ avoids the film boiling regime. Though a TF coil chargeup time of about 60 seconds results in a cheaper power supply, to restrain the average temperature to $\simeq 150 \mathrm{~K}$ requires a shorter chargeup time of $\approx 20 \mathrm{sec}$.

The crucial space from the edge of the plasma to the high field side of the TF coils has been reduced in comparison to prior TNS studies by reducing the shield thickness on the inside to $10 \mathrm{~cm}$. For this low voltage system, radiation damage will not be an overriding concern, and the edge cooling ensures that local neutron heating will be tolerable. Otherwise the liner/limiter spacing of $14 \mathrm{~cm}$, and the vacuum vessel and support space of $15 \mathrm{~cm}$, has been carried over from prior work. The total of $29 \mathrm{~cm}$ for liner/limiter and vacuum wall is probably an upper bound in that the smaller plasma dimensions and shorter pulse 
length may permit these spacings to be reduced. The total space is then about $45 \mathrm{~cm}$. Any reduction in this spacing would of course have favorable effects on major radius., allowable $\beta_{t}$ and overall cost.

About three energy confinement times $\left(\tau_{E} \simeq 1 \mathrm{~s}\right)$ suffice to demonstrate ignition. The TF coil flat-top time is about $10 \mathrm{sec}$, which allows adequate time for startup, heating, burn, and shutdown. Twenty minutes have been allowed between pulses. During startup $40 \%$ of the required flux swing is assumed to be contributed by the equilibrium field system; this is likely to be a pessimistic estimate. Though early injection of neutral beams may induce a toroidal current, the effect has not been included. (Should this effect be established experimentally it can be exploited later to reduce $\mathrm{OH}$ requirements and/or increase the burn time.)

The power supplies for the IDR have been simplified and reduced in cost as compared to previous TNS work as permitted by the device size and operating scenario. A simple phase controlled rectifier drives the EF coil. Mechanical switches in the $\mathrm{OH}$ circuit replace the expensive solid-state switches assumed in the TNS trade studies. The more modest demands on the EF circuit, due to the nil to moderate elongation, permit a lower-rated, less expensive circuit.

The main conclusion of this work is that there is reason to believe that a device and associated facility directed primarily at the early demonstration of ignition can be constructed for operation in the mid-1980's, at a cost not exceeding that of TFTR by more than about $10-25 \%$. No credit has been taken for the availability of existing components or structures and this could conceivably provide some cost relief. We find that the cost of the tokamak system itself is typically between $20 \%$ and $30 \%$ of the total. Therefore, dramatic cost reductions should not be expected in this area. In small compact devices, the neutral beams and power supplies are probably the most crucial areas from a cost point-of-view and would offer the greatest potential for cost reduction through innovative design and improved understanding of plasma startup and heating scenarios.

This report is organized as follows. Section 2 reviews the design options for the IDR. Two options are selected for investigation. In Section 3, plasma considerations 
are discussed, and reference plasma parameters are picked for each option. Section 4 describes the machine configuration for each option, compares them, and recommends one for further investigation. In Section 5, the costs for each option are calculated. Appendices deal with specialized design topics which bear on the engineering feasibility of the devices. 


\subsection{DESIGN OPTIONS FOR AN IGNITION DEMONSTRATION REACTOR}

In the specification of design requirements for a low-cost ignition tokamak, some trade-offs appear quickly. So far as ignition is concerned, good attributes include high toroidal field, large minor radius, plasma elongation, high density, and high temperature. Attributes leading to low cost include low toroidal field, small size, no elongation, and small distance from the plasma to the high-field side of the TF coils. The major design issues and considerations for the IDR are summarized in Table 2-1.

A long pulse length is not required; this in turn removes the requirement for active impurity control. Similarly, plasma refueling during the pulse and on-site tritium reprocessing are not required and need not be demonstrated. On the other hand, a substantial margin in the predicted ignition conditions must be provided to ensure that the objective is achieved. Likewise, the device must have good access to the plasma for neutral beam heating and for extensive instrumentation.

Only minimal integral device shielding is required in view of the limited neutron fluences expected. It is assumed that required biological shielding is provided external to the device, therefore shielding space is not a factor in sizing the tokamak. Femote handling must be considered in the design, however, minimum capability is provided for extensive remote maintenance operations.

Specific configurational issues for a near-term (i.e., no superconductors) tokamak IDR can be grouped into a crude taxonomy as follows:

- TF coils

- Bitter coils vs. discrete coils

If discrete, washer vs. wound construction

- Water vs. liquid nitrogen $\left(\mathrm{LN}_{2}\right)$ coolant

- Pulsed vs. steady-state 
TABLE 2-1

IDR DESIGN CONSIDERATIONS

- COMPACT, HIGH FIELD CONFIGURATION

- COST-EFFECTIVE OPERATION SCENARIO

- NO DIVERTOR

- circular plasma or modest elongation

- CRYORESISTIVE COILS (COPPER OR ALUMINUM) VS. WATER COOLED COPPER

- NO TRITIUM PROCESSING AND PLASMA FUELING

- WOUND VS. BITTER VS. DISCRETE WASHER-TYPE TF COILS

- IRON VS. AiR CORE OH. CONSIDER SATURATING CENTRAL CORE AND NON-SATURATING LEGS

- PF WINDING LOCATION - INSIDE, OUTSIDE, MIXED

- SIMPLIFIED POWER SUPPLIES - MECHANICAL VS. SOLID STATE SWITCHES

- Minimal INTEgRAL DEVICE SHIELDING

-... MINIMIZE REMOTE HANDLING PROVISIONS

- tFtr nEUTRAL bEAMS 
- PF coils

- Inside TF coils vs. outside vs. mixed

- Coil distance from plasma vs. power supply cost

- Iron core vs. air core transformer.

Bitter coils have great appeal for a small physics experiment: they are simple conceptually, do not require complicated cooling arrangements, and resist bending and out-of-plane forces well. For larger experiments, drawbacks appear: access for auxiliary heating and diagnostics is poor, and plasma shaping is costly to incorporate.

Discrete coils allow good access for auxiliary heating and diagnostics, but require structural support to resist out-of-plane forces. There exists at least the possibility of placing the poloidal field (PF) coils inside the TF coils, to reduce PF power supply costs and/or ease plasma shaping. The latter two considerations weigh heavily, since computational experiments show considerable savings on $\mathrm{OH}$ amp-turns and power supply costs with all of the PF coils inside the TF coils. Physical access for asseumbly and maintenance is severely limited, however.

One design feature which can yield both high field and compact configuration is high current density in the TF coil conductors. Cooling copper conductor to cryogenic temperacures helps achieve high current density for either steady state or pulsed operation. In steady state operation the resistivity, and hence the dissipated energy, is substantially less at cryogenic temperatures than at room temperature. In pulsed operation the relatively smaller drop in specific heat allows a larger temperature excursion. The potential advantages of high current density justify the design effort to incorporate cryogenic cooling.

Figures 2-1, 2-2 and 2-3 show the preliminary device concepts which have been examined. Concept I is similar to the MIT ITR concept, in that the TF coils are tightly packed Bitter plates. Concept II differs from Concept I in that the TF coils are discrete, though the individual coils may be of washer-type construction. In Concept III, all poloidal field coils are inside the TF coils.

Based primarily on the poor access for neutral beams and diagnostics, Concept I (Bitter plates) was rejected for this study and Concepts II and III investigated 


\section{VERY HIGH FIELD \\ CIRCULAR PLASMA \\ PF COILS EXTERNAL}

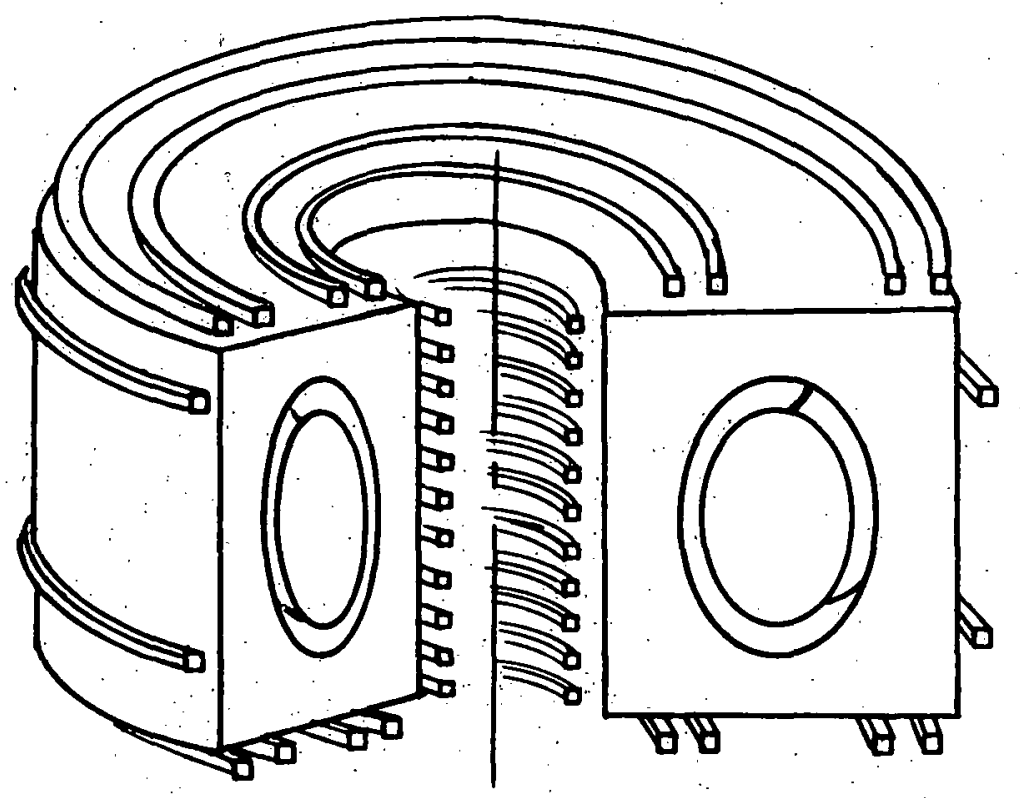

Figure 2-1. Ignition Demonstration Reactor Concept IDR I 


\section{MEDIUM HIGH FIELD. . \\ CIRCULAR PLASMA \\ PF COILS EXTERNAL}

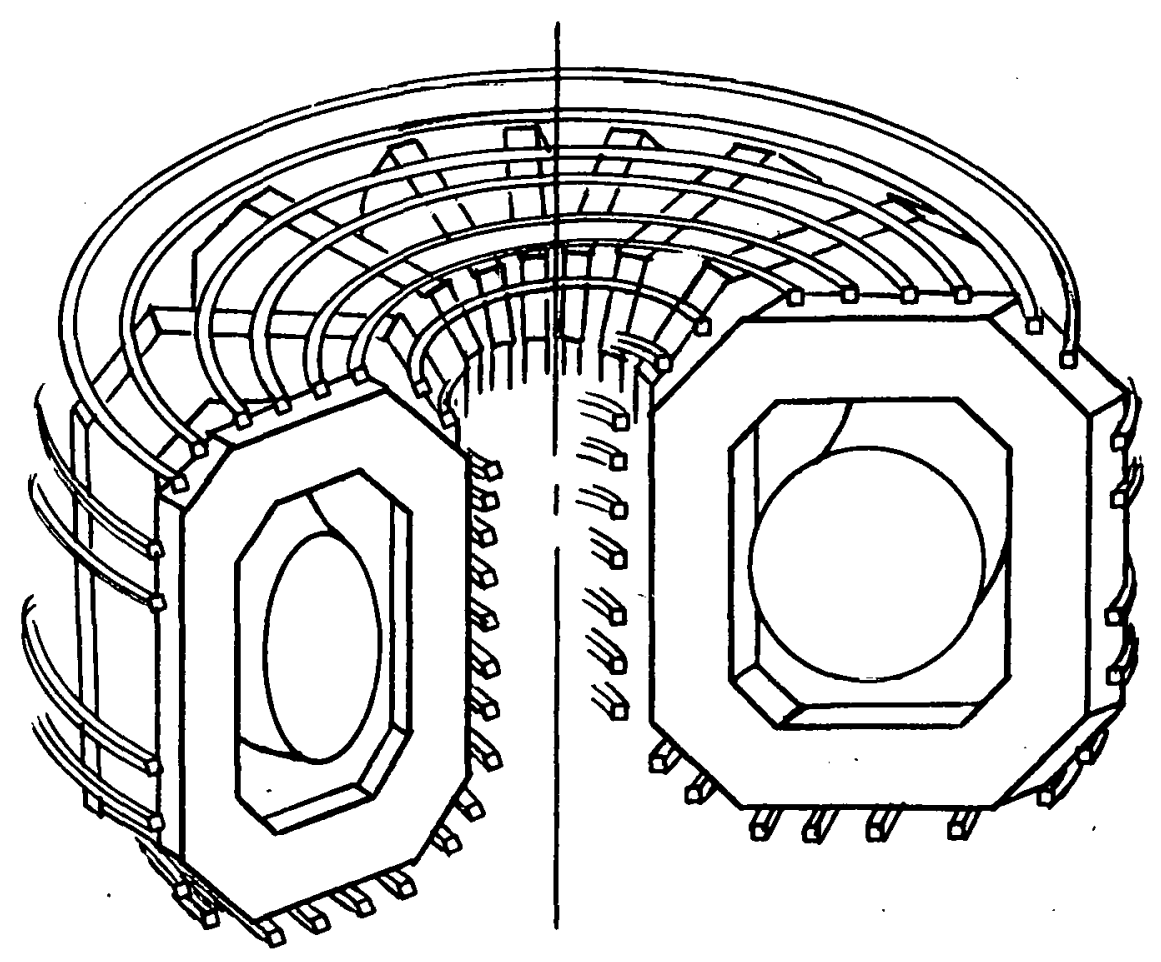

Figure 2-2. Ignition Demonstration Reactor Concept IDR II 


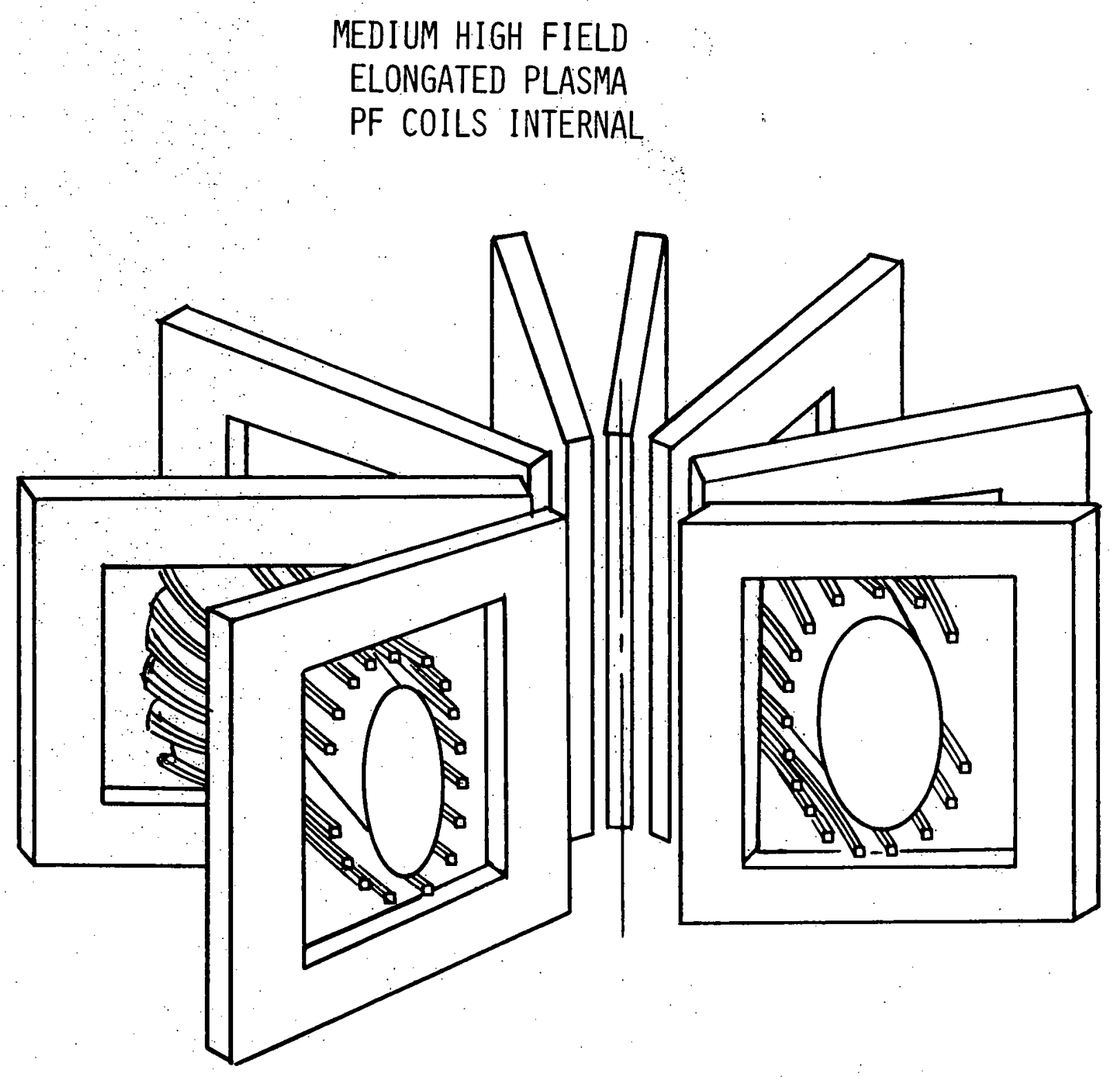

Figure 2-3. Ignition Demonstration Reactor Concept IDR III 
further. The coils in these cases were chosen to be of washer-type construction to preserve favorable features of good resistance to in-plane bending and simplicity of construction.

These tentative selections still pose significant design challenges. A major challenge for Concept III is how to assemble and maintain the PF coils. Some scheme for breaking the TF coils intentionally would be desirable.

Granted operation at liquid nitrogen $\left(\mathrm{LN}_{2}\right)$ temperatures ( $(20 \mathrm{~K})$, the choice is between cooling mainly between pulses, continuous cooling, or some combination thereof. Considerations of possible extended flat-top time indicate continuous cooling would be preferred. However, consistent with the objective of lowest cost and maximum simplicity, we have elected to provide for nearly adiabatic temperature rise during the pulse with edge cooling afterward. This choice is discussed in Appendix A. 


\subsection{SELECTION OF REFERENCE PLASMA PARAMETERS}

\subsection{INTRODUCTION}

The purpose of this section is to discuss qualitatively the plasma considerations for an ignition demonstration reactor, arrive at reference plasma parameters, and an operating scenario suitable for this mission.

There is reasonable agreement within the fusion community that high density yields ignition most easily. Various groups have diverged in their approach to achieving $i t$, and in the resulting concerns or uncertainties. At one end of the spectrum is a high $\beta$, low field machine, for which the greatest concerns are equilibrium and stability considerations. At the other end is a low $\beta$, high field device, for which equilibrium and stability are more easily satisfied, but the details and consequences of transport processes are of greater concern. The approach here is to try to steer somewhere in between the polar extremes described above in choosing the parameters to follow. By relaxing the field and density requirements as compared to the MIT high-field ITR (Reference 5), sufficient reductions in TF coil and neutral beam energy requirements will be achieved to overcome the cost penalties associated with slightly higher plasma temperature. Conversely, by increasing the field on axis and lowering $\beta$, as compared to the ORNL/WFPS copper coil TNS-1, configurational size and cost will decrease faster than the TF coil requirements increase.

\subsection{SCOPING RANGES FOR PLASMA PARAMETERS}

An initial review of the major plasma design issues yielded the following set of parameter ranges and design assumptions.

Size

$\begin{array}{ll}\text { Major Radius: } & 2 \mathrm{~m} \leq \mathrm{R}_{0} \leq 4 \mathrm{~m} \\ \text { Minor Radius: } & 0.5 \mathrm{~m} \leq \mathrm{a} \leq 7 \mathrm{~m} \\ \text { Elongation: } & 1 \leq \delta \leq 1.3\end{array}$




\section{Confinement Scaling}

Convection (ions and electrons): pseudoclassical and empirical

Ion Conduction: neoclassical

Electron Conduction: pseudoclassical

The formula to be used for empirical scaling is (MKS):

$$
\tau_{d}^{E M P}=3.2 \times 10^{-21} n_{e}(a s)^{2} q^{1 / 2}
$$

For a discussion of the other scalings see Reference 6.

While the least acceptable value of the collisionality parameter is not settled, values of $v_{\text {eff }}^{\star} \gtrsim 0.01-0.1$ seem appropriate in order that equation ( 1 ) hold.

\section{Alpha Particle Confinement}

Plasma Current: $I_{p} \geq 3$ MA

Low-Field Ripple: $\varepsilon_{r} \leq 7 \%$ (peak-to-average)

In order that the $3.52 \mathrm{MeV} \alpha$-particles heat the plasma, they must be trapped within the plasma long enough to give up their energy to the hydrogenic species. With perfect. symmetry in the toroidal field a suitable criterion is $\rho_{\alpha \theta} / a \leq 1 / 2-4$ (Reference 7), which leads to the plasma current criterion above. With imperfect axisymmetry, due to TF coil ripple, non-symmetric trapping results in drift orbits leading to the wall (Reference 8).

\section{Stability}

Confinement Parameter: $\beta \leqslant 5 \%$

Stability Criterion:

$$
\beta_{\max }=\frac{C(\delta)}{A\left(q_{\text {edge }} / q_{\text {axis }}\right)^{2}}=\frac{C(\delta)}{A q^{2}(a)}
$$

Safety Factor: $2.5 \leq q \leq 3$

The formula for greatest toroidal beta is still under investigation, but several experts have recommended it for provisional use (References 9 and 10). Computations have shown (Reference 9) that $\delta=1.6$ gives $C \simeq 3$, and $\delta=1$ gives $C=1$. For the purposes of this scoping effort, linear interpolation seems adequate. 


\section{Density and Temperature}

Density: $2 \times 10^{20} \mathrm{~m}^{-3} \leq \overline{\mathrm{n}}_{\mathrm{e}} \leq 5 \times 10^{20} \mathrm{~m}^{-3}$

Temperature: $6 \mathrm{keV} \leq \overline{\mathrm{T}}_{\mathrm{e}} \leq 10 \mathrm{keV}$

Profile Effects:

$$
\begin{aligned}
& \text { - density: } n=\bar{n} f(r), f(r)=\frac{5}{3}\left(1-\left(\frac{r}{a}\right)^{3}\right) \\
& \text { - temperature: } T=\bar{T} g(r), g(r)=2\left(1-\left(\frac{r}{a}\right)^{2}\right)
\end{aligned}
$$

\subsection{SELECTION OF REFERENCE PLASMA PARAMETERS}

As discussed previously, both circular and elongated plasmas were considered. These options were evaluated in order to gauge the overall differences in cost, taking into account all the effects of the configurations.

A moderate elongation of 1.3 has been chosen on the basis of three compromises: some benefit is gained from elongation, stability is not challenged, and the requirements on the poloidal field coil system are not increased greatly over those for a circular plasma.

For both the circular and elongated plasmas, the common parameters of $q=3$, $a=0.8$, and $B_{t}=10-11 \mathrm{~T}$ were chosen as being near the center of the design ranges. For the purposes of the confinement scaling, a major radius of $3.0 \mathrm{~m}$ was assumed initially. The densities and temperatures were then varied to achieve a global density-confinement time for the ignition. Inclusion of profile effects indicates a substantial margin in the confinement for ignition. The reference plasma designs are shown in Tables 3-1 and 3-2 for the IDR-II and IDR-III concepts.

The elongated plassma has a greater margin for ignition than the circular plasma, and achieves it at a lower temperature. The lower temperature and longer confinement time reduces neutral beam power requirements as compared to the circular plasma. The higher density of the IDR III plasma implies higher neutral beam particle energy, through the energy is within the state-of-the-art projected for the next five-to-ten years. 
TABLE 3-1

PRELIMINARY IDR PLASMA PARAMETERS

CONCEPT II

MACHINE PARAMETERS

MAJOR RADIUS, $R_{0}(m) \quad \simeq 3$

$\begin{array}{ll}\text { PLASMA RADIUS, a }(\mathrm{m}) & 0.8\end{array}$

PLASMA ELONGATION, $\therefore \delta(-) \quad 1.0$

FIELD ON AXIS, $B_{t}(T)$

PLASMA PARAMETERS

SAFETY FACTOR, $q(\mathrm{a})(-) \quad 3.0$

AVERAGE ELECTRON DENSITY, $\bar{n}_{\mathrm{e}}\left(\mathrm{m}^{-3}\right) \quad 3.4 \times 10^{20}$

AVERAGE TEMPERATURE, $\bar{T}(\mathrm{keV}) \quad 10.0$

PLASMA CURRENT, I $\mathrm{p}$ (MA) $\quad 3.9$

AVERAGE TOROIDAL BETA, $B_{t}(-) \quad 0.028$

GLOBAL ENERGY CONFINEMENT TIME, ${ }^{\tau} E(s)$

GLOBAL DENSITY-CONFINEMENT TIME PRODUCT, $\quad 3.4 \times 10^{20}$

$\bar{n}_{\tau}\left(s m^{-3}\right)$

$n \tau(\mathrm{emp}) / \mathrm{n} \tau_{\mathrm{ig}}$ AT PLASMA CENTER

$n \tau(T P M) / n \tau_{i g}$ AT PLASMA CENTER $\quad 1.7$

NEUTRAL BEAM PARTICLE ENERGY (PROFILED), 125

$W_{b}(\mathrm{keV})$

NEUTRAL. BEAM POWER, $P_{b}(M W) \ldots 60$

FUSION POWER DENSITY, $\mathrm{P}_{\mathrm{f}}\left(\mathrm{MW} \mathrm{\textrm {m } ^ { - 3 } )} 9.3\right.$

IMPURITY LEVEL, $Z_{\text {eff }}(-) \quad \simeq 1$

NEUTRON WALL LOADING, $L_{n}\left(M W \mathrm{~m}^{-2}\right)$ 
TABLE 3-2

PRELIMINARY IDR PLASMA PARAMETERS

CONCEPT - III

MACHINE PARAMETERS

MAJOR RADIUS, $R_{0}(m) \quad \underline{m}$

PLASMA RADIUS, a (m) 0.8

PLASMA ELONGATION, $\delta(-) \quad 1.3$

$\begin{array}{ll}\text { FIELD ON AXIS, } B_{t}(T) & 10\end{array}$

PLASMA PARAMETERS

SAFETY FACTOR, q (a) (-) 3.0

AVERAGE ELECTRON DENSITY, $\bar{n}_{\mathrm{e}}\left(\mathrm{m}^{-3}\right) \quad 4.0 \times 10^{20}$

AVERAGE TEMPERATURE, $\bar{\top}(\mathrm{keV}) \quad 8.0$

PLASMA CURRENT, I (MA) 4.8

AVERAGE TOROIDAL BETA, $\beta_{t}(-) \quad 0.033$

GLOBAL ENERGY CONFINEMENT TIME, $\tau_{E}(s)$

GLOBAL DENSITY-CONFINEMENT TIME PRODUCT, $\quad 5.4 \times 10^{20}$ $n_{\tau}{ }_{E}\left(\mathrm{sm}^{-3}\right)$

$n \tau(\mathrm{emp}) / \mathrm{n}_{\mathbf{i g}}$ AT PLASMA CENTER $\quad 11.0$

$n_{\tau}($ TPM $) / n \tau_{i g}$ AT PLASMA CENTER $\quad 2.3$

NEUTRAL-BEAM PARTICLE ENERGY (PROFILED), $W_{b}(\mathrm{keV}) \quad 150$

NEUTRAL BEAM POWER, $P_{b}$ (MW), $\simeq 40$

FUSION POWER DENSITY, $\mathrm{P}_{\mathrm{f}}\left(\mathrm{MW} \mathrm{M}^{-3}\right) \quad 6.8$

IMPURITY LEVEL, $Z_{\text {eff }}(-) \quad \simeq 1$

NEUTRON WALL LOADING, $L_{n}\left(M W \mathrm{~m}^{-2}\right) \quad 2.2$ 


\subsection{IDR OPERATING SCENARIO}

The total time that the TF coils need to produce full field can be deduced from the requirement that this device need only demonstrate ignition.

The period of D-T burn needs to be $2-3 \tau_{E}$ in order to allow the ignited core to reach its ultimate temperature and to allow short-term burn dynamics to be studied. For $\tau_{E} \simeq 1 \mathrm{~s}$, a burn time of $2-3$ seconds is required.

The remainder of the flat-top time comes from plasma current initiation, $\simeq 2 s$, neutral beam heating, $2-3 \mathrm{~s}$, and prasma shut-down, $\approx 2 \mathrm{~s}$. The sum of these and the burn time is $\simeq 10 \mathrm{~s}$, which is the design reference selected. No credit has been taken here for neutral beam heating after plasma current initiation, in order to arrive at a conservative figure for volt-second requirements. Since high duty factor is not an objective, the recovery time for vacuum pump-out, coil cooling, etc., has been set arbitrarily at about 20 minutes in order to furnish a reference. The initial IDR operating scenario is shown in Table 3-3. 
TABLE 3-3

INTITIAL IDR OPERATING SCENARIO

\begin{tabular}{ll} 
- & TF FlAT-TOP \\
- & PLASMA START-UP \\
- & NB INJECTION \\
- & D-T BURN \\
- & PLASMA SHUT-DOWN \\
\hline
\end{tabular}

$8-10 s$
$2 s$
$2-3 s$
$3 s$
$2 s$
$\simeq 20$ minutes




\subsection{IDR SYSTEM DESIGN CONCEPTS}

of the three generic machine configurations discussed in Section 2, machines with discrete cryoresistive coils were chosen for further study. The plasma designs in Section 3 showed that modest elongation produces advantages in ignition margin. The purpose of this section is to review TF coil design concepts and the overall machine configurations associated with these plasmas. The topics addressed here are PF system cost, accessibility, TF coil shape, construction, and cooling as well as assumptions used in the definition of the balance of facility systems.

The IDR II and IDR III machine concepts are shown in Figures 4-1, 4-2, and.4-3. Dimensions for the IDR III machine are shown in Table 4-1. Specifications for the IDR II are similar. The configuration with poloidal field coils inside the TF coils has the generic advantage that the cost of the PF coil power supply is minimized for equivalent functions. For a modest increase in cost, magnetic shaping and elongation of the plasma, leading to a larger $\beta^{2} \mathrm{a}^{2} \mathrm{~B}_{t}^{4}$ product, can be achieved; equivalent shaping would be more costly with PF coils outside. The TF coil size and stored energy of the IDR III is only slightly larger than that of IDR II.

Two design concepts common to these configurations are TF coil construction and cooling. The TF coils are constructed of discrete packages of washer-type coils, pressed together in conductor-structure-insulation sandwiches. The amount of wedging outside the coil nose region can be decided on in later design stages, depending on a trade-off between TF coil power supply costs (more area of copper), access to the inner components, and access for auxiliary heating. The trade-off becomes more acute for IDR III because of requirements for access to the inner poloidal field coils.

Both configurations involve new engineering design problems concerned with the cryoresistive nature of the TF coils. Cryoresistive TF coils have been used previously in the Alcator and ORMAK reactors. However, simple scale-ups of the earlier machines will not permit adequate cooling or support structures for. long 
pulse experiments and large machines. While it is not felt that a low-cost ignition demonstration reactor should be designed primarily for long ignited pulses, because of the high initial cost associated with low current density or thick shielding requirements, the thermal design should allow for occasional longer pulses. A desirable approach to the thermal design should attempt to combine the rapid cooling of the ORMAK with the simplicity and low-cost of the Alcator. Immersing the TF coils and $\mathrm{OH}$ coils in a pool of nitrogen, in contact with all coil surfaces, was chosen as a reasonable compromise. A plastic or styrofoam dewar would surround the machine. An internal dewar would protect the shield and vacuum vessel from the liquid nitrogen. The internal dewar would have to be metal, and might also provide some of the shielding requirements. Pumping would be used only to replace nitrogen boil-off and to provide positive pressure within the dewar to avoid water vapor condensation. The rationale for the thermal configuration selection is discussed further in Appendix A.

In order to guarantee access to the poloidal field coils inside the TF coils of IDR III, some non-standard concepts may be required. For machines using only mildly elongated elliptical plasmas, it may be possible to gain access to inside PF coil joints, without radical design concepts. As can be seen from Figure 4-1, only the innermost coil position is effectively "masked" from vertical access. Figure 4-2 shows that with little TF coil wedging there may be adequate access between the TF coils to reach a joint in the innermost coil. Further access could be created by reducing the number of TF coils and moving the outer legs of the TF coils away from the vertical center line (to prevent an increase in lowfield ripple). Without further wedging of the TF coils, it would only be necessary to move the neutral axis of the outside legs to a major radius of $\simeq 6 \mathrm{~m}$ in order to allow a 12 .coil design.

The IDR III configuration shown in Figures 4-1 and 4-2 incorporates joints in the TF coils, in order to allow direct access to the poloidal field coils and allow vertical removal of the inner components. The inner joint is a finger joint, and the outer joint is a bolted lap joint. While joints are desirable for access, they require additional care in assembly and disassembly, and may interfere with the functioning of the TF coil itself. The design must ensure that (1) the conductor contact 
resistance is sufficiently low, and (2) the forces are transmitted effectively within the conductor and structure. The outer lap joint is straightforward, since there is enough space at the outside to strengthen the joint. The inner finger joints require more care in the design. As discussed in Appendix C, a tentative concept consists of shear keys tying the conductor and structure plates to each other. The joints require study beyond the scope of this effort to establish feasibility.

Alternatives to joints in each TF coil include joints in only one or two TF coils, and removable nose panels with TF coil rotation in the toroidal direction. The advantage of joints in only one or two TF coils is that it requires much less external support structure than joints in every coil. Its disadvantage is that it is unsuited to removing half the poloidal field coil system vertically as a single unit. Conceivably, all the PF coil connections could be placed beneath the removable TF coils, removing the need to rotate the toroidal field system as a unit.

The insertion of vertical panels between the TF coils in the inside nose does not compromise the tensile strength of the TF coils. However, it increases highfield ripple, takes up valuable space in the nose volume and is unsuited to removing half the poloidal field system as a unit. Another disadvantage of using nose panels is that TF coil assemblies would have to be rotated along the machine toroidal axis in order to gain access to the inside PF coils.

The coil shape for IDR III is an approximation to a constant tension "D" (in practice the corners would be rounded to avoid stress concentrations). The resistance of the washer-type construction to in-plane bending has been utilized in concept to arrive at a coil shape for IDR II that is more nearly circular than $D$, in order to reduce magnetic stored energy and power supply requirements of both the PF and TF systems. If bending moments are unacceptably high, the shape. can be backed off toward that of a D-coil.

While these concepts have been distinguished by an elongated plasma, in the case . of IDR III, and a circular plasma, in the case of IDR II, no quantitative studies 
have been performed to calcullate the net cost of elongating the plasma of the IDR II concept. This: would be an investigation worth undertaking, since the extra cost of the equilibrium field system of an elongated pliasma in IDR II might be a price worth paying for both plasma performance and machine simplicity. 


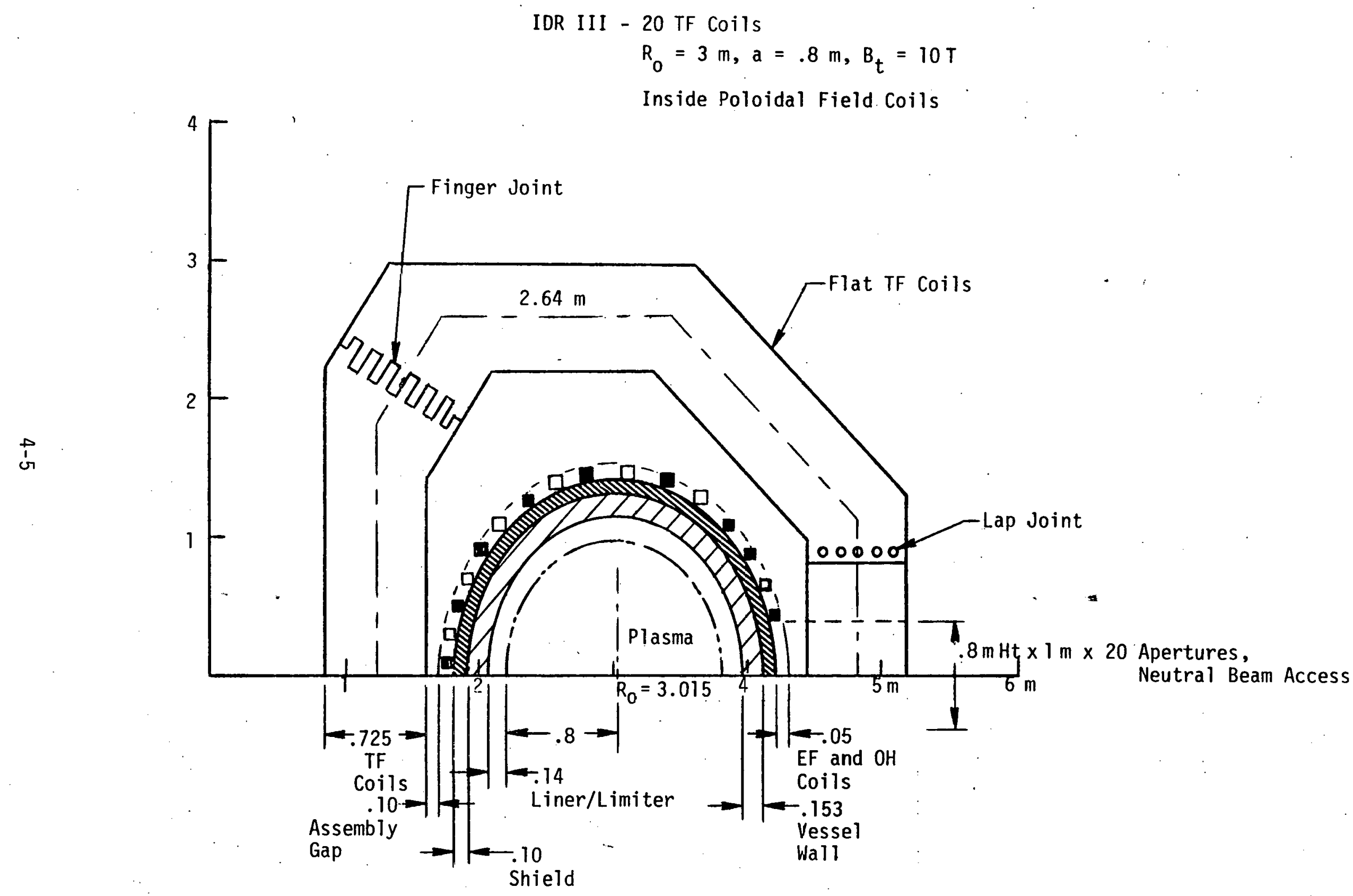

Figure 4-1. Conceptual Arrangement of IDR III Components. 
IDR II - 20 TF Coils

$R_{0}=3 \mathrm{~m}, a=0.8 \mathrm{~m}, B_{t}=11 \mathrm{~T}$

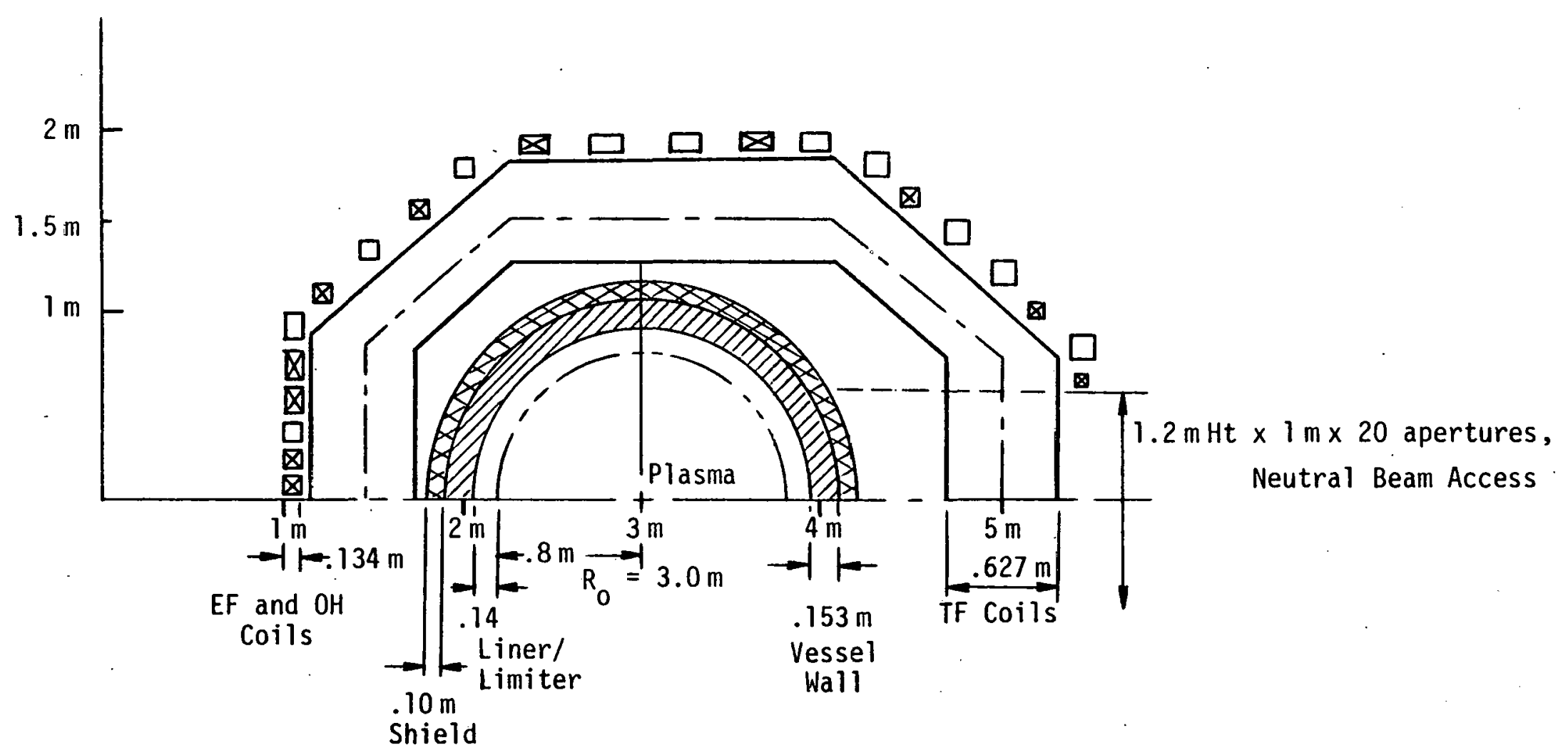

Figure 4-3. Conceptual Arrangement of IDR II Components. 


\section{TABLE 4-1}

PARAMETER SUMMARY FOR THE IDR III CONCEPT

\section{PLASMA PARAMETERS}

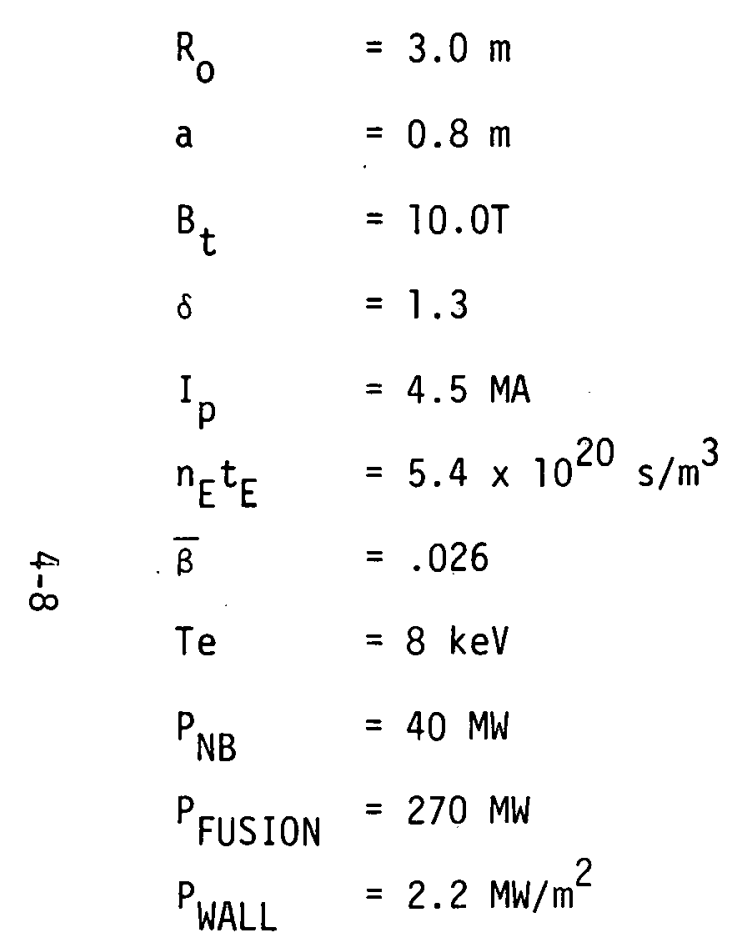

\section{MACHINE SIZE}

MAJOR RADIUS, $R_{0}(m)$

LINER/LIMITER SPACE, $\triangle L L$ (m)

0.14

VACUUM VESSEL WALL THICKNESS, $\triangle W(m)$

0.15

SHIELD THICKNESS, $\triangle S$ (m)

0.1

TF COILS

PEAK FIELD AT COIL, $B_{\max }(T)$

18.0

AVERAGE CURRENT DENSITY IN CONDUCTOR, $J_{C}\left(\mathrm{KA} / \mathrm{cm}^{2}\right)$

PEAK STRESS IN COPPER, $\sigma \mathrm{Cu}_{\max }$ (kpsi) 30.0

PEAK STRESS IN STEEL, $\sigma S_{\max }$ (k psi) $\quad 50.0$

PEAK TEMPERATURE IN TF COIL, $T_{\text {MAX }}$ (K)

300.0

HORIZONTAL CLEAR BORE, $A_{h}$ (m)

2.9

VERTICAL CLEAR BORE, $A_{v}(m)$

4.6

PF COILS

TOTAL OH FLUX SWING, $\triangle \phi_{O H}$ (Wb)

26.0

AVERAGE CURRENT DENSITY IN CONDUCTOR, $\mathrm{J}_{O H}\left(\mathrm{kA} / \mathrm{cm}^{2}\right)$

FIELD IN BORE OF OH COIL, $\mathrm{B}_{\mathrm{OH}}(\mathrm{T})$
2.5

1.3 


\subsection{BALANCE OF SYSTEMS DEFINITION AND COST ESTIMATES}

The development of specifications and costs for supporting systems and facilities are based on the TNS -1 point design and associated performance and cost algorithms in the COAST ${ }^{(1)}$ systems model. This same COAST model has been used to reproduce the estimated cost for TFTR to within $5 \%$. Thus there is excellent justification for making a meaningful cost comparison (on both a relative and absolute basis) between TFTR, TNS-1 and the two reference IDR concepts.

Some of the important aspects of the IDR representations are summarized below:

Vacuum Vessel - A water-cooled stainless steel structure with tungsten limiters was assumed (same as TNS-1).

Torus Vacuum Pumping - Cryopanels with mechanical roughing pumps were assumed (same as TNS-1).

Biological Shielding - The same site boundary dose criterion was assumed for the IDR as was used for TNS and the quantity of external device and reactor cell shielding adjusted accordingly.

Reactor Cell - A cylindrical concrete cell was assumed, with horizontal clearances provided for the neutral beam arms and vertical clearances provided for cranes.

Water cooling System - The size and capacity of the water cooling system and cooling tower for TNS-1 were scaled downward by removing the TF coil heat load.

Liquid Nitrogen Cooling System - Costs were added for liquid nitrogen handling (plumbing, insulation and storage tanks).

Tritium Handling - A once-through tritium system was assumed for IDR, however, capability equivalent to that assumed for TNS-1 was provided for tritium storage, gaseous tritium fuel delivery and tritium clean-up. 
Remote Handling - The overall cost of remote servicing equipment provided for TNS-1 (18.2 M\$) was reduced to $10 \mathrm{M} \$$ for the IDR systems to account for a reduction in automation and handling fixtures. An equivalent hot cell was. provided, however, in the IDR systems.

Facility Structures - The TNS-1 estimate provided $31.5 \mathrm{M} \$$ for site structures, including various technical shops, office buildings, mockup areas and a neutral beam testing facility. Some of these latter features were deleted for IDR, bringing the total down to $30 \mathrm{M}$.

Electrical Power Systems - Design and costing considerations for. IDR are discussed in Appendix B.

A comparison of the key features of the two IDR concepts with TFTR and a version of TNS with water-cooled copper TF coils is provided in Table 5-1. While the IDR devices are relatively close to TFTR in terms of size, the moderately high field on axis (10T) provides considerably more margin for ignition than TNS-1, with comparable neutral beam heating requirements. The ignition devices generate substantially more fusion energy than TFTR, require active cooling of the toroidal vacuum vessel and require considerably greater provisions for biological shielding in view of their higher neutron yields.

Cost estimates for the four tokamak systems (TFTR, IDR II, IDR III, and TNS-1) are compared in Table 5-2. The cost of the two IDR systems are very similar, as would be expected from the similarity in their sizes and performance features. The tokamak system of IDR III is slightly more expensive than that of IDR II primarily because the poloidal field windings are located inside the bore of the TF coils and necessitates larger TF windings. The power siupply costs on the other hand reflect the poorer coupling of the PF system to the plasma in IDR II. The cost of the neutral beam system in IDR III is lower, because of the higher energy confinement time associated with its elongated plasma. The use of liquid nitrogen cooled TF coils in the IDR sys.tems provides a striking reduction in electrical power supply costs over TFTR, even though the TF flat-top times are increased a factor of ten. The cost estimates for TNS-1 systems exceed those of the IDR systems in all 
TABLE 5-1

COMPARISON OF THE KEY FEATURES OF TFTR, IDR II, IDR III AND TNS-1

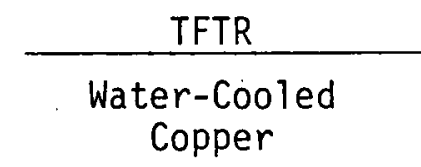

Plasma Minor Radius, m

Plasma Major Radius, $m$

Plasma Elongation

Plasma Current, MA

Mean Ion Temperature, keV

$n_{e}{ }^{\tau},\left(m^{-3} s\right)$

Toroidal Beta $(\%)$

Toroidal Field on Axis, $T$

Peak Field at TF Coil, $T$

TF, MAT

OH, MAT

EF, MAT

Core Flux Swing, V-s

Neutral Beam Power, MW

Neutral Beam Energy, keV

Nominal Burn Time, $s$

Fusion Power, MW

Neutron Yield Per Pulse

Relative Neutron Yield

Reactor Cell Size

$\begin{array}{ll}0.54 & 0.85 \\ 2.48 & 2.48 \\ 1.0 & 1.0 \\ 1.0 & 2.5 \\ 3.2 & 5.6\end{array}$

$9.6 \times 10^{18} \quad 1.2 \times 10^{19}$

$$
0.61
$$

5.2

9.5

64.4

4.5

5.1

14.8

20

120

\section{5}

20
$5.7 \times 10^{17} \quad 1.3 \times 10^{18}$
1
$33.5 \mathrm{~m}$ width
$13.7 \mathrm{~m}$ height

$\frac{\text { IDR II }}{\begin{array}{c}\mathrm{LN}_{2} \text {-Cooled } \\ \text { Copper }\end{array}} \frac{\text { IDR III }}{\begin{array}{c}\text { LN } 2 \text {-Cooled } \\ \text { Copper }\end{array}}$

0.8

3.0

1.0

3.56

10.0

$3.3 \times 10^{20}$

2.8

11.0

18.8

165

16.3

7.0

21.6

60

125

5

381

$8.8 \times 10^{20}$

1544

49.8 ID

$16 \mathrm{~m}$ crane ht $16 \mathrm{~m}$ crane ht

$21 \mathrm{~m}$ dome $\mathrm{ht}$

0.8

3.0

1.3

4.8

8.0

$5.4 \times 10^{20}$

3.3

10.0

18.0

152

11.7

5.38

25.5

40

150

5

270

$6.0 \times 10^{20}$

1053

49.8 ID

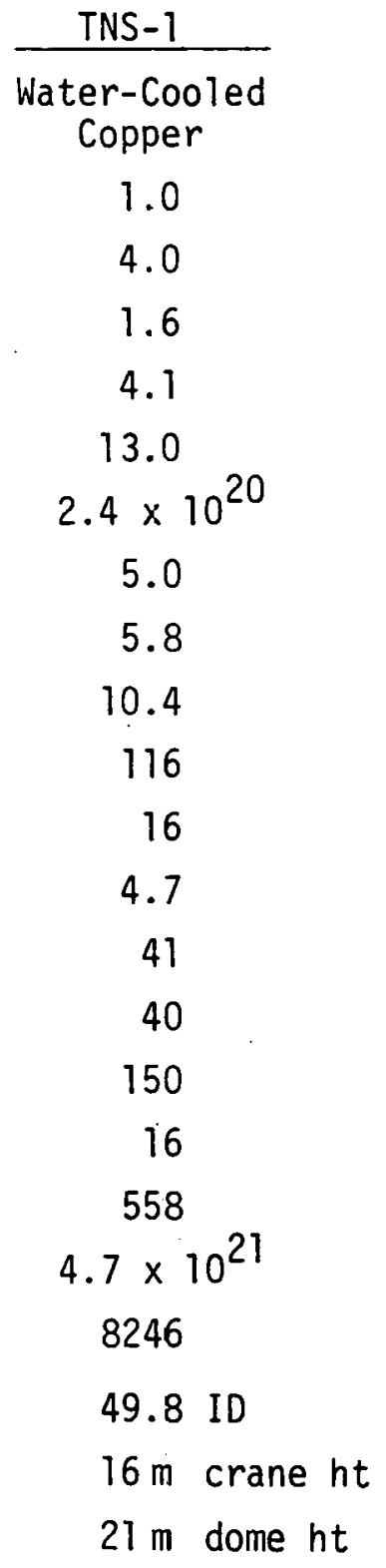


TABLE 5-2

COMPARISON OF COST ESTIMATES FOR TFTR, IDR II, IDR III AND TNS- -

(MILLIONS OF 1977 DOLLARS)

in

Tokamak System

TFTR

$\underline{\text { IDR II }}$

IDR III

TNS-1

Electrical Systems

17.1

26.5

29.6

79.3

43.3

28.5

21.2

94.6

Tokamak Support Systems

12.3

14.8

14.9

48.8

Architectural and Facilities

28.5

30.0

30.0

31.5

Neutral Beam Systems

20.0

4.4 .2

37.2

34.5

Toțal: Buildings and Equipment

1.21 .2

144.0

132.9

288.7 
categories except the neutral beam injectors, where the lower plasma density of TNS allows a reduction in total heating power. The electrical system cost of TNS-1 reflect the use of water-cooled copper TF coils for a relatively long pulse and considerably more demanding PF power supply requirement in view of the low volt-seconds requirement and a plasma elongation of 1.6. The tokamak support systems of TNS- 1 reflect the cost of a full-fledged tritium recovery plant and the cost of rejecting over 500 MW of fusion power plus the resistive heat load generated in the TF coils. 


\section{APPENDIX A \\ COOLING DESIGN CONSIDERATIONS}

By cooling the TF coil conductor to cryogenic temperatures, high current densities and a compact configuration can be achieved. The design problems are to ensure that the cooling is achieved, and to calculate the interrelation of the time scenario, power supply requirements, and cooling design, in order to choose a. cost-effective design. Though aluminum was considered, no alloy could be identified with thermal conductivity and mechanical strength approaching that of copper. Therefore, copper has been chosen as the reference conductor material. The TF coil mechanical concept consists of discrete TF coils composed of sandwiched copper plate, structural stainless steel plates, and insulator clamped together to form the coil. For the purposes of calculation, the parameters of the reference IDR III configuration were used.

Liquid nitrogen is the reference coolant, due to its combination of low cost, inertness, and availability compared to other cryogenic fluids. With these starting points, the design choices considered in this appendix are mode of coolant delivery, cooling regime, power supply implications, and effect of restricting temperature at the end of a pulse.

The two thermal models analyzed are adiabatic joule heating of the TF coils (pulsed heating and cooldown) and steady-state equilibrium joule heating (steady-state TF coil operation). Adiabatic joule heating implies pulses which are limited in length by temperature rise in the copper and cooldown time. Limited length pulses are acceptable so long as the length permits ignition to be demonstrated. Steady-state TF coil operation would permit a longer burn time, but that is not essential to IDR objectives. 
In the following sections, a few first order design considerations are employed to assess these two cooling modeis and their implications. Within the ground rules and the limitations of these analyses, qualitative results are summarized here briefly:

- Either mode of cooling is feasible thermally; electrically, and mectianicatily:

- The cost of boiled-off $L_{2}$ for a single pulse is about $\$ 5,000-7,000$, with adiabatic heating the cheaper;

- Due to Tower peak power requirements, steady-state operation permits more options for sitting thán pulsed heating and cooldown, and also has marginally less capital cost;

- A machine designed for pulsed heating and cooldown presents fewer problems in design: and construction, and i's less risky technologically.

The first two conclusions do not differentiate the two options. The peak power requirements, and time scale for chargeup, do not eliminate any of the leading contending sites for an ignition machine. The last conclusion, however, does relate to the IDR objectives directiy. Pulsed cooling has been chosen as the refernece mode of cooling on the grounds of engineering feasibility and technological risk.

No attempt has been made in this study to trade off capital cost against operating cost, only to minimize capital cost. For that reason $L_{2} N_{2}$ refrigeration and recovery has been omitted. However, the trade off can be made in future should the need arise.

The remainder of this Appendix consists of three main sections. In the first section, the basic cooling regime and material properties are discussed. Design for pulsed heating and cooldown: is discussed in the second section, including trades on power supply requirements, cooldown time, and initial and final temperatures. In the third section a point design for steady state operation is established on the basis of scoping relations, and implications of the point design are analyzed. 


\section{A.1 COOLING REGIME AND BASIC DATA}

The reference coolant is liquid nitrogen $\left(\mathrm{LN}_{2}\right)$. In this section, a preferred cooling regime is established, and material properties over the temperature range of interest are given. The discussions in the following sections are founded on the data given here.

The boiling heat transfer of $\mathrm{LN}_{2}$ surrounding a heated body may by characterized by curves of the boiling heat flux vs. the temperature difference between body surface temperature and the $L N_{2}$ bath temperature $\left(\Delta T_{W}=T_{W}-T_{B}\right)$. There are numerous experimental data and curves in the published literature on boiling $\mathrm{LN}_{2}$ and other cryogens. These curves are obtained by experiments under various test conditions, such as pressures, surface finishes and geometry of the heated body. A representative curve by Brentari and Smith ${ }^{(12)}$ as shown in Figure A-1 is used for this analysis. As shown in the figure the nucleate boiling regime ceases at the critical heat flux, Q/A, of about $15 \mathrm{~W} / \mathrm{cm}^{2}$ at $\Delta T_{W}=12 \mathrm{~K}$ (point $B$ ) and the minimum film boiling point is at a heat flux of about $0.8 \mathrm{~W} / \mathrm{cm}^{2}$ at $\Delta T_{W}=50 \mathrm{~K}$ (point $\mathrm{C}$ ). The dashed $l i$ ne between $B$ and $C$ indicates a transition region in which few experimental data are available. For this analysis it was assumed that during the heating process, heat transfer as a function of temperature difference follows the sequence $A-B-C-D$. During the cooling process it follows the reverse sequence $D-C-B-A$. The heat transfer coefficient is therefore temperature difference dependent and computed by the relationship:

$$
h=\frac{Q / A}{\left(T_{W}-T_{B}\right)}
$$

Film boiling heat transfer should be avoided if possible, in order to minimize copper temperature rise and consequently to permit fast cooldown after a pulse to a reasonable period of time. For the work to follow, staying in the nucleate boiling regime will be a major design objective. 


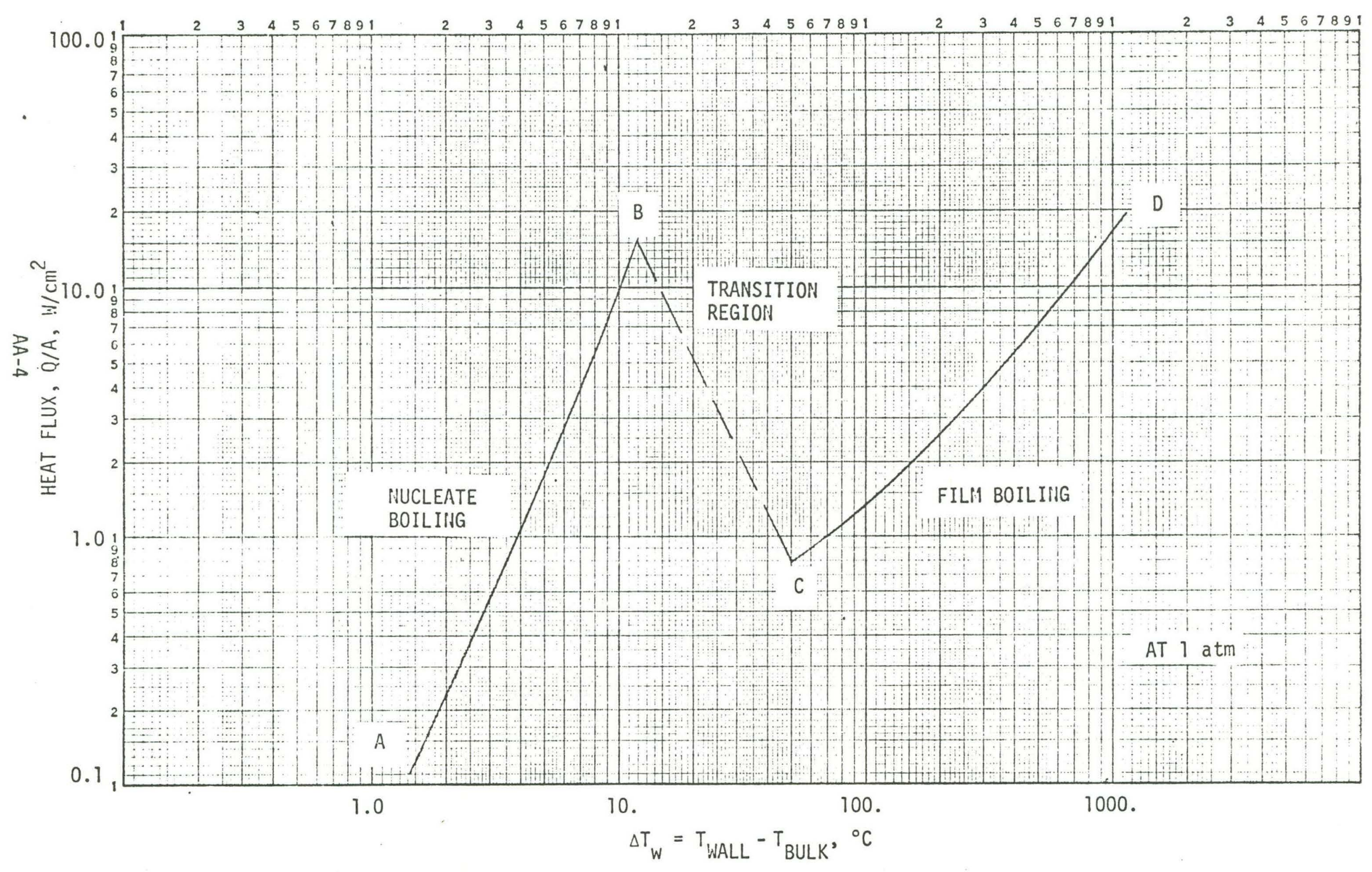

Figure A-1. Pool Boiling Heat Transfer Data for $\mathrm{LN}_{2}$ 
Note that while the curve in Figure $A-1$ is for atmospheric pressure, at higher pressures heat flux versus temperature curves show similar same behavior (12).

Throughout this Appendix, the data for resistivity, specific heat, and thermal conductivity of copper and aluminum are as shown in Figures A-2, A-3, and A-4 (Reference 13). The effect of magnetic field on resistivity is taken as an additive term linear in field strength ${ }^{(13)}$ :

$$
\rho=\rho(T)_{B=0}+0.605 B \times 10^{-8} \Omega-\mathrm{cm} .
$$

where $B$ is in tesla. The data for aluminum are shown even though a preliminary investigation identified no aluminum alloy with both the mechanical strength and electrical conductivity approaching those of selected copper alloys. 


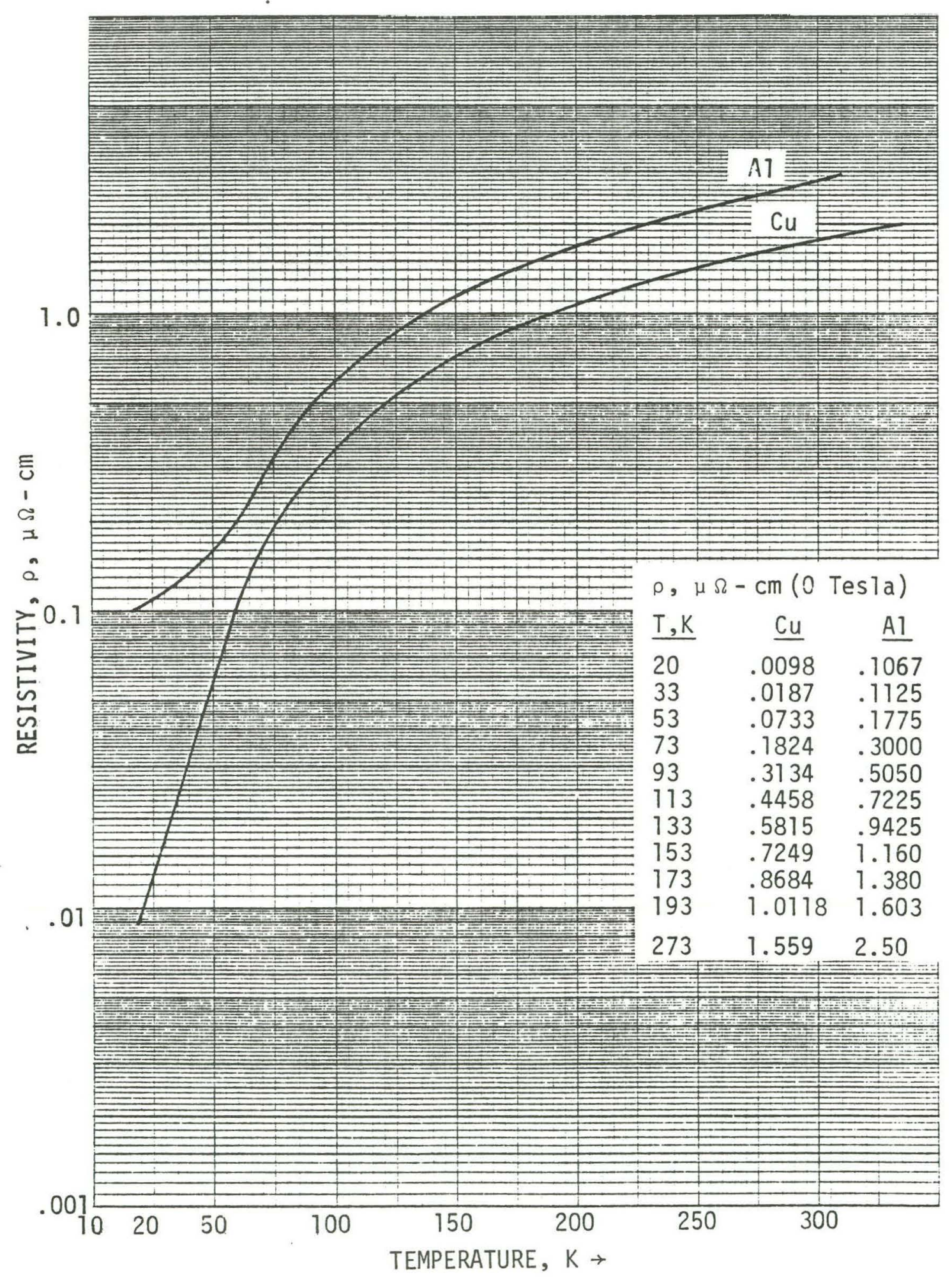

Figure A-2. Resistivity of Copper and Aluminum as a Function of Temperature 


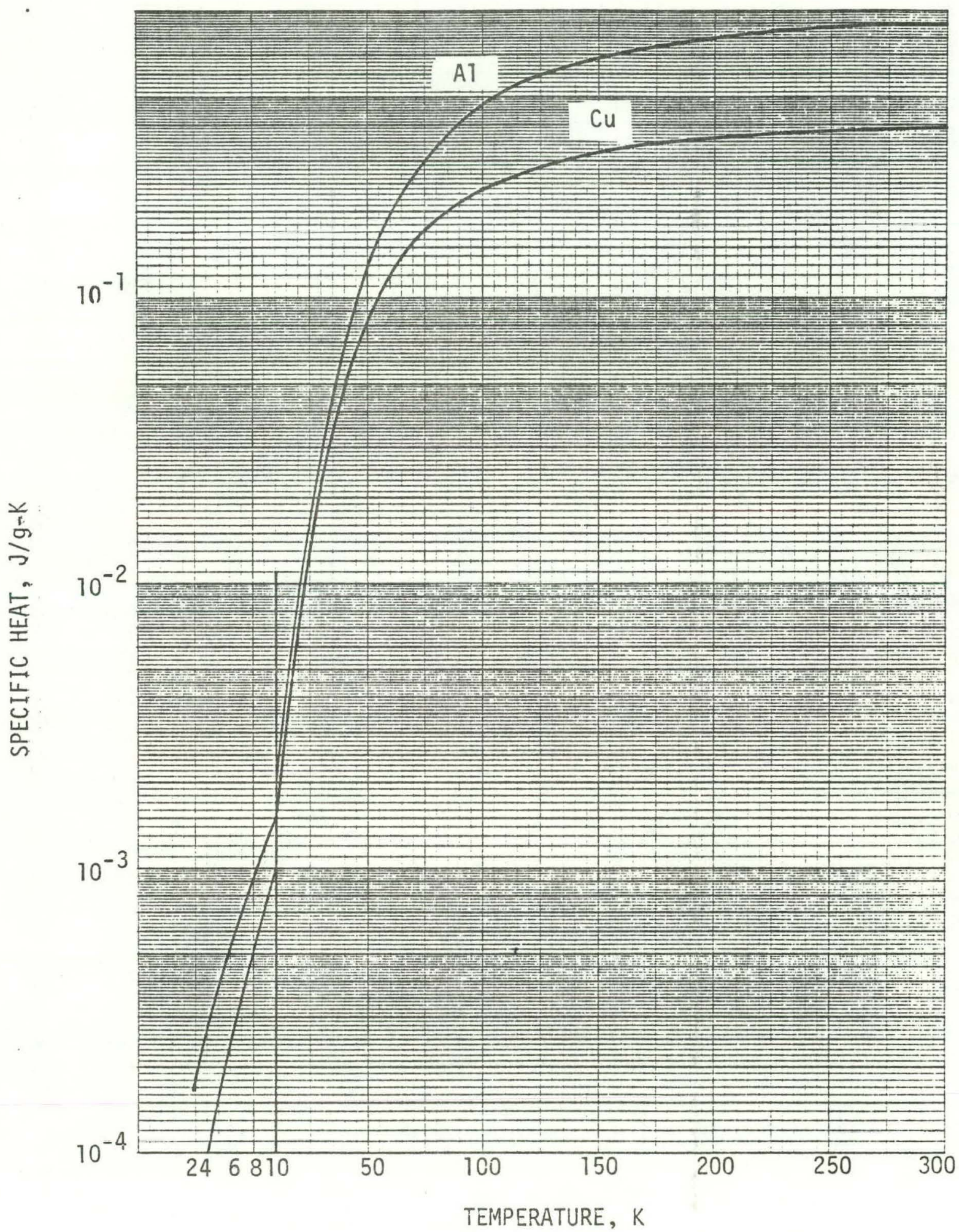

Figure A-3. Specific Heat of Copper and Aluminum as a Function of Temperature 


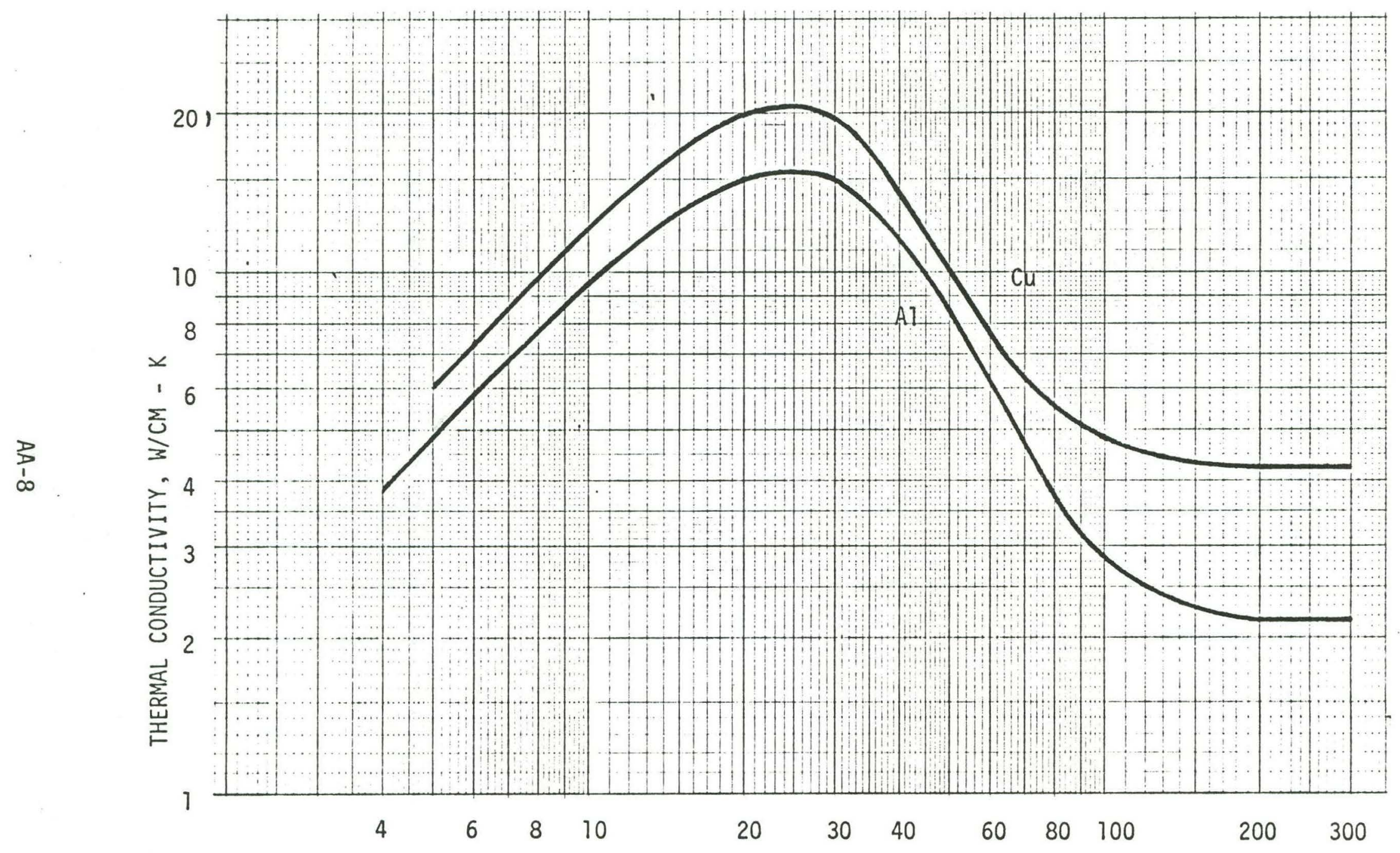

Figure A-4. Thermal Conductivity of Copper and Aluminum as a Function of Temperature 


\section{A.2 PULSED HEATING AND COOLDOWN ANALYSEŚ}

For the purposes of this discussion, pulsed heating and cooldown refers to mechanical design and cooling arrangements such that joule heat is generated in the conductor during the pulse faster than it can be removed, with consequent temperature rise. The design requirements for cooling are that the time between pulses should be no greater than $\simeq 20$ minutes, that the period of full TF coil field strength (flat-top time) is $\approx 8$ seconds, and, in order to avoid annealing the hardened copper conductor, the peak temperature anywhere in the conductor is less than $300 \mathrm{k}$. The design problems are to find a suitable mechanical arrangement for coolant delivery, and to choose a cost-effective combination of operating scenario, power supply requirements, and allowable temperatures.

The principal numerical parameters selected are shown in Table A-1. The principal conclusions of this section are as follows:

- Pulsed cooling is feasible-mechanically, thermally, and electrically-and is simple conceptually;

- The requirements for a 20 minute cooldown is more restrictive then material temperature limitations, forcing a relatively faster chargeup and more expensive power supplies;

- Initial temperatures below $77 \mathrm{~K}$ would reduce power supply requirements, but means for attaining those temperatures were not explored.

\section{MECHANICAL DESIGN FOR PULSED COOLING}

In the reference TF coil design concept, copper plates are sandwiched between insulation and structural steel plates. The coils are divided into discrete units composed of these alternating layers. The simplest arrangement for cooling is to surround the TF coils with liquid nitrogen.

A desirable approach to the thermal design should attempt to combine the rapid cooling of the ORMAK with the simplicity and low cost of the Alcator. Immersing the TF coils and $\mathrm{OH}$ coils in a pool of nitrogen, in contact with all coil surfaces, was chosen as a reasonable compromise. A plastic or styrofoam dewar would surround the machine. An internal dewar would protect the shield and vacuum vessel from the liquid nitrogen. The internal dewar would have to be 


\section{TABLE A-1}

PARAMETER SUMMARY FOR PULSED HEATING AND COOLDOWN

COOLANT DELIVERY METHOD: LN 2 IN CONTACT WITH EDGES (OUTER SURFACE) OF TF COIL CONDUCTORS.

CURRENT DENSITY IN CONDUCTOR, $\mathrm{A} / \mathrm{cm}^{2}$

INITIAL CONDUCTOR TEMPERATURE, $K$

FINAL CONDUCTOR TEMPERATURE; $K$

CHARGEUP TIME, SEC

FLAT-TOP TIME, SEC

COOLDOWN TIME, SEC

PEAK INDUCTIVE POWER, MW

PEAK RESISTIVE POWER, MW

COST OF LN 2 PER 'PULSE, $\$$
4,000

80

150

18

8

1200

817

417

4,650 
metal, and might also provide some of the shielding requirements. Pumping would be used only to replace nitrogen boil-off and to provide positive pressure within the dewar to avoid water vapor condensation. The space required between the high field side of the TF coil and the dewar would be $\simeq 5 \mathrm{~cm}$.

An alternate approach, enclosing each TF coil in its own $\mathrm{LN}_{2}$ - filled dewar, was dismissed because of the much greater space requirements and possible consequent increase in machine size.

It is recognized that the pool immmersion approach requires a leakproof enclosure for the vessel and the neutral beamlines (as well as diagnostic and other penetrations). However these problems appear to have been overcome on other devices (e.g., ALCATOR), and the desire to minimize machine size overrides the objections.

\section{ADIABATIC HEAT RISE AND TRANSIENT COOLDOWN ANALYSIS}

Assuming that the copper plates are cooled at the edges only, the interior of the plates will rise in temperature during the pulse. The maximum operating copper plate temperature during a pulse cycle is an important design parameter; here it is $300 \mathrm{~K}$ maximum. But in addition, the bulk average temperature of the copper determines in large part the length of time required to cooldown between pulses. Two analyses were performed to determine the approximate boundaries of the parameter space for cooling. In the first, transient analys is for cooldown is studied. It is shown that for the reference TF coil radial build $(73 \mathrm{~cm})$ and current density $\left(4,000 \mathrm{~A} / \mathrm{cm}^{2}\right)$, cooldown within 20 minutes can be achieved. In the second, the effect of varying TF coil radial build on peak temperature and cooldown time is studied. The results show that the peak temperature is relatively insensitive to radial build, but that the cooldown time varies from 900 to 1500 seconds for radial builds varying from 50 to $100 \mathrm{~cm}$.

For this analysis each TF coil was assumed to be cooled only on the outer edges. The heat capacity of the adjacent steel plate is ignored. Due to symmetry, a thin copper plate with a conduction length half of the radial build of the coil was considered. The TF coil flat top time is taken to be 8 seconds. But the exact TF coil current ramp up and down times are not defined at this time. 
An equivalent 30 seconds square power pulse was, therefore assumed for the analysis. This assumed square pulse duration is quite conservative. A parametric transient calculation was performed considering several values of volumetric Joule heating rates ranging from 1.5 to $7.0 \mathrm{~W} / \mathrm{cm}^{3}$. The plate width considered was $37 \mathrm{~cm}$ (a half of the $73 \mathrm{~cm}$ TF coil radial build) and the surface heat transfer coefficients as a function of temperature difference (between plate edge and $L_{2}$ bulk temperatures) were obtained from Figure $A-1$ and eq. $(A-1)$. The calculated transient average copper temperatures at the various volumetric heating rates considered are shown in Figure A-5. The results for the two cases with $q^{\prime \prime \prime}=4.7$ and $4.8 \mathrm{~W} / \mathrm{cm}^{3}$ were replotted with temperature difference as a function of the cooldown time in Figure $A-6$.

It is seen from these figures that a Joule heating of $4.7 \mathrm{~W} / \mathrm{cm}^{3}$ is about the maximum value for a 30 seconds square pulse without raising the copper temperature into the film boiling regime. This corresponds to a maximum operating copper average temperature of $137 \mathrm{~K}$ and a peak copper temperature of $142 \mathrm{~K}$. Below this temperature the copper cooldown time is short. From this maximum heating rate the 1 imiting current density can then be determined by $Q^{\prime \prime}=J^{2} \rho(T, B)$, once the average copper resistivity $\rho(T, B)$ at an average temperature $T$ and magnetic field $B$ is known. For $\rho(90 \mathrm{~K}, 10 \mathrm{~T})=0.29 \times 10^{-6} \Omega-\mathrm{cm}, \mathrm{J}=\left(\frac{4.7}{0.29 \times 10^{-6}}\right)^{1 / 2}$ $=4000 \mathrm{~A} / \mathrm{cm}^{2}$, which is the reference current density. It is emphasized that the pulse length used in the calculation was assumed to be 30 seconds. With a shorter pulse duration, the maximum allowable current density could be higher than $4000 \mathrm{~A} / \mathrm{cm}^{2}$ without raising the copper temperature into the film boiling regime.

For plates with longer or shorter conduction length $(l)$, the peak copper temperatures at the end of a 30 second power pulse with the same heating rates are similar to that shown in Figure $A-5$. The difference in the peak average temperature for each case is about a few degrees, because the heating during the power pulse is nearly adiabatic for a very thin plate which is cooled at the narrow edges only. However, the length of the conduction path ( $l$ ) has a significant effect on the cooldown time of the plate. For a plate with a given conduction length $(\ell)$, the cycle time must be selected in such a way that if the copper is not cooled down to its initial temperature at the end of a cycle, the copper temperature oscillation should stabilize after a few cycles. Otherwise, a temperature excursion will occur. 


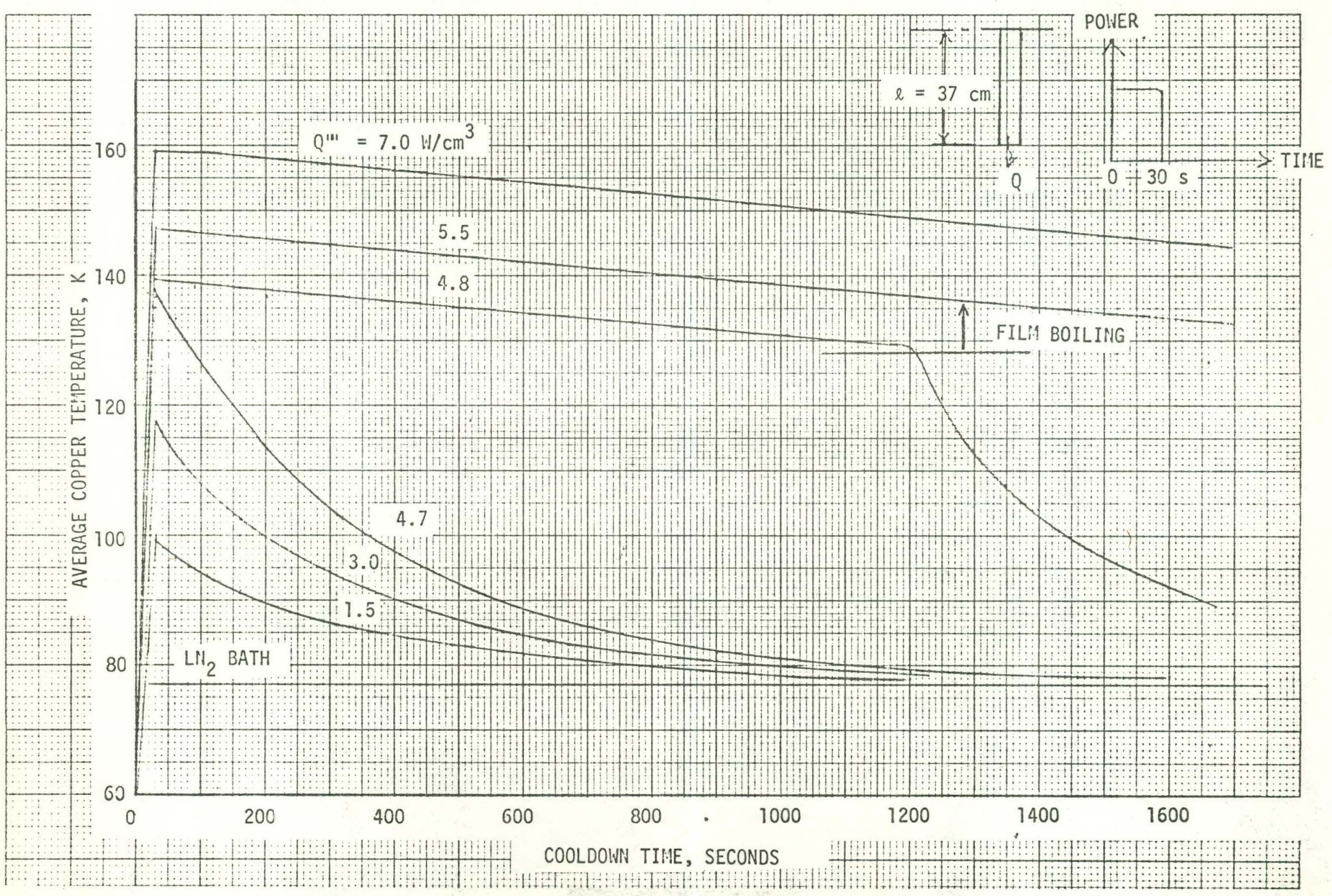

Figure A-5. Cooldown of Copper Plate Edge Cooled by $\mathrm{LN}_{2}$ 


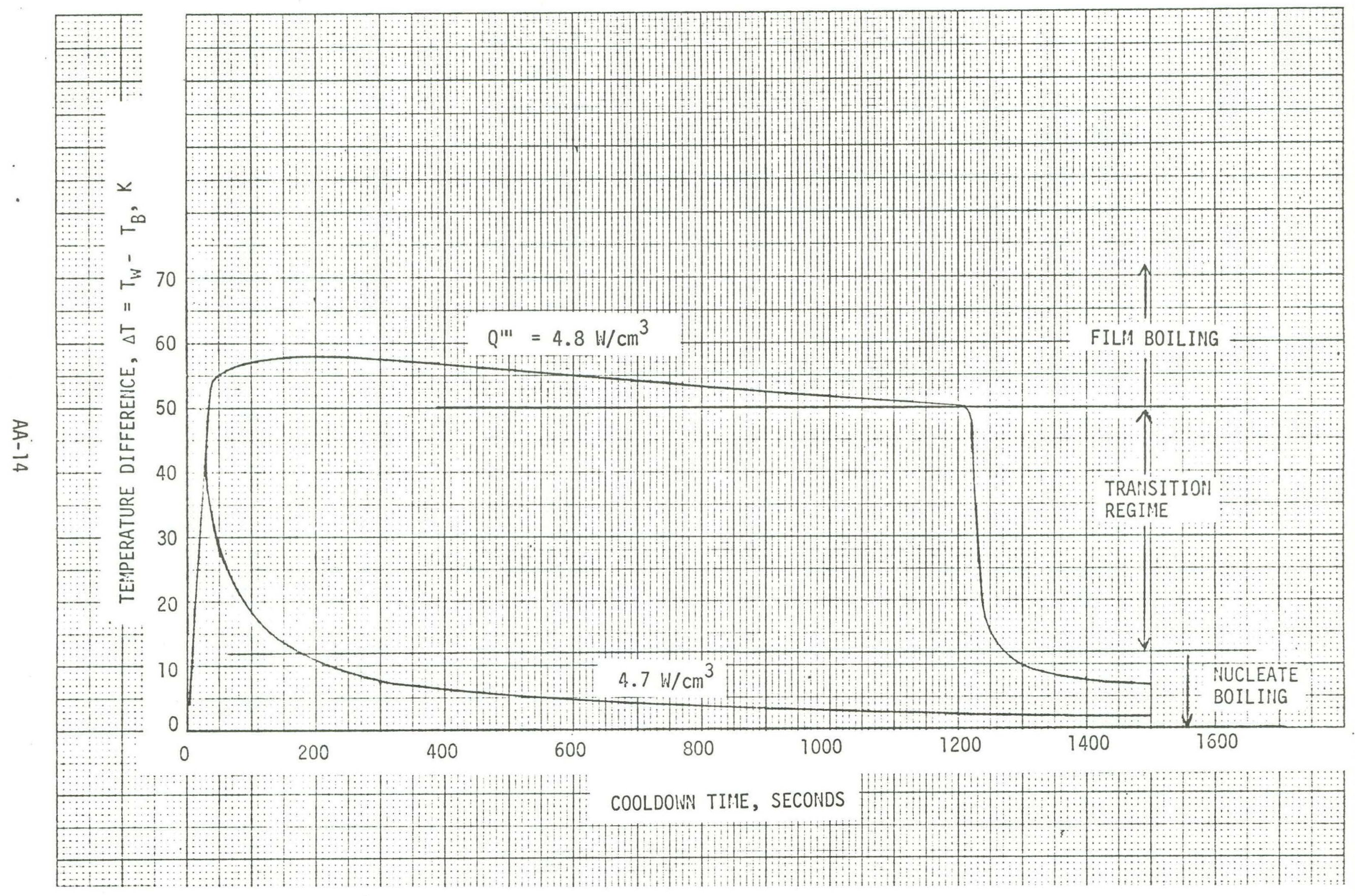

Figure A-6. Hall and Bach Temperature Difference During Cooldown of Copper Plate. 
Transient cyclic temperature distributions were computed for a plate with 3 different half widths $\ell=25,37$, and $50 \mathrm{~cm}$, but the same heating rate of $4.7 \mathrm{~W} / \mathrm{cm}^{3}$. The criterion for selecting the cycle period is that the equilibrium condition must be reached after 5 cycles. The results are that with $\ell=25 \mathrm{~cm}$, the cycle time is 900 seconds; with $\ell=37 \mathrm{~cm}, 1,200$ seconds and with $\ell=50 \mathrm{~cm} 1,500$ seconds. This indicates that different sizes of TF coils can be operated with the same maximum heating rate, but with different cycle times, to have about the same maximum copper operating temperature. The width of the coil is thus not constrained by the copper operating temperature, but rather by other design considerations, such as current density, power conversion system design and cost, and magnetic field requirements. These results indicate that the reference current of $4000 \mathrm{~A} / \mathrm{cm}^{2}$ and cooldown time of 20 minutes can be achieved to meet the design objections.

POWER SUPPLY IMPLICATIONS OF PULSED COOLING

In this section, TF coil peak resistive power and peak charging power are calculated for various coil initial temperatures and final temperatures. The calculations relate operating scenario, initial coil temperature and final coil temperature, and indicate ways to minimize power supply requirements. The relation between TF coil power supply requirements and power supply cost is qualitative, and based on two rules of thumb: a) the lower the requirements the better, and b) the more nearly equal the peak resistive and inductive powers the better.

Two studies were performed for this effort. In the first, resistive and charging powers are calculated for various starting temperatures based on a temperature at the end of the pulse limited by the material properties of the copper conductor. The average effective magnetic field is a parameter, being either $B=0 . T$ or $B=10 T$ to bound the effects of magnetoresistivity. In the second, these powers are calculated for a final temperature constrained by the time to cool the TF coils back to the initial temperature within 20 minutes (1200 seconds). Initial analyses provide the data for the main studies. 
The assumptions for these analyses are conservative, the principal one being that there is no cooling from the beginning to the end of the pulse. The coils heat adaibatically and uniformly during the pulse, so that the peak and average coil temperatures are the same. The operating scenario is idealized to that shown in Figure A-7. The flat-top time $\left(t_{f}-t_{r}\right)$ is held fixed at 8 seconds. The ramp-up $\left(t_{r}\right)$ and ramp-down $\left(t_{p}-t_{f}\right)$ times are assumed to be equal, and linear in shape. The effect of these conservative assumptions is indicated qualitatively in the text.

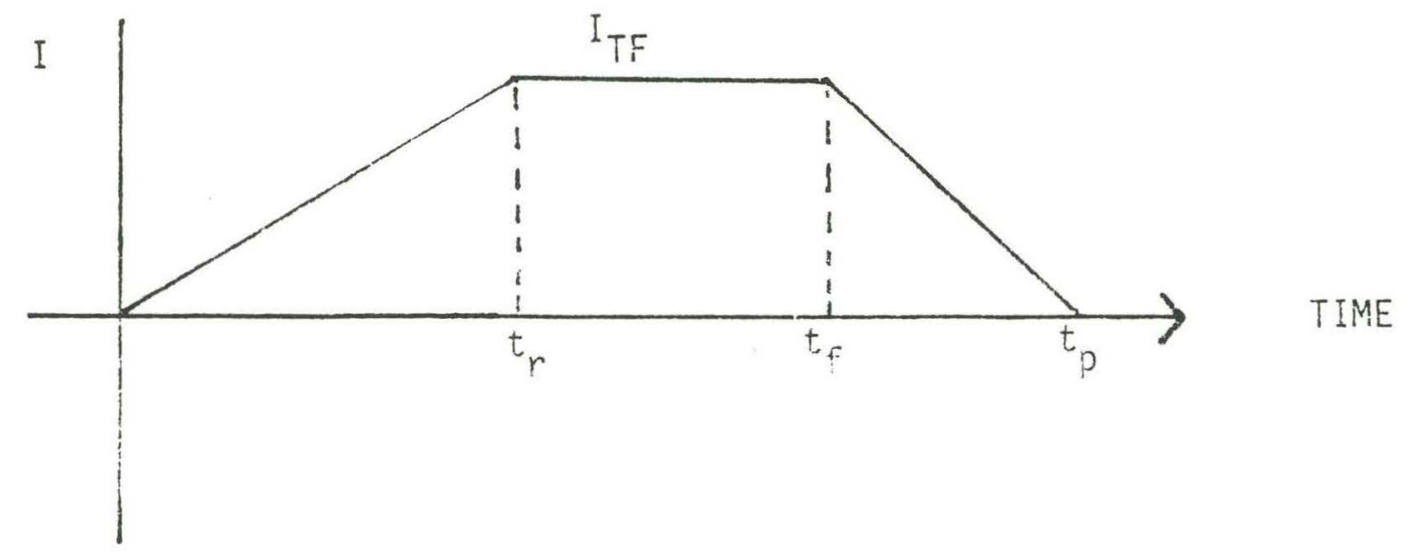

Figure A-7. Idealized Current Waveform in TF Coil 


\section{Adiabatic Temperature Rise of Copper}

In order to study the effect of current density $(J)$ and pulse time $(t)$ on the TF coil material temperature and to aid the assessment of the power supply system for the TF coils of the IDR, curves of coil temperature rise vs. (current) ${ }^{2}$ time were generated for the adiabatic heating of copper.

For adiabatic heating of the coil material, the coil temperature history can be computed for a unit volume of coil material by the following equation:

$$
D C_{p} \frac{d T}{d t}=J_{\rho}^{2}, W / \mathrm{cm}^{3}
$$

where

$$
\begin{aligned}
D & =\text { material density, } \mathrm{g} / \mathrm{cm}^{3} \\
C_{p} & =\text { specific heat, } \mathrm{J} / \mathrm{g}-\mathrm{K} \\
T & =\text { temperature, } \mathrm{K} \\
t & =\text { time, } \mathrm{s} \\
\mathrm{J} & =\text { current density, } \mathrm{A} / \mathrm{cm}^{2} \\
\rho & =\text { resistivity, } \Omega-\mathrm{cm}
\end{aligned}
$$

and $\quad C_{p}$ and $\rho$ are functions of temperature.

Rewriting Equation (2) and integrating, one obtains

$$
D \int_{T_{0}}^{T} \frac{C_{p}(T)}{\rho(T)} d T=\int_{t_{0}}^{t} J^{2} d t
$$




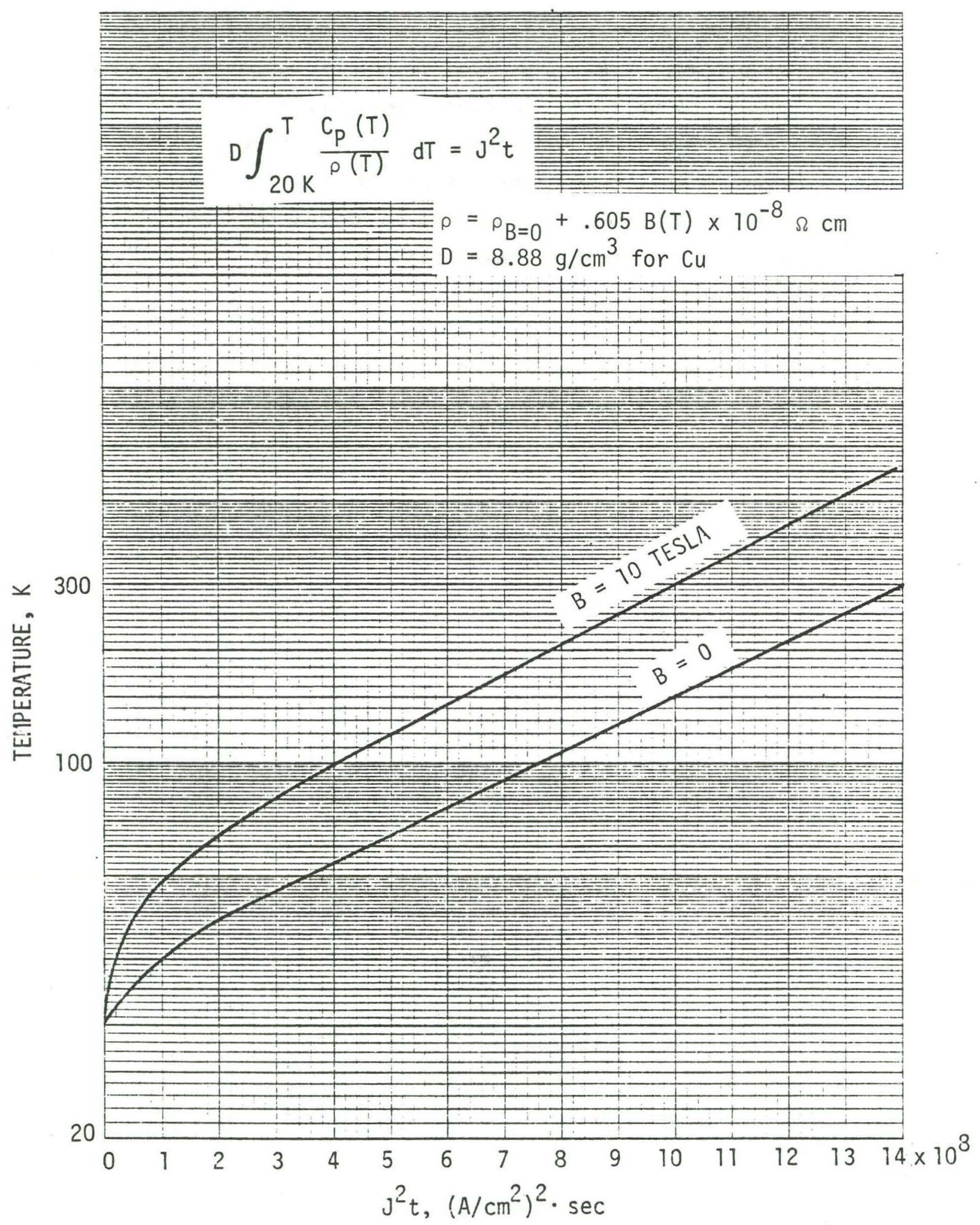

Figure A-8. Temperature VS. $\mathrm{J}^{2} \mathrm{t}$ of Copper at $\mathrm{B}=0$ and $\mathrm{B}=10 \mathrm{~T}$ 
Using the $C_{p}$ and $\rho$ values for $C u$ and $A 1$ as functions of temperatures shown previously, the left hand side of Equation $(A-3)$ at various temperatures is plotted in Figure $A-8$ as a function of $\mathrm{J}^{2} \mathrm{t}$ with $\mathrm{T}_{0}=20 \mathrm{~K}, \mathrm{t}_{0}=0 \mathrm{~s}$, and $B=0$ and $B=10 \mathrm{~T}$. These curves can be used for any starting or final temperature and $\mathrm{J}^{2} \mathrm{t}$ increment within the bounds of the graphs.

In the operating scenario of Figure A-7, the current ramps up linearly to current $\mathrm{I}_{\mathrm{TF}}$ (at current density $\mathrm{J}_{\mathrm{TF}}$ ), remains at that current for 8 seconds, and falls linearly with the ramp down time equal to the ramp up time. The latter is conservative, since the TR drop in the coil will allow it to be run down faster than it is run up.

The assumption of adiabatic temperature rise during the pulse and the scenario of. Figure A-7 allow the coil temperature at times $t_{r}$ (end of ramp), $t_{f}$ (end of flat top), and $t_{p}$ (end of pulse) to be calculated conveniently from the $T$ vs $J^{2} t$ curves. The reference flat-top current density is $4000 \mathrm{~A} / \mathrm{cm}^{2}$ for 8 seconds, so that in all case the integral of $\mathrm{J}^{2} \mathrm{t}$ is $1.28 \times 10^{8} \mathrm{~A}^{2} \mathrm{~cm}^{-2} \mathrm{~s}$. During ramp up the current density is $J(t) t / t_{r}$ for $0 \leq t \leq t_{r}$. The integral $J^{2} t$ is then

$$
\int_{0}^{t r} J^{2}(t) d t=\int_{0}^{t r} \frac{J^{2}{ }_{T F} t^{2}}{t_{r}{ }^{2}} d t=\frac{J_{T F} t r}{3}
$$

Since ramp-down is symmetric, the integral of $\mathrm{J}^{2} \mathrm{t}$ during combined ramp-up and ramp-down then equals $2 \mathrm{~J}^{2} \mathrm{TF} \mathrm{tr} / 3$. 


\section{TF Coil Set Resistive Power}

The total TF coil set power, $I^{2} R$, is equivalently given by $J^{2} \rho V$, where $V$ is the total volume of conductor in the TF coil set. That quantity is conveniently given by the total cross-sectional, area of conductdr $A c$, times the perimeter of a TF coil, which is approximately given by $0.5 \pi\left(R_{2}-R_{1}+2 H_{\max }\right)$. For the IDR III reference, $A C=4.22 \mathrm{~m}^{2}, R_{2}=4.99 \mathrm{~m}, R_{1}=1.34 \mathrm{~m}$, and $H_{\max }=5.31 \mathrm{~m}$, giving a coill conductor volume of about $60 \mathrm{~m}^{3}$. For the reference current density, $4000 \mathrm{~A} / \mathrm{cm}^{2}$, the TF, coil set power is then $\mathrm{J}_{\rho}^{2} \mathrm{~V} \simeq 9.6 \times 10^{16} \rho$, with $\rho$ in $\Omega-\mathrm{m}$.

The peak power requirement occurs at the end of the flat-top at time $t_{f}$. Taking the temperature at $t_{f}$ from the $J^{2} t$ curve of Figure $A-8$, the value of $\rho$ at that temperature from Figure $A-2$, and substituting into the formula above gives the peak resistive power.

\section{IF Coil Set Charging Power}

The peak charging (inductive) power for the linear ramp-up occurs just at the end of the ramp, and is given by:

$$
P \text { ind }=L I_{T F} \times \frac{I_{T F}}{t_{r}}
$$

This can be calculated most conveniently on a per-turn basis. For the IDR III reference, assuming a $D$-shaped coil, the inductance on a single-turn bas is is given by (11)

$$
L=\frac{0.4 \pi N^{2}\left(R_{2}-R_{1}-0.333 \Delta_{T F}\right)^{2} H_{\max } \times 10^{-6}}{\left(R_{2}-R_{1}\right)\left[R_{2}+R_{1}+\sqrt{4 R_{2} R_{1}-0.666 \Delta_{T F}\left(R_{2}-R_{1}\right)}\right]}
$$


With the parameters $R_{2}=4.99 \mathrm{~m}, R_{1}=1.34 \mathrm{~m}, H_{\max }=2.66 \mathrm{~m}, \Delta_{T F}=0.727 \mathrm{~m}$, and $N I=152 \mathrm{MAT}$, we have $L=0.938 \mu \mathrm{H} /(\text { turn })^{2}$ and $L I=0.938 \mu \mathrm{H} / \mathrm{T}^{2}(152 \mathrm{MAT})$ $=143 \mathrm{~V}-\mathrm{s} /($ turn $)$. Then

$$
\widehat{p}_{\text {ind }}=\text { peak charging power }=\frac{152 \mathrm{MAT}}{\mathrm{t}_{\mathrm{r}}} \times 143 \mathrm{~V}-\mathrm{s} / \mathrm{T}=21.7 \mathrm{GJ} / \mathrm{t}_{\mathrm{r}} .
$$

The disadvantage of linear charging appears to be too great to ignore. Exponential $\left[I=I_{0}\left(I-e^{-t / \tau}\right)\right]$ charging reduces peak charging power by a factor of $\sim 1.4$, so assume exponential charging for the purposes of calculations, i.e., use

$$
\widehat{P}=15.5 \mathrm{GJ} / \mathrm{tr}
$$

As a general indication of power supply requirements, note that

$$
\frac{1}{2} L I^{2}=\frac{1}{2} 0.938 \mu H / T^{2}(152 M A T)^{2}=10.8 \mathrm{GJ}
$$




\section{Power Supply Requirements with Material - Constrained Final Temperature}

In this section peak resistive and charging (inductive) power supply requirements are calculated for final coil temperature (at the end of a pulse) limited by the necessity to avoid annealing the hardened copper conductor. This is done in order to provide data for determining the capital cost of the TF coil power supply. Since the power supply requirements depend heavily on the operating scenario - the ramp up and ramp done times - and on the interrelation with coil temperature, the TF coil power supply requirements have been treated parametrically in order to help select the least costly power supplies, within the limitations of the approximations and assumptions of this scoping study. Power supply requirement based on cooldown time constrained final copper temperature is discussed in the next section.

The initial temperature of the TF coil set was varied from $30 \mathrm{~K}$ to $110 \mathrm{~K}$ to indicate not only the effect of starting at various temperatures above $L_{2}$, but also to investigate whether subcooled $\mathrm{LN}_{2}$ or some other fluid, such as argon or hydrogen, might be advantageous. The final temperature of the TF coil was fixed at $300 \mathrm{~K}$, the assumed limit to avoid annealing the hardened copper, for initial temperatures of $77 \mathrm{~K}$ up. For initial temperatures of $77 \mathrm{~K}$ down, the final temperature was fixed at $250 \mathrm{~K}$.

The magnetic field inside the TF coil varies from a peak of $18 \mathrm{~T}$ to $\approx 5 T$ with increasing distance from the vertical axis, and down to zero across the radial build of the coil. For this scoping study the effect of magnetoresistivity was bracketed by performing the calculations above assuming resistivity corresponding to $B=0$ and to $B=10 T$.

The method of performing the calculations was as follows. The temperature rise from the initial to the final temperature corresponds to an increment of. $J^{2} t$ read from the graph in Figure A-8. Subtracting the constant increment for the 8 - second flat-top portion of the pulse, $1.28 \times 10^{8} \mathrm{~A}^{2} \mathrm{~cm}^{-2} \mathrm{~s}$, leaves the $\mathrm{J}^{2} \mathrm{t}$ increment to be divided evenly between ramp up and ramp down. The temperatures at the end of ramp up and at the beginning of ramp down were then read from 
Figure A-8. The peak charging power is calculated from the ramp time and coil inductance. The temperature at the end of the pulse flat top determines the resistivity at the end of the flat-top and thus the peak resistive power. By this method entries in Table $A-2$, for $B=0 T$, and Table $A-3$, for $B=10 T$, were calculated.

While subcooled liquid nitrogen, argon, or hydrogen can achieve various of the temperatures below $77 \mathrm{~K}$, no evaluation of the capital or operating costs of these has been made, in particular for cooling, recycle and safety equipment.

The calculations above indicate that further study would be necessary in order to show clear superiority of cooling the TF coils below $77 \mathrm{~K}$. On the other hand, the penalty for cooling to temperatures only slightly above $77 \mathrm{~K}$ cannot be evaluated more closely than to indicate an increase in power supply requirements of $\simeq 5-10 \%$ for starting at $90 \mathrm{~K}$ and rising to $300 \mathrm{~K}$.

The peak resistive power snown in these Tables is higher than would occur in reality since, as noted before, to simplify the mechanics of the analysis it has been assumed that the entire TF coil is at the hot spot temperature, and that there is no cooling at all over the entire pulse period. Nonetheless, some conclusions can be drawn even in the presence of the assumptions.

Firstly, the variation in initial temperature appears to offset the peak charging and resistive powers much more than the variation in assumed field, except, plausibly, at very low temperatures where magnetoresistance begins to dominate.

Secondly, the power supply must be capable of delivering about $1 / 2 \mathrm{GW}$ into a resistive load, and that at the end of the flat top portion of the pulse. 
Table A-2. Peak Resistive and Charging Powers for Material Limited Final Temperature, $\mathrm{B}=\mathrm{OT}$

\begin{tabular}{|c|c|c|c|c|c|c|c|}
\hline & $T_{0}$ & $J^{2} t$ & $t_{\text {ramp }}$ & $T_{r}$ & $T_{f}$ & $L I \frac{d I}{d t}$ & $I^{2} R$,peak \\
\hline & $30 \mathrm{~K}$ & $12.1 \times 10^{8}$ & $101 \mathrm{sec}$ & $82 \mathrm{~K}$ & $103 \mathrm{~K}$ & $153 \mathrm{MW}$ & $.286 \mathrm{MW}$ \\
\hline$\uparrow$ & $40 \mathrm{~K}$ & $10.8 \times 10^{8}$ & $88.8 \mathrm{sec}$ & $91 \mathrm{~K}$ & $114 \mathrm{~K}$ & $775 \mathrm{MW}$ & $347 \mathrm{MW}$ \\
\hline$T_{f}=250 \mathrm{~K}$ & $50 \mathrm{~K}$ & $9.5 \times 10^{8}$ & $76.7 \mathrm{sec}$ & $100 \mathrm{~K}$ & $126 \mathrm{~K}$ & $202 \mathrm{MW}$ & $417 \mathrm{MW}$ \\
\hline$\downarrow$ & $60 \mathrm{~K}$ & $8.4 \times 10^{8}$ & $67.3 \mathrm{sec}$ & $110 \mathrm{~K}$ & $137 \mathrm{~K}$ & $230 \mathrm{MW}$ & 479. MW \\
\hline$\uparrow$ & $80 \mathrm{~K}$ & $7.8 \times 10^{8}$ & $60.7 \mathrm{sec}$ & $140 \mathrm{~K}$ & $170 \mathrm{~K}$ & $255 \mathrm{MW}$ & $664 \mathrm{MW}$ \\
\hline$=300 \mathrm{~K}$ & $90 \mathrm{~K}$ & $7 \times 10^{8}$ & $53.3 \mathrm{sec}$ & $145 \mathrm{~K}$ & $180 \mathrm{~K}$ & $291 \mathrm{MW}$ & $726 \mathrm{MW}$ \\
\hline & $100 \mathrm{~K}$ & $6.4 \times 10^{8}$ & $47.7 \mathrm{sec}$ & $155 \mathrm{~K}$ & $193 \mathrm{~K}$ & $325 \mathrm{MW}$ & $776 \mathrm{MW}$ \\
\hline t & $110 \mathrm{~K}$ & $5.9 \times 10^{8}$ & $43.0 \mathrm{sec}$ & & & & \\
\hline
\end{tabular}

Table A-3. Peak Resistive and Charging Powers for Material Limited Final Temperature, $\mathrm{B}=10 \mathrm{~T}$

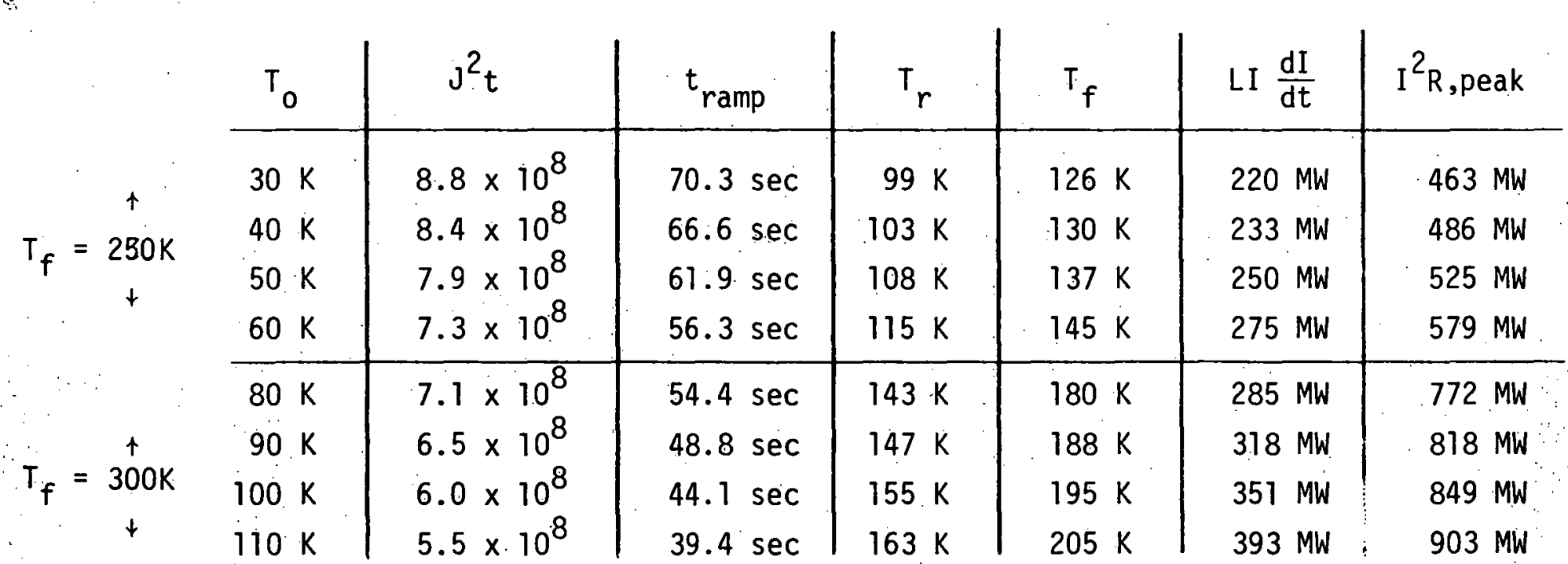


Since the real $I^{2} R$ peak will be somewhat lower than that calculated, and thus more nearly comparable to the charging power, for least power requirements it may be advantageous to take about a minute to charge up to full coil current. This seems plausible in view of the TF coil set stored energy, $\simeq 10 \mathrm{GJ}$. Longer charging times are allowable for lower initial temperatures, and conversely.

Cooling below the temperature of liquid nitrogen appears to be desirable from the standpoint of reducing power supply requirements, but nonetheless it does not appear that these requirements can be reduced by much more than a factor of two by cooling below $77 \mathrm{~K}$.

\section{Power Supply Requirements with Cooldown Constrained Final Temperature}

A ground rule of this study is that the cooldown time between pulses should be no greater than twenty minutes. The cooldown time and the maximum average operating copper temperature were discussed in the section on adiabatic heat rise and transient cooldown. A conservative design can then be made by limiting the hot-spot temperature at the end of a pulse to less than the average temperature which gives a 20 minute cooldown time, with pool boiling cooling by $\operatorname{LN}_{2}$.

Retaining the ground rule that cool-down must be accomplished in 20 minutes, the results in Figure $A-5$ restrict the final temperature to $150 K_{\text {; }}$ Using the same coil charging model as in the previous calculations and including the effects of magnetoresistance at $10 \mathrm{~T}$, the table below is derived.

Table A-4. Power Supply Requirements with Final Hot-Spot Temperature of $150 \mathrm{~K}$, $B=10 \mathrm{~T}$.

\begin{tabular}{c|c|c|c|c|c|c}
\multicolumn{1}{c|}{$T_{0}$} & $\mathrm{~J}^{2} \mathrm{t}$ & $t_{\text {ramp }}$ & $T_{r}$ & $T_{f}$ & $L I \frac{\mathrm{dI}}{\mathrm{dt}}$, peak & $\mathrm{I}^{2} \mathrm{R}$, peak \\
\hline $40 \mathrm{~K}$ & $5.6 \times 10^{8}$ & $40.3 \mathrm{sec}$ & $76 \mathrm{~K}$ & $100 \mathrm{~K}$ & $385 \mathrm{MW}$ & $324 \mathrm{MW}$ \\
$60 \mathrm{~K}$ & $4.5 \times 10^{8}$ & $30.0 \mathrm{sec}$ & $86 \mathrm{~K}$ & $113 \mathrm{~K}$ & $517 \mathrm{MW}$ & $386 \mathrm{MW}$ \\
$80 \mathrm{~K}$ & $3.2 \times 10^{8}$ & $17.8 \mathrm{sec}$ & $98 \mathrm{~K}$ & $125 \mathrm{~K}$ & $871 \mathrm{MW}$ & $417 \mathrm{MW}$ \\
$90 \mathrm{~K}$ & $2.7 \times 10^{8}$ & $13.1 \mathrm{sec}$ & $104 \mathrm{~K}$ & $133 \mathrm{~K}$ & $1,183 \mathrm{MW}$ & $494 \mathrm{MW}$ \\
$100 \mathrm{~K}$ & $2.2 \times 10^{8}$ & $8.4 \mathrm{sec}$ & $110 \mathrm{~K}$ & $140 \mathrm{~K}$ & $1,845 \mathrm{MW}$ & $540 \mathrm{MW}$
\end{tabular}


The limitation on final temperature reduces the time allowable to charge the TF coil set to full current, and in contrast to the previous cases, the charging power now exceeds the inductive power. With a restriction of $150 \mathrm{~K}$ final temperature, sub-cooling becomes more attractive in matching charging and resistive powers. If cooling can be achieved within a reasonable time and for a reasonable operating cost, cooling below boiling nitrogen temperatures appears to be desirable from the standpoint of lowering power supply costs and particularly of lowering charging requirements below the 111 -defined crossover point, below which motor-generator-flywheel buffers are unnecessary. More information is needed before the credibility of reasonable times for cooldown can be established.

Also, the penalty for cooling the coil set to temperatures much greater than $77 \mathrm{~K}$ is much greater for the cooldown limited peak temperature $(150 \mathrm{~K})$ than for the material limited peak temperature $(300 \mathrm{~K})$. While more definitive analyses, which would include the effect of cooling during the pulse and the spatialtemporal variation, must be performed, it appears that an initial temperature $90 \mathrm{~K}$ or below will be required in order to avoid the film boiling regime.

\section{LIQUID NITROGEN OPERATING COST FOR PULSED HEATING AND COOLDOWN}

Remembering that adiabatic heating is a pessimistic assumption and that we are only calculating an upper bound on operating costs, we will examine the cost of cooling the TF coil set from $150 \mathrm{~K}$ to $80 \mathrm{~K}$. The enthalpy change in vaporizing $\mathrm{LN}_{2}$ is about $8.12 \times 10^{4} \mathrm{~J} / 1 \mathrm{~b}$ (Reference 14 ). The cost of $L_{2}$ delivered is about $0.25 \$ / g a l i o n$. To cool down to $80 \mathrm{~K}$ from $150 \mathrm{~K}$, requires a $\Delta H$ of 24.5 $5.4=19.1 \mathrm{~J} / \mathrm{g} \times 59.5 \mathrm{~m}^{3} \times 8,940 \mathrm{~kg} / \mathrm{m}^{3} \times 10^{3} \mathrm{~g} / \mathrm{kg}=10.2 \mathrm{GJ} / \mathrm{pulse}$. In a pool of liquid nitrogen, this would cost:

$$
\begin{aligned}
\$, \text { pulse } & =\frac{\$ 0.25}{\text { gal }} \times \frac{10.2 \times 10^{9} \mathrm{~J}}{\text { pulse }} \times \frac{1 \mathrm{lb}}{81.2 \times 10^{4} \mathrm{~J}} \times \frac{7.48 \mathrm{gal}}{1 \mathrm{ft}^{3}} \times \frac{1 \mathrm{ft}^{3}}{50.5 \mathrm{lb}} \\
& =\$ 4,650 / \text { pulse. }
\end{aligned}
$$

and consume $=18,600$ gallons of fluid. At an annual operating cost of $\$ 20 \mathrm{M}$, this would allow $\$ 20 \mathrm{M} / \$ 11=4,300 \mathrm{pulses} /$ year. 


\section{A.3 STEADY STATE TF COIL OPERATION}

As used here, steady state operation means that joule heat generated in the TF coil conductor is removed as rapidly as it is generated, and the peak temperature anywhere in the conductor is not much above the temperature of the liquid nitrogen coolant. The motivation for steady-state cooling is two fold. First, the pulse length is not limited by cooling considerations. This enhances the value of the machine as an experiment, since the flat-top time can be extended to study burn dynamics and other phenomena of interest. Second, operating at a lower average temperature gives hope that resistive power requirements can be reduced, and that the charging time can be extended to some convenient interval, thus reducing power supply capital costs.

From the outset, it should be recognized that there is no particular advantage in the operating cost for liquid nitrogen. If the ultimate heat removal is by boiling $\mathrm{LN}_{2}$, then all joule heat generated translates directly to $\mathrm{LN}_{2}$ loss, and a scenario like that for pulsed cooling will imply nearly the same $\mathrm{LN}_{2}$ cost per pulse.

The design changes imply some increases in capital cost. Mechanical design of the TF coil becomes more complex, since liquid nitrogen must be circulated within the coil to ensure adequate cooling. Thermal and mechanical design interact strongly, and in some ways the necessity to prevent thermal excursions is reminiscent of design problems for forced-flow cooled superconductors. Headers are required to bring in and carry away the coolant. Extra equipment, in the form of pumps, headers, etc., are required, and these contributions both to capital and operating costs.

The intent of the studies performed here is to establish the major requirements and basic feasibility for steady-state operation. The TF coil set has been the focus of attention, and the peripheral equipment has only been indicated. As before, requirements and consequences have been estimated conservatively, i.e., on the side of more stringent requirements and higher costs. A preliminary scoping analys is sets the geometry of coolant delivery 
to the conductors. This geometry forms the basis for scoping relations for $I^{2} R$ loss, pressure drop, and pumping power. From these scoping relations, point parameters are picked, and $\mathrm{LN}_{2}$ flow rate and pumping power are calculated. Power supply implications are also derived.

The incremental capital cost with respect to a machine designed for pulsed cooling is calculated based on manufacturing considerations for the TF coils, extra equipment required, and savings in TF coil power supplies. The operating cost for $\mathrm{LN}_{2}$ is calculated both on a per unit time basis, and for a pulse scenario with an 8 second flat-top time.

The principal numerical parameters of the point design are shown in Table A-5. The principal conclusions of this section are as follows:

- Steady state operation of the reference design is feasible - thermaliy, mechanically and electrically;

- The capital cost of TF coil power supplied would decrease significantly, by $5 \mathrm{M} \$$ or more; and the peak power to the TF coil set would decrease by about $300 \mathrm{MW}$;

- The net capital cost of the machine, including extra equipment and TF coil machining, would decrease by 2 - $3 M \$$ compared to the cost of a pulse cooled machine;

- The $L N_{2}$ operating cost, for an equivalent single pulse, ${ }^{2}$ for a machine designed for steady state operation would increase by about $25 \%$ over that of a machine designed for pulsed heating and cooldown;

- The technological risk, and possibly the time required for construction, uwould increase as compared to a machine designed for puilsed cooling, due to extra equipment, plumbing, and TF coil conductor machining. 
TABLE $A-5$

PARAMETER SUMMARY FOR STEADY-STATE TF COIL OPERATION

COOLANT DELIVERY METHOD: SINGLE-PHASE LN 2 PUMPED THROUGH CHANNELS CUT INTO CONDUCTOR PLATES

CURRENT DENSITY (AVERAGED OVER CONDUCTOR

AND CHANNELS), $A / \mathrm{cm}^{2}$

4,000

$\mathrm{T}_{j}, \mathrm{LN}_{2}$ ENTRY TEMPERATURE, $K$

$\mathrm{T}_{\mathrm{e}}, \mathrm{LN}_{2}$ EXIT TEMPERATURE, $K$

90

$P_{e}$, EXIT PRESSURE, psia (atm)

$50(3.4)$

$W_{T}, L_{2}$ TOTAL FLOW RATE, $\mathrm{kg} / \mathrm{s}$

$1.26 \times 10^{4}$

$\triangle \mathrm{P}$, PRESSURE DROP, (over $9 \mathrm{~m}$ channel) psi (atm)

$100(6.8)$

$P_{e}$, PUMPING POWER, MWe

$I^{2} R$, RESISTIVE LOSS IN TF COIL, MW

328

NET SAVINGS IN CAPITAL COST w.r.t. PULSED COOLING

$\gtrsim 2 M \$$

OPERATING COST OF $\mathrm{LN}_{2} \$ / \mathrm{S}$

COST OF LN 2 FOR REFERENCE PULSE, \$

7,000 
MECHANICAL CONCEPT FOR COOLING DELIVERY

The purpose of this section is to define the basic mechanical concepts for coolant delivery. This will set the stage for the point thermal design establishing the feasibility of steady-state cooling, and also. sharpen the perception of further mechanical design work required.

The basic mechanical design concept for the TF coils remains as before: al ternating plates of copper, stainless steel and insulation, divided into 20 discrete TF coil packages. In order to hold the thermal path length to a value consistent with low-temperature operation, it is necessary to deliver the $\mathrm{LN}_{2}$ through channels within the $T F$ coil. To maximize the perimeter of the channel in contact with the copper, the channels are cut into the copper. These channels are aligned approximately with the neutral axis of the TF coil at the inner and outer legs, as shown in Figure A-9. This figure also shows a header at the top and bottom of each coil. The coolant enters at the bottom header, divides into two streams feeding the inner and outer legs of the TF coils and exits at the top. "No analysis has been done to determine the extent of stress concentrations at the channels feeding from and to the headers. Though dewars around the TF coils have been considered, arguments for economy of space in the tokamak assembly still lead to immersing the Tokamak assembly in a pool of liquid nitrogen as in the pulse heating case. The mechanical difference simply is the channels and headers for the TF coil legs. Immersion of course provides edge as well as internal cooling to the TF coils, but this effect is ignored in the analysis for conservatism.

The reference geometry for coolant channels is shown in Figure A-10. Liquid nitrogen enters a channel under pressure and absorbs joule heat as it traverses the channel. Simultaneously the pressure drops due to frictional losses. 


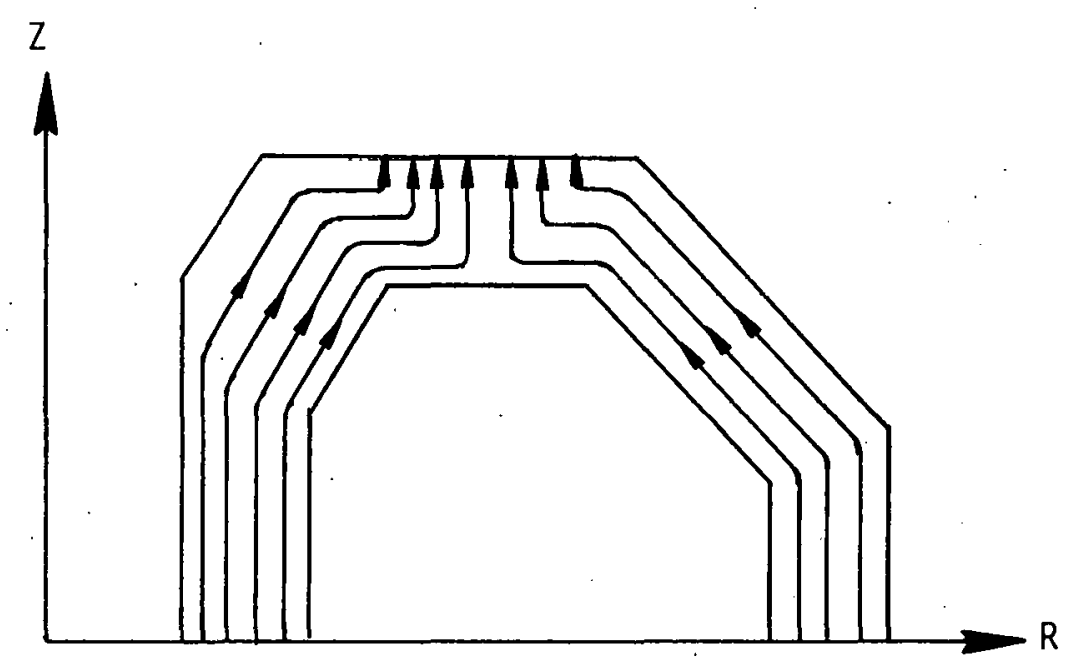

Figure A-9. Coolant Flow and Channel Orientation for Steady-State Operation. 


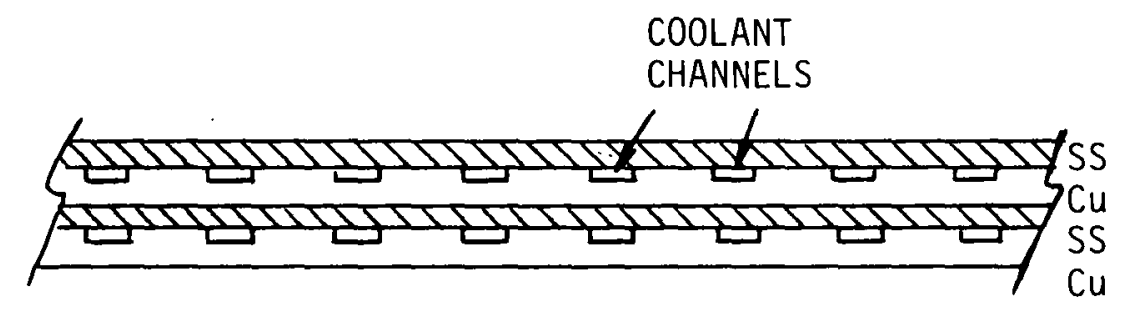

(a) TF Coil Cross-Section Showing Coolant Channels

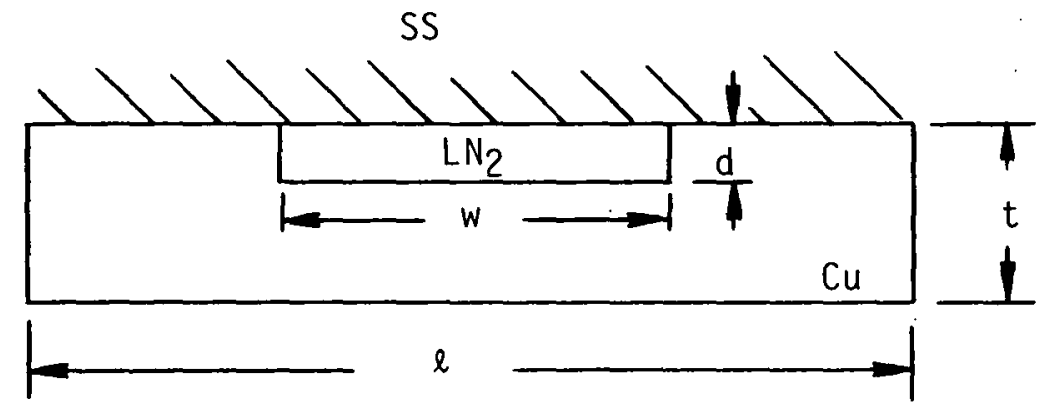

(b) Symmetric Segment for Thermal - Hydraulic' Analys is

Figure A-10. Reference Coolant Channel Geometry. 
STEADY STATE THERMAL AND HYDRAULIC DESIGN

In this section a point thermal design for steady-state cooling is performed, with the objective of determining basic feasibility and illustrating the principal trade-offs involved. The total $I^{2} R$ loss in the coil set, pressure drop and pumping power are formulated as a function of the average current density and fraction of area devoted to the channels, based on a single phase flow model. The point design so derived is checked against computations for copper temperature. The operating cost per unit time is calculated.

\section{Design Considerations}

From the point of view of the machine size, the current density averaged over conductor and channel area is a crucial design parameter. The reference value is $4 \mathrm{k} \mathrm{A} / \mathrm{cm}^{2}$. From the point of view of the TF coil set power supply, the current density in the conductor itself is a crucial design parameter. Ideally it approaches the reference value. The conductor current density also determines the joule heat the channel coolant must remove. The less joule heat the easier thermal design becomes. From the point of view of the pressure drop and pumping power required, the joule heat, channel geometry, and channel area are key design parameters. The larger and more compact the coolant channel, the less the pressure drop, pumping power, and pump cost. In order that the copper transmit force to the steel plate, the copper-steel contact area should be preserved as much as possible. From the point of view of TF coil machining cost, the fewer plates, channels, and the less material removed the cheaper. These desires cannot be achieved simultaneously. Rather it is a matter of tradeoffs, largely due to the basic design requirements. These requirements and tradeoffs are made explicit in the following sections. 


\section{Design Assumptions}

Some starting points for thermal and hydraulic design have been determined al ready by the reference configurational size. These are shown in Table A-6. In this analysis it is necessary to be somewhat particular about the composition of the inner legs of the TF coils (nose area), where the conditions for cooling are most critical. Of the total area for copper, coolant channels, and insulation, $10 \%$ was alloted arbitrarily to insulation in the reference design.

For the purposes of thermal design it is assumed that no heat is transmitted through the steel plate, and that the coolant carries away all joule heat. The current density is assumed constant throughout the copper. The copper plates are assumed to be of constant thickness $t$. The channel length shown in Table A-7 is more than half the TF coil neutral axis perimeter shown in Table A-6 and is intended to take into account the extra length of channels near the headers.

Though a thorough thermal-hydraulic-electrical analysis would require extensive computation, it has not been felt necessary to apply computer programs for a scoping study. Rather, simplifying but realistic and representative assumptions have been invoked to make hand calculations. The basic assumptions are that the copper temperature is constant throughout at $90 \mathrm{~K}$, and that the $\mathrm{LN}_{2}$ coolant stays in single phase in turbulent flow. Liquid nitrogen is assumed to enter the channel at $77 \mathrm{~K}$ and exit at $90 \mathrm{~K}$ and $3.4 \mathrm{~atm}$. (50 psia). From Reference 14, the appropriate constants for the analys is are shown in Table A-7. The constants $\rho, H, V$, and $\operatorname{Pr}$ vary sufficiently slowly with pressure over the range $3.4 \mathrm{~atm}$. $13.6 \mathrm{~atm}$. that the values for $3.4 \mathrm{~atm}$. are used for this scoping analysis. 
TABLE A-6

REFERENCE CONFIGURATIONAL PARAMETERS FOR THERMAL HYDRAULIC DESIGN

NI, TOTAL AMPERE-TURNS

$\bar{J}=\left(N I /\left(A_{c}+A_{h}\right)\right)$, AVERAGE CURRENT DENSITY

$A_{n}$, TOTAL NOSE AREA

$A_{S}$, AREA OF STEEL

$A_{i}$, AREA OF INSULATION

$A=\left(A_{c}+A_{h}\right)$, AREA OF CONDUCTOR AND COOLANT.

$\mathrm{R}_{\mathrm{m}}$, RADIUS OF HIGH FIELD SIDE OF TF COIL

$R_{1}$, RADIUS OF NEUTRAL AXIS AT, NOSE

$\triangle T F$, TF COIL RADIAL BUILD

$L_{c}$, PERIMETER OF NEUTRAL AXIS

$V$, REFERENCE VOLUME OF CONDUCTOR AND COOLANT CHANNELS
152 MAT

$4 \mathrm{kA} / \mathrm{cm}^{2}$

$6.06 \mathrm{~m}^{2}$

$1.84 \mathrm{~m}^{2}$

$0.422 \mathrm{~m}^{2}$

$3.8 \mathrm{~m}^{2}$

$1.69 \mathrm{~m}$

$1.34 \mathrm{~m}$

$0.73 \mathrm{~m}$

$14 \mathrm{~m}$

$53.2 \mathrm{~m}^{3}$ 
TABLE A-7

REFERENCE CONSTANTS AND CONVERSION FACTORS FOR

THERMAL-HYDRAUL IC DESIGN

$T_{i}$, ENTRANCE TEMPERATURE

$T_{e}$, EXIT TEMPERATURE

$P_{e}$, EXIT PRESSURE

L, CHANNEL LENGTH

$\rho$, DENSITY OF LN 2 AT $90 \mathrm{~K}, 3.4 \mathrm{~atm}$

H $(90 \mathrm{~K}, 3.4 \mathrm{~atm})$, ENTHALPY

H $(77 \mathrm{~K}, 3.4 \mathrm{~atm})$, ENTHALPY

$\mu(90 \mathrm{~K}, 3.4 \mathrm{~atm})$, VISCOSITY

$\operatorname{Pr}(90 \mathrm{~K}, 3.4 \mathrm{~atm})$

$\rho_{C}$, RESISTIVITY OF COPPER AT $90 \mathrm{~K}$

$k_{c}$, THERMAL CONDUCTIVITY OF COPPER AT $90 \mathrm{~K}$

g, ACCELERATION OF GRAVITY

1 Btu

$\mathrm{lft}$

$\mathrm{lft}-\mathrm{lb}$

1 psi

$1 \mathrm{ft}^{3}$

1 $1 \mathrm{~b}, \mathrm{LN}_{2}$ \& $77 \mathrm{~K}, 14.7 \mathrm{psia}$
$77 \mathrm{~K}$

$90 \mathrm{~K}$

$3.4 \mathrm{~atm}(50 \mathrm{psia})$

$9 \mathrm{~m}$

$46.8 \mathrm{lb} / \mathrm{ft}^{3}\left(749.7 \mathrm{~kg} / \mathrm{m}^{3}\right)$

$-41.27 \mathrm{Btu} / 1 \mathrm{~b}(-95.99 \mathrm{~kJ} / \mathrm{kg})$

$-52.47 \mathrm{Btu} / \mathrm{lb}(-122.04 \mathrm{~kJ} / \mathrm{kg})$

$1.1 \times 10^{-5} \mathrm{lb} / \mathrm{ft}-\mathrm{sec}\left(1.637 \times 10^{-5} \mathrm{~kg} \mathrm{~m}^{-1} \mathrm{~s}^{-1}\right)$

2.14

$0.28 \mu \Omega-\mathrm{cm}$

$4 \mathrm{~W} / \mathrm{cm}-\mathrm{K}$

$32.2 \mathrm{ft} / \mathrm{s}^{2}\left(9.814 \mathrm{~m} / \mathrm{s}^{2}\right)$

$1055 \mathrm{~J}$

$30.5 \mathrm{~cm}$

$1.356 \mathrm{~J}$

$6.895 \mathrm{kPa}$

$7.48 \mathrm{gal}$

0.148 
Power Dissipation, Pressure Drop, and Pumping Power

From the assumptions made in the previous section it suffices to consider a single channel and surrounding copper segment as shown in Figure A-10. The heat flux is zero on the boundary except at the wetted channel perimeter. The design requirements considered here are:

- The thermal path length in the copper from the coolant to the furthest boundary must not lead to a temperature gradient, $\Delta T$, greater than some fixed number;

- The total flow rate of liquid nitrogen must be sufficient to remove the TF coil ${ }^{2}{ }^{2}$ dissipation under the assumed conditions;

- The flow rate and coolant channel parameters must result in a wall-bath temperature difference compatible with the assumed conditions.

In terms of the segment dimension, the number of copper and steel plates in the TF coil set is given approximately by:

$$
n_{p} \cong \frac{A}{\Delta T F t}
$$

and the total number of cooling channels is given approximately by

$$
n_{c} \cong \frac{2 A}{\ell t}
$$

where both the inner and outer legs are counted.

Some design requirements can be written in terms of the geometry and the void fraction

$$
\bar{\varepsilon}=\frac{w d}{\ell t}=\frac{A_{h}}{A}
$$

For the volumetric heat generation we have

$$
q^{\prime \prime \prime}=J_{c}^{2} \rho_{c}=\frac{J^{2} \rho_{c}}{(1-\varepsilon)^{2}}=\frac{4.48 \mathrm{~W} / \mathrm{cm}^{3}}{(1-\varepsilon)^{2}}
$$


This gives the TF coil set power dissipation in terms of the average current density, nose area, and coil neutral axis perimeter as:

$$
I^{2} R=\frac{\bar{J}^{2}{ }{ }_{C} A{ }^{A}{ }_{C}}{1-\varepsilon}=\frac{265}{1-\varepsilon}
$$

evaluated at the reference parameters. Note that the $I^{2} R$ power can be $40 \%$ less than the peak $I^{2} R$ power for cooldown constrained pulsed cooling starting at $80 \mathrm{~K}$. The total flow rate is the joule heat divided by coolatn enthalpy change:

$$
H_{T}=\frac{I^{2} R}{\Delta H}=\frac{\overline{J^{2}{ }_{{ }_{C}} A{ }_{C} C}}{(1-\varepsilon) \Delta H}
$$

The enthalpy change is by assumption:

$$
\Delta H=H_{90 K}-H_{77 . K}=26.05 \mathrm{~J} \mathrm{~g}^{-1}
$$

at the reference parameters.

There are various rules of thumb as to the minimum value of void fraction based on considerations of forcing bubbles through the channel, $\varepsilon \simeq 0.2$. Numerical experimentation shows that the $I^{2} R$ loss is much greater than the - pumping power, so that the tradeoff reduces to a balance between $I^{2} R$ loss and pressure drop. This experimentation resulted in a choice of $\varepsilon=0.18$.

The segment size and coolant channel parameters are determined in part by the thermal path length from coolant to segment. Since for a steady state heat distribution

$$
\Delta T=\frac{q^{\prime \prime \prime}}{2 k_{c}}(\text { pàth length })^{2}
$$

K 
For $\varepsilon=0.18, \ell \leqq 8.47 \mathrm{~cm}$, or 9 channels per plate for conservatism. "The segment width $\ell$ is then $8.11 \mathrm{~cm}$. Restricting the loss of copper-steel contact area to half $i$ ts value without channels leads to a channel width $w=4.055 \mathrm{~cm}$. The conductor plate thickness $t$ is $1.084 \mathrm{~cm}$, implying 480 conductor plates in the coil set. The total number of coolant channels is then 8640 . The channel depth $d$, is $0.39 \mathrm{~cm}$. These results are summarized in Table A-8. The single phase pressure drop is given by ${ }^{(15)}$ :

$$
\Delta P=\frac{4 f L}{D}\left(\left(\frac{W}{a_{h}}\right)^{2} \frac{1}{2 p}\right) \quad P a
$$

where

$f=$ channel friction factor, (-)

$\mathrm{L}=$ channel length, $\mathrm{m}$

$D=$ hydraulic diameter, $m$

$a_{h}=$ channel area, $m^{2}$

$W=$ channel mass flow, $\mathrm{kg} \mathrm{s}^{-1}$

$\rho=$ density of fluid, $\mathrm{kg} \mathrm{m}^{-3}$

The individual terms above in turn are defined by the following relations.

$$
D=\frac{4 a_{h}}{p}
$$

where

$$
p=\text { channel perimeter, } 2(w+d)
$$

The flow per channel is given by

$$
w=W_{T} / n_{c} \quad \mathrm{~kg} \mathrm{~s}^{-1}
$$

where

$$
W_{T}=\text { total coolant flow, } \mathrm{kg} \mathrm{s}^{-1}
$$


TABLE $A-8$

CHANNEL GEOMETRY PARAMETERS

$E$, VOID FRACTION

0.18

^, SEGMENT WIDTH

$8.11 \mathrm{~cm}$

$t$, SEGMENT THICKNESS

$1.084 \mathrm{~cm}$

W, COOLANT CHANNEL WIDTH

$4.055 \mathrm{~cm}$

d, COOLANT CHANNEL DEPTH

$0.39 \mathrm{~cm}$

$n_{p}$, CONDUCTOR PLATES IN TF COIL SET

480

$n_{c}$, NUMBER OF COOLANT CHANNELS

8640 
The friction factor $f$ results from a correlation with the Reynolds number, Re, as follows:

$$
f=1.4 \times 10^{-3^{\prime}}+0.125 \mathrm{Re}^{-0.32}
$$

where

$$
\text { Re }=\text { Reynolds number, } \frac{W D}{a_{h^{\mu}}}
$$

and

$$
\mu=\text { viscosity, } \mathrm{kg} \mathrm{m}^{-1} \mathrm{~s}^{-1}
$$

The total $L N_{2}$ pumping power is simply the total volumetric flow rate times the pressure drop along a channel,

$$
\mathrm{PP}_{\mathrm{e}}=\frac{1}{n_{\mathrm{p}}} \frac{\Delta P W_{\mathrm{T}}}{\rho} \text { watts }
$$

where

$$
n_{p}=\text { pump efficiency } \simeq 0.5
$$

For the assumed conditions and channel geometry, the resulting parameters for single phase cooling are as shown in Table A-9.

Consistency with the assumed copper temperature can be checked by calculating the wall-bath temperature difference from the equation:

$$
h\left(T_{w}-T_{b}\right)=q^{\prime \prime}=q^{\prime \prime} \frac{a_{c}}{p_{w}} \quad \frac{w}{m^{2}}
$$

where the heat transfer coefficient, $h$, is given by the Dittus-Boelter equation $(15)$ :

$$
h=2.3 \times 10^{-2} \frac{k}{D} \operatorname{Re}^{0.8} \operatorname{Pr}^{0.4}
$$


TABLE A-9

PARAMETERS FOR SINGEE PHASE COOLING

$I^{2} \dot{R}, \quad T F$ COIL JOULE HEATING O $90 \mathrm{~K}$

$\triangle H$, ENTHALPY CHANGE IN LN

$W_{T}$, TOTAL FLOW OF LN

$n_{C}$, NUMBER OF CHANNELS

$W$, FLOW PER CHANNEL

$G$, FLOW PER UNIT AREA

D, HYDRAUL TC DIAMETER

Re, REYNOLDS NUMBER

f, FRICTION FACTOR

L, CHANNEL LENGTH

$\triangle P$, PRESSURE DROP

$\mathrm{PP}_{\mathrm{e}}, \mathrm{LN}_{2}$ PUMPING POWER
$328 \mathrm{MW}$

$26.05 \mathrm{Jg}^{-1}$

$1.26 \times 10^{4} \mathrm{~kg} \mathrm{~s}^{-1}$

$8.64 \times 10^{3}$

1.457. kg s $\mathrm{s}^{-1}$

$9.22 \times 10^{3} \mathrm{~kg} \mathrm{~m}^{-2} \mathrm{~s}^{-1}$

$7.1 \times 10^{-3} \mathrm{~m}$

$4.0 \times 10^{6}$

$2.4 \times 10^{-3}$

$9 \mathrm{~m}$

$690 \mathrm{kPa}$ (100 psi)

23 MWe 
Performing these calculations results in an axial heat flux, $q^{\prime \prime}$, of $8: 72 \mathrm{~W} / \mathrm{cm}^{2}$, a heat transfer coefficient, $h$, of $1.54 \mathrm{l} / \mathrm{cm}^{2}-k$, and a wall-bath temperature difference of $5.66 \mathrm{~K}$. Since the average bath temperature along the length of the channel is $83.5 \mathrm{~K}$, the average wall temperature is $89.1 \mathrm{~K}$. The average temperature in the copper segment differs negligibly from the wall temperature for the segment and channel dimensions. The results then are consistent, to a first approximation, with an assumed average copper temperature of $90 \mathrm{~K}$.

\section{Power Supply Implications of Steady State Cooling}

The purpose of this section is to determine the time to charge up the TF coil for least costly power supplies, and to calculate the resistive energy dissipation during ramp up. The results are summarized in Table A-10.

The least costly power supplies, by the rule stated previously, result from matching inductive and resistive powers. Assuming as before exponential charging in two time constants, the peak inductive power is

$$
\hat{\mathrm{P}}_{\text {ind }} \cong 1.4 \mathrm{E}_{\mathrm{s}} / \mathrm{t}_{\mathrm{r}}=15.5 \mathrm{GJ} / \mathrm{t}_{\mathrm{r}}
$$

where $E_{S}$, the TF coil set stored energy, is about $11 \mathrm{GJ}$, and $t_{r}$ is the time to reach full current. The resistive power is $I^{2} R=328 \mathrm{MW}$. Equating these two leads to

$$
t_{r}=\frac{1.4 \mathrm{ES}}{I^{2} R}=\frac{1.55 \times 10^{10} \mathrm{~J}}{3.28 \times 10^{8} \mathrm{~J} / \mathrm{sec}}=47 \mathrm{sec}
$$

for charging time.

This contrasts to the chargeup time of 18 seconds, the peak inductive power of $871 \mathrm{MW}$ and peak resistive power of $417 \mathrm{MW}$ for cooldown constrained pulsed cooling beginning at $80 \mathrm{~K}$. The power supply cost can then be decreased from the reference value. The magnitude of the saving will be calculated in the following section. 


\section{TABLE. A-10}

TF COIL SET POWER SUPPLY REQUIREMENTS WITH STEADY STATE COOLING
$I^{2} R$, RESISTIVE POWER
$328 \mathrm{MW}$
$t_{r}$, CHARGEUP TIME
47. sec
$P_{\text {ind }}$, PEAK INDUCTIVE POWER
$328 \mathrm{MW}$
$E_{R C}$, RESISTIVE ENERGY DISSIPATION
$7.7 \mathrm{GJ}$
IN CHARGEUP
I, CURRENT PER TURN
$316 \mathrm{kA}$
$V$, VOLTAGE ACROSS TF COIL SET
$1039 \mathrm{~V}$ 
On the assumption of exponential chargeup in two time constants, the resistive energy dissipation is about

$$
E_{R C}=\int_{0}^{t r} I^{2}(t) R d t \simeq \frac{t_{f}}{2} I_{0}{ }^{2} R=\frac{47}{2} 328 \mathrm{MJ}=7.7 \mathrm{GJ}
$$

Assuming the power supply is reversed at the termination of the pulse, the current will fall to zero in about half the chargeup time and the resistive energy dissipation will be about $\frac{1}{4}$ that during chargeup. This will be ignored. The total resistive energy dissipation is then

$$
E_{R}=7.7 \mathrm{GJ}+\left(t_{p}-t_{r}\right) 328 \mathrm{MW}
$$

over a pulse.

The current and voltage requirements for the TF coil can be derived from the design parameters determined so far. The current per turn (plate) is given by

$$
I=\frac{N I}{n_{p}}=\frac{152 M A T}{480}=316 \mathrm{kA} / \text { turn }
$$

Since there are twenty coil packages, each of 24 plates, the voltage across the entire TF coil system is

$$
V=\frac{I^{2} R}{I}=\frac{328 \mathrm{MW}}{0.316 \mathrm{MA}}=1,039 \text { volts }
$$

which is reasonable. The turn-to-turn voltage is only about 2 volts, indicating that the minimum thickness insulation is governed by quality control and fault protection considerations. 
COSTS OF STEADY TF COIL OPERATION

In this section the differences in capital cost of the reference machine, IDRIII, for steady state cooling are calculated. The operating cost for $\mathrm{LN}_{2}$ per unit time and for the reference scenario is calculated. These costs are summarized in Table A-11. The capital cost decreases by about $2 \mathrm{M} \$$ on net. The $\mathrm{LN}_{2}$ boiled off under the reference scenario with steady state cooling is comparable to the amount boiled off with pulsed cooling. These results are derived below.

\section{Capital Cost Increments}

One motivation for considering steady state cooling is potentially to reduce the TF coil power supply capital cost. Offsetting this saving are additional costs in machining cooling channels in the TF coil plates, and the costs of additional equipment, such as headers, pumps, and plumbing. These increments are discussed in turn below.

The reference TF coil power supply cost is based on pulsed cooling with cooldowntime constrained peak conductor temperature, $150 \mathrm{k}$, starting from $80 \mathrm{k}$; from Table A-4 this leads to peak power requirements of 817 . MVA inductive and $417 \mathrm{MW}$ resistive. By contrast the peak resistive and inductive TF coil power supply requirements are $328 \mathrm{MN}$. For the purposes of this comparison it is assumed that in either case the TF coils are driven directly from a line through a threephase controlled rectifier.

The estimated TF power supply costs are $\$ 8.30 \mathrm{M}$ and $3.25 \mathrm{M}$, respectively, for pulsed cooling and steady state cooling. The cost saving thus calculated is $\$ 5.1 \mathrm{M}$. This cost saving must be regarded as a lower bound, since the choice of locations which can furnish 817 MVA on a pulsed basis is more restricted than for $328 \mathrm{MW}$ with slower ramp up and ramp down requirements. 
TABLE $A-11$

COST INCREMENT FOR STEADY STATE COOLING

CAPITAL COST (STEADY-STATE LESS PULSED-COOLED)

TF COIL POWER SUPPLY

$\$(>5.1 \mathrm{M})$

TF COIL MACHINING

$\simeq 1.5 \mathrm{M}$

EXTRA EQUIPMENT (PUMPS, HEADERS, ETC.)

$\leq 1.6 \mathrm{M}$

TOTAL

$\$(>2 M)$

OPERATING COST

PER UNIT TIME AT FULL FIELD

$\$ 214 / \mathrm{sec}$

REFERENCE PULSE, TOTAL

$\$ 7,000$ 
To calculate the additional cost of machining cooling channels into the conductor plates requires consideration of the manufacturing method. The channels are $4.055 \mathrm{~cm}\left(1.6^{\prime \prime}\right) \times 0.39 \mathrm{~cm}\left(0.154^{\prime \prime}\right) \times 9 \mathrm{~m}\left(354^{\prime \prime}\right)$. There are 8640 channels total. The channel path is irregular (non-circular), and thus requires a numericaily controlled milling machine. In order to avoid burrs and chips in the channêl, standard industrial finish RMS 125 suffices.

The channels are shallow enough to accomplish cutting with one rough pass and one finish pass. The feed rate (hrs/inch) formilling copper is about half that for stainless steel. Using standard cost estimating relations leads to cutting time (including set-up) of $29,300 \mathrm{hrs}$ at a total cost of $\simeq \$ 1.5 \mathrm{M}$. Note, however, that this would require $3+$ years on a $24 \mathrm{hr} /$ day schedule. This time requirement appears excessive unless this manufacturing operation is carried out in parallel with construction of other components and assemblies.

The extra equipment considered here is a cryogenic pump capable of sustaining a pressure head of $100 \mathrm{psi}$ at a flow rate of $19.5 \times 10^{3} \mathrm{lb} / \mathrm{sec}(288 \mathrm{gal} / \mathrm{sec})$, a correspondingly powerful motor, a heat exchanger which transfers the $I^{2} R$ loss of the TF coil, $328 \mathrm{MW}$, plus pumping power, $24 \mathrm{MW}$, from $90 \mathrm{~K}$ to $77 \mathrm{~K}$, and associated heaters and plumbing. Using cost-estimating relations from COAST ${ }^{(11)}$, the total cost of this equipment is about $\$ 1.6 \mathrm{M}$. Much of this cost $(\simeq \$ 1 \mathrm{M})$ is due to the heat exchanger, and it might be possible to do without it entirely, e.g., by 50 psia pressure valves in each header with return tubes to the $L^{2}$ pool, and the pump drawing from the pool.

\section{Operating Cost}

Since one objective of the IDR is to minimize capital cost, boiled $\mathrm{LN}_{2}$ is not recycled through refrigerators. The expense of the $\mathrm{LN}_{2}$ lost in operation is calculated here, both on a per unit timeat full field and for the reference scenario. 
The thermal power to be removed by boiling $L N_{2}$ is the $T F$ coil $I^{2} R$ loss and the total pumping power. There will be in addition losses due to thermodynamic efficiency; this is estimated at $\eta_{p}=0.75$. The $L N_{2}$ boiling rate per second is then

$$
W_{b}=\frac{1}{\eta_{\mathrm{p}}} \cdot \frac{\mathrm{I}^{2} \mathrm{R}+\mathrm{P}_{\mathrm{e}}}{\Delta \mathrm{H}_{\mathrm{b}}, 77 \mathrm{~K}}=\frac{1}{0.75} \frac{328+24 \mathrm{MW}}{81 \mathrm{~kJ} / 1 \mathrm{~b}}=5.790 \mathrm{lb} / \mathrm{sec}=858 \mathrm{gal} / \mathrm{sec}
$$

at $\$\left(\mathrm{LN}_{2}\right)=0.25 / \mathrm{gal}$, this translates to $214 \$ / \mathrm{sec}$ at full field,

For the purposes of comparison with the reference pulsed cooling scenario, the total amount of $L_{2}$ boiled off in a pulse with ramp-up time of $47 \mathrm{sec}, 8$ second flat-top time, and negligible (or neglected) ramp-down time is, from eq.

$$
\begin{aligned}
\int W_{b} & =\frac{1}{n p} \frac{E_{R}+P_{e} \times 55}{\Delta H_{b}, 77 \mathrm{~K}}=\frac{7.7 \mathrm{GJ}+8 \times 328 \mathrm{MJ}+24 \times 55 \mathrm{MW}}{0.75 \times 81 \mathrm{~kJ} / 1 \mathrm{~b}} \\
& =\frac{11.64 \times 10^{4} 5}{6.075 \times 10^{4} \mathrm{~J} / 1 \mathrm{~b}}=1.9 \times 10^{4} \mathrm{lb}=28,120 \mathrm{gal}
\end{aligned}
$$

At $\$\left(\mathrm{LN}_{2}\right)=0.25 / \mathrm{gal}$, the cost of one pulse is $\simeq \$ 7,000$ in liquid nitrogen.

Again, it should be emphasized that this latter calculation is for the purpose of comparison with pulsed cooling only. Given that $7.7 \mathrm{GJ}$ are required just in chargeup, it may make more sense to charge up the coil and make as many experiments as possible within constraints imposed by $\mathrm{LN}_{2}$ storage. 


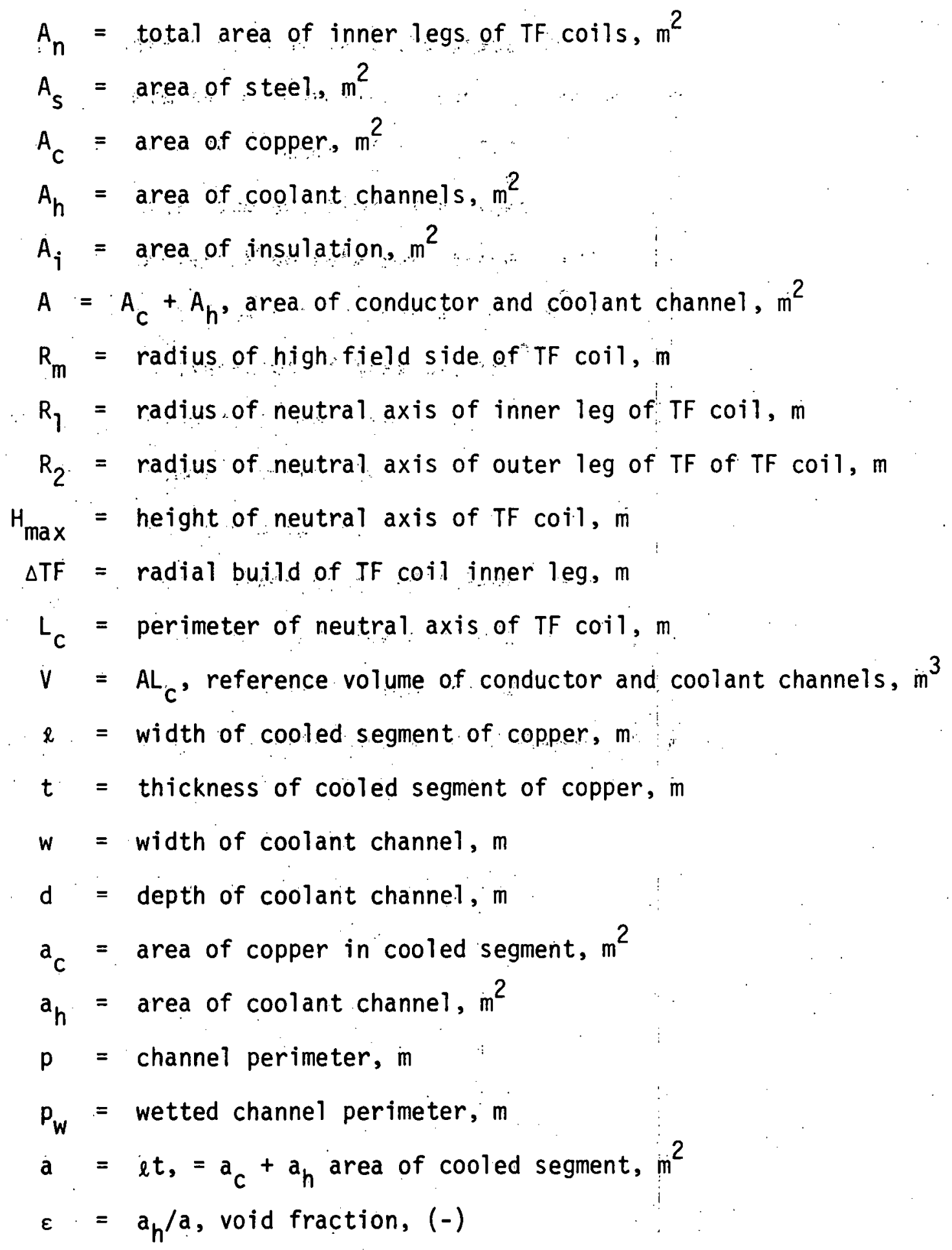


$n_{p}=$ number of plates in TF coil set

$n_{c}=$ total number of coolant channels

$N I=$ total ampere turns in TF coil set, A

$\rho_{c}=$ resistivity of conductor, $\Omega-m$

$I^{2} R=$ resistive power in $T F$ coil set, $m$

$\mathrm{J}_{\mathrm{C}}=$ current density in conductor, $\mathrm{A} / \mathrm{m}^{2}$

$\bar{J}=$ current density averaged over conductor and coolant channels, $\mathrm{A} / \mathrm{m}^{2}$

$t_{r}=$ charging time for TF coil, sec

$t_{f}=$ time at end of flat-top, sec

$t_{p}=$ time at end of pulse, sec

$\mathrm{L}=$ inductance of TF coil (in context), $\mathrm{H}$

$I=$ current per turn, $A$

$E_{S}=T F$ coil set stored energy, $J$

$\mathrm{LN}_{2}=$ liquid nitrogen

$\mathrm{Cu}=$ copper

$A l=$ aluminum

$T=$ temperature, $\mathrm{K}$

$c_{p}=$ specific heat, $\mathrm{J} / \mathrm{kg}-\mathrm{K}$

$k=$ thermal conductivity, $W / m-k$

$\rho=$ mass density, $\mathrm{kg} / \mathrm{m}^{3}$

$H=$ enthalpy, $\mathrm{J} / \mathrm{kg}$

$\mu=$ viscosity, $\mathrm{kg} / \mathrm{m}-\mathrm{sec}$

$Q=$ heat, $W$

$q^{\prime \prime}=$ surface heat flux, $W / m^{2}$

$q^{\prime \prime \prime}=$ volumetric heat generation, $\mathrm{W} / \mathrm{m}^{3}$ 
$h=$ heat transfer coefficient, $w / m^{2}-k$

$L=$ length of coolant channel (in context), $m$

$Z_{S P}=$ length of flow in fluid phase, $m$

D = hydraulic diameter of coolant channel, $m$

$f^{\prime}=$ friction factor of flow, $(-)$

$W_{T}=$ total coolant flow rate, $\mathrm{kg} / \mathrm{s}$

$W=$ coolant flow rate per channel $\mathrm{kg} / \mathrm{s}$

$G=$ area flow rate of coolant, $\mathrm{kg} / \mathrm{m}^{2}-\mathrm{s}$

$\mathrm{g}=$ acceleration of gravity, $\mathrm{m} / \mathrm{s}^{2}$

$\operatorname{Re}=$ Reynolds number; $(-)$

$\operatorname{Pr}=$ Prandt number, $(-)$

$\Delta P=$ pressure $d r o p, P a$

$n_{p}=$ pump thermodynamic efficiency, $(-)$

$n_{e}=$ heat exchanger thermndynamic efficiency, (-)

$P \cdot P_{e}=$ pumping power for coolant, $W$.

$W_{b}=$ rate of boiling of $\mathrm{LN}_{2}$ - $14.7 \mathrm{psia}, 77 \mathrm{~K}, \mathrm{~kg} / \mathrm{s}$ 


\section{APPENDIX B}

\section{POWER SUPPLY DESIGN CONSIDERATIONS}

The original TNS objectives in relation to which power supplies were designed included the specification of $10^{6}$ total pulses and the ability to shutdown the plasma current at any time. The first specification led to the selection of solid-state switches over less expensive and less reliable mechanical switches. The second specification led to the selection of active current control by phasecontrolled voltage sources during startup and shutdown, instead of a passive switched resistor-capacitor network. For a low-cost ignition demonstration reactor, both of these assumptions can be questioned. However, recent information indicates that, while large initial cost savings can be made by the use of mechanical switches, active control is cost competitive with passive control. during startup and shutdown. The ability to achieve controlled shutdown at any time may well be necessary for ensuring vacuum vessel integrity during ignited pulses. This feature, while it is absent from the design of most other large tokamak devices, is felt to be too desirable to abandon for marginal cost advantages. However, initiation switch failures can be repaired quickly, and it does not appear that the effectiveness of the experimental program will be compromised by the small amount of unscheduled down-time inherent in the selection of mechanical: switches.

The IDR poloidal field reference circuit designs are shown in Figure B-1. The same circuit topology would be used in both the IDR II and IDR III reference designs. The circuit shown as the typical EF circuit is different from that used in the COAST trade-studies, only in that there is no option to commutate current from the initiation switch before the initiation capacitor voltage goes through zero. For simplified costing, a single equivalent EF circuit is costed, with a rating equal to the sum of the ratings of the three independent (EF-I, EF-O and EF-D) circuits. The EF-D circuit is actually somewhat simpler than the other two. Because net power is being delivered to the circuit by the EF-0 coil during initiation, it doesn't require a precharged capacitor. However, since the EF-O circuit is easily the smallest and least expensive of the three circuits, the use of a single equivalent EF circuit should not introduce detectable modeling error. 
The TF circuit is considered to run directly from the utility line as shown in Figure B-2. The option of running from a motor-generator-flywheel buffer has also been modeled, but not selected. This is a controversial choice, because the TNS site can not be assumed to have the excellent utility line stiffness of the TVA Y-12 site at 0ak Ridge. The permissible power that can be drawn at the Y-12 site, without buffering, is not known. However, a plausibility argument can be made that model ing unbuffered operation is more realistic than modeling buffered operation. With liquid nitrogen operation, the TF power supply requirements are reduced from those with water-cooled TF coils. The thermal analysis in Appendix A indicates that over half a minute can be used to charge the coils with peak powers of less than $800 \mathrm{MW}$. This is a considerably less severe transient than the one second pulses which have typified tokamak power supplies. It appears to be no more severe a transient than the 350 MW pulse drawn from Chicago Edison by the Fermilab accelerator. If most, but. not all, of the power needed for the TF coils can be drawn directly from the line, then the unbuffered model will still be fairly accurate. Another consideration is that several experimental programs, such as Alcator $C$ and Doublet III, may be drawing to a close when an ignition demonstration reactor is due to come on line. For instance, if the 220 MVA generator and rectifier for the relatively tiny Alcator $C$ were appropriated, it would supply $30-40 \%$ of the TF coil requirements at very low cost. The possibility of borrowing power supplies from older machines could even make the present costing assumptions overly conservative. 


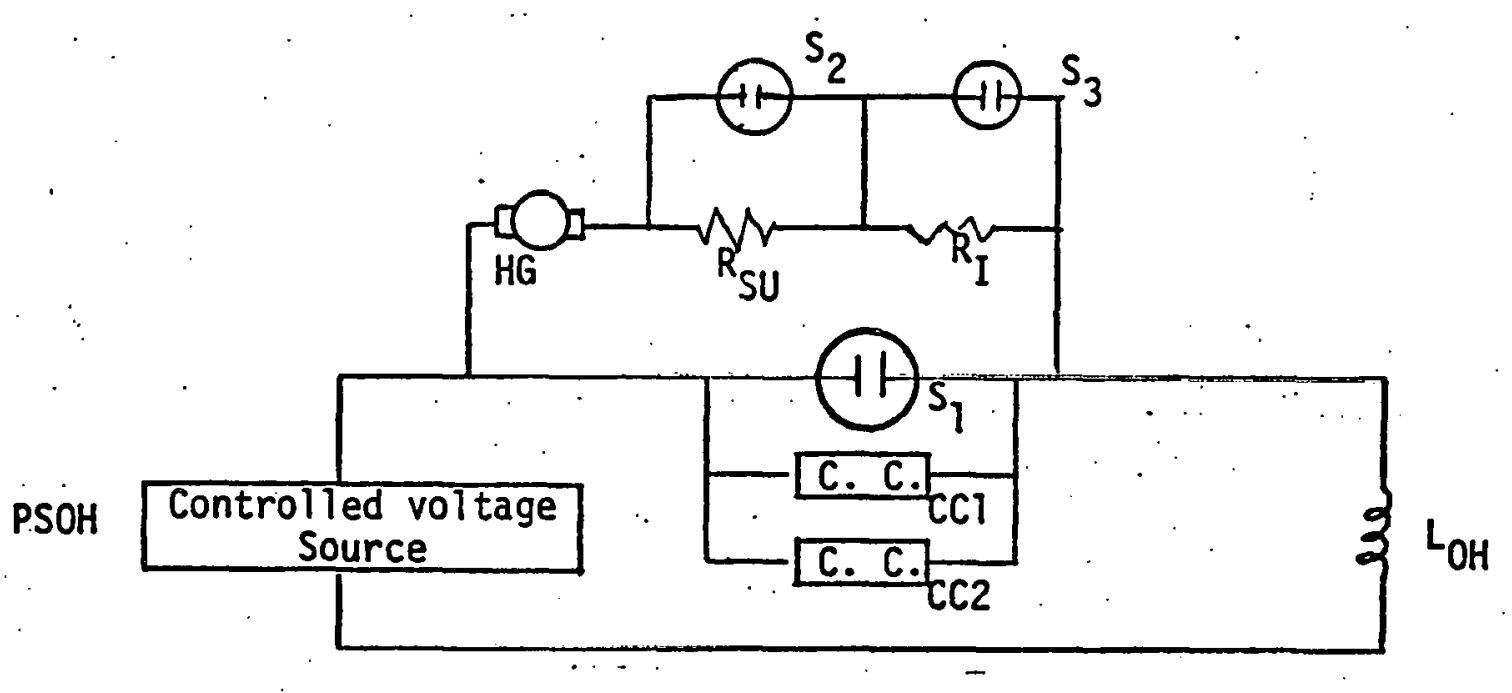

(a) OH CIRCUIT

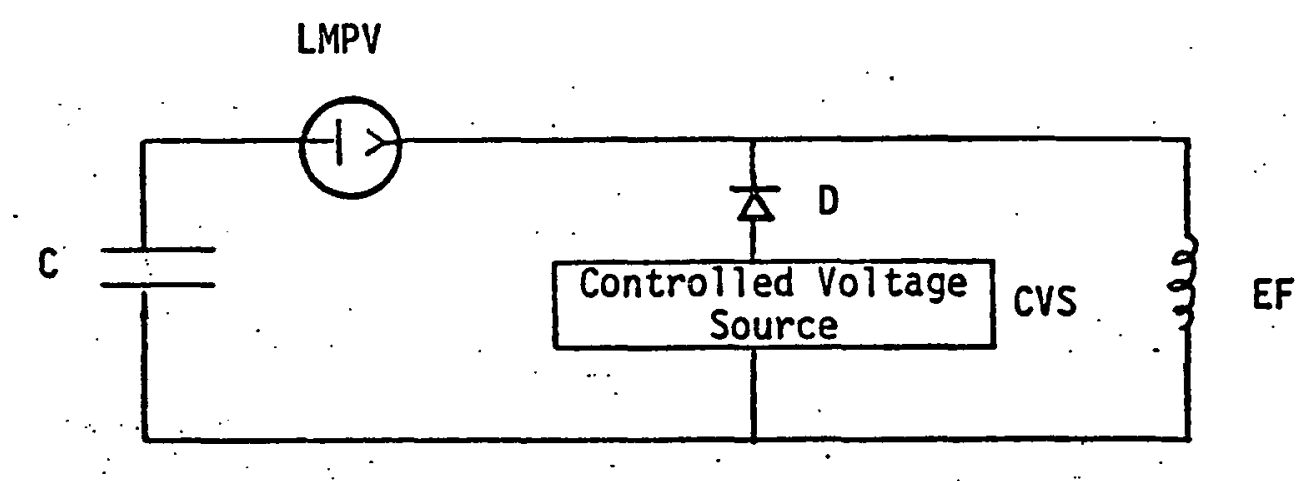

(b) EF CIRCUIT

Figure B-1. Poloidal Field Coil Circuit Concepts

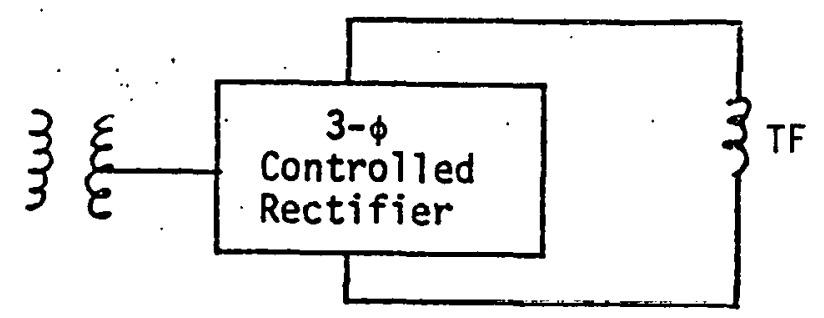

Figure B-2. TF Coil Direct Drive Circuit 


\section{APPENDIX C}

TF COIL DESIGN AND SUPPORT STRUCTURE CONSIDERATIONS

The reference IDR III configuration (Figure 4-1) shows the poloidal field coils to be inside the bore of the toroidal field coils. The toroidal field coils is shown with a finger joint and a lap joint. The purpose of these joints would be to permit TF coil removal to increase access for maintenance and repair of the PF coils.

The TF coil is assembled as a laminar construction of conductor, insulator and structural plates. By the nature of plate construction, a finger joint design similar to the Doublet III concept (Figure C-1) should prove to be quite difficult. At the Doublet III joint location the coil tension is transmitted through conducting bars.

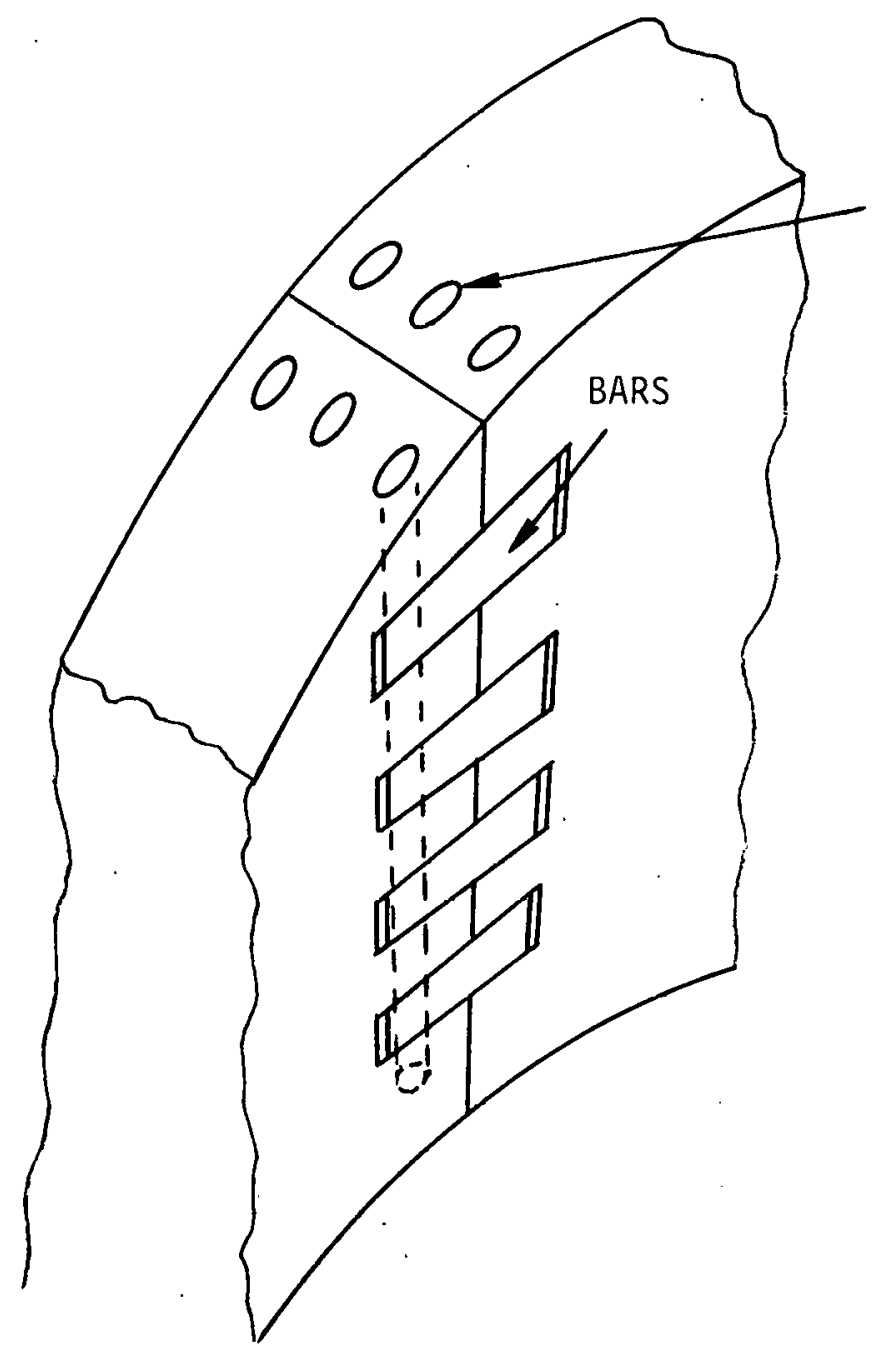

REMOVABLE SHEAR STUDS

Figure $\mathrm{C}-1$. DOUBLET II I FINGER JOINT CONFIGURATION 
A major complication with a joint in the IDR TF coil concept arises from the need for structure to assist the conductor with coil tensile load sharing resulting in a laminar TF coil plate construction. The finger joint concept (a) in Figure $\mathrm{C}-2$ shows each plate of structure and conductor requiring its own pin. The disadvantages of this concept from structural considerations include: (1) no mechanism other than friction is provided for parallel load sharing by the conductor and structure plates: (2) all of the tensile loads that are not carried

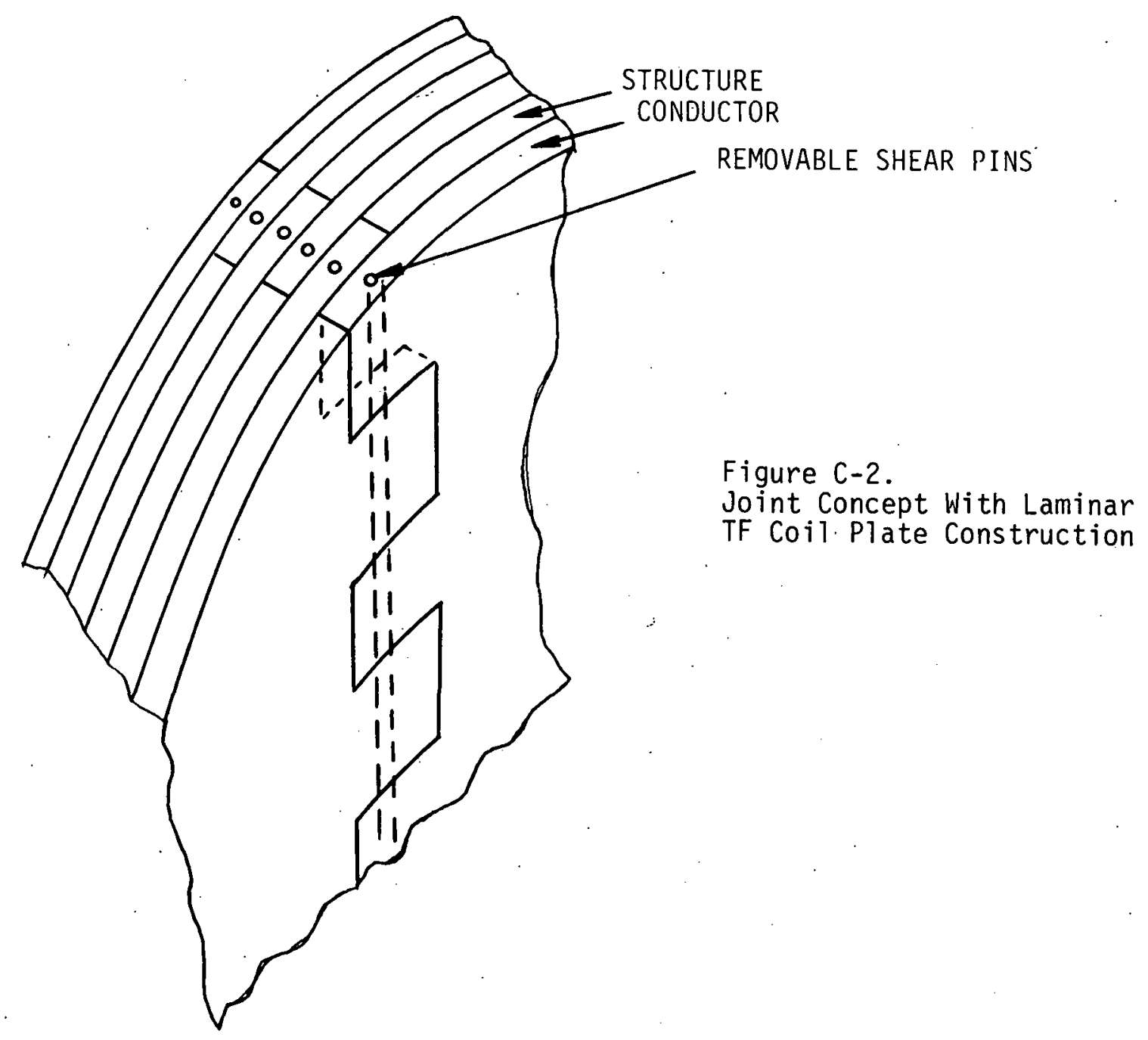


by the structure from friction or by the conductor interfaces from friction are carried by the shear poins, (3) the tension carried by the conductors is transmitted through a cross-section reduced by the pin diameter, (4) the presence of the shear pin hole introduces are additional stress concentration at that reduced cross-section of the conductor, and (5) at its very best, even with friction, the load carrying cross-section of the conductor or structural plate is reduced by at least a factor of two with evenly sized fingers on the two sides of the joints. From an electrical point of view, the types of conducting surfaces at the joints for concept (a) do not appear to be very efficient unless the pins can compress the fingers down on to each other. The surfaces parallel to the pin are likely to be open, especially after several cycles of operation.

The reference configurations for the IDR concept could employ the bar concept (b), shown in Figure C-3, similar to the Doublet III. The bar would also have to be a conductor as it is in the. Doublet III design.

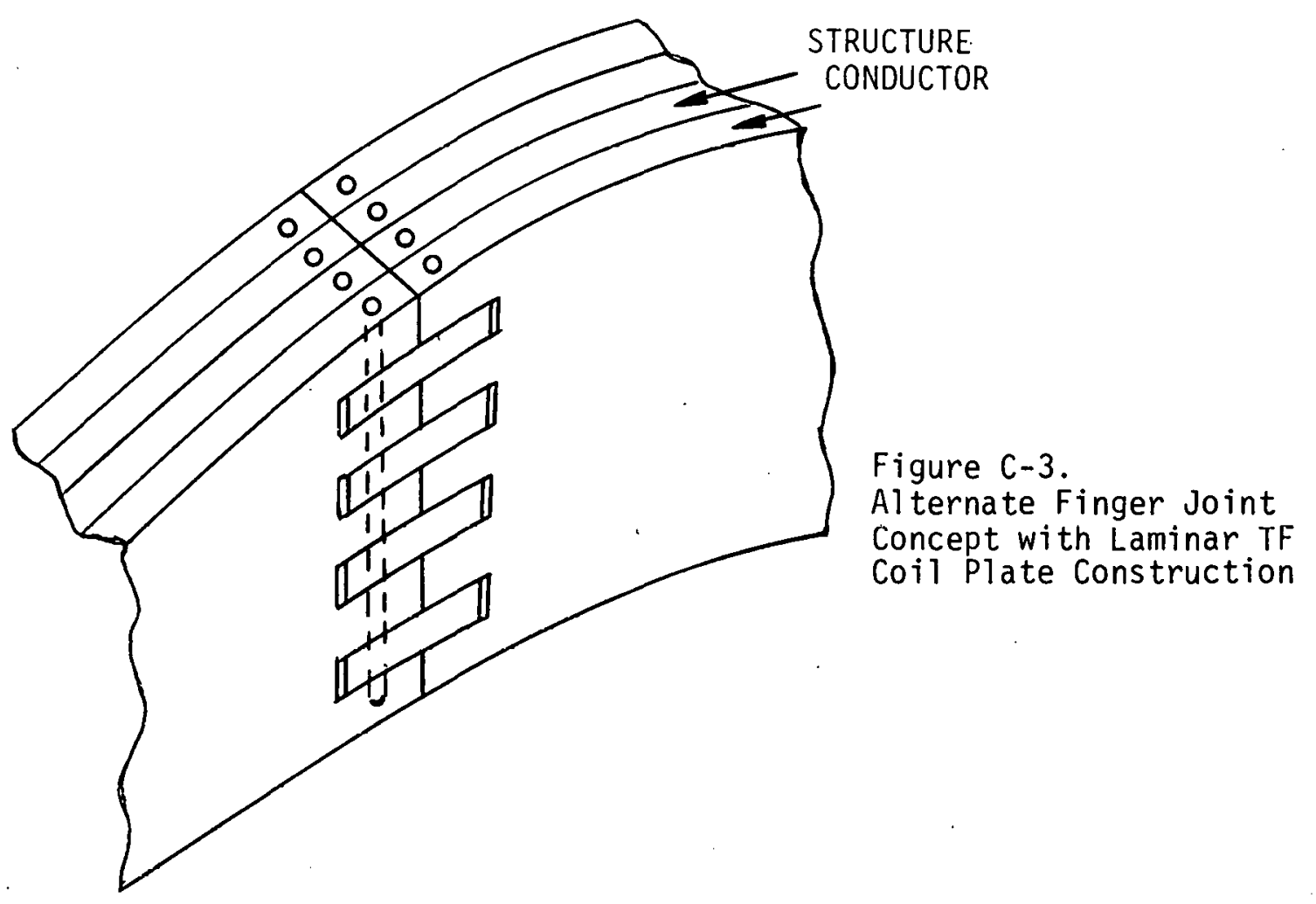


The major disadvantage to concept (b) from a structural point of view in addition to items (1) through (4) as discussed above for concept (a) is that the conductor material bars become the primary load path for the entire tensile load in the TF coil with both adverse factors of reduced cross-section and stress concentrations due to the presence of the shear pin holes. This concept is structurally worse than concept (a) because of the total loss of load path through the structural plate due to the presence of the conductor bar passing through the structural plates. A strengthening al ternative for concept (b) could be many pieces of bar in a slot of alternating conductor and structural material. The real difficulty here lies with the large number of pieces to assemble combined with the disadvantage that the copper and structure cannot act in parallel to carry the in-plane laods with this type of joint, unless one can rely upon friction. In any event concept (b) is no better thạn concept (a).

An alternate concept that eliminates the idea of finger or bars is to replace the shear pins with equivalent shear keys that would tie the conductor to the structure for the achievement of parallel loadsharing without dependence upon friction. Concept (c), shown in Figure $c-4$, illustrates this keying.

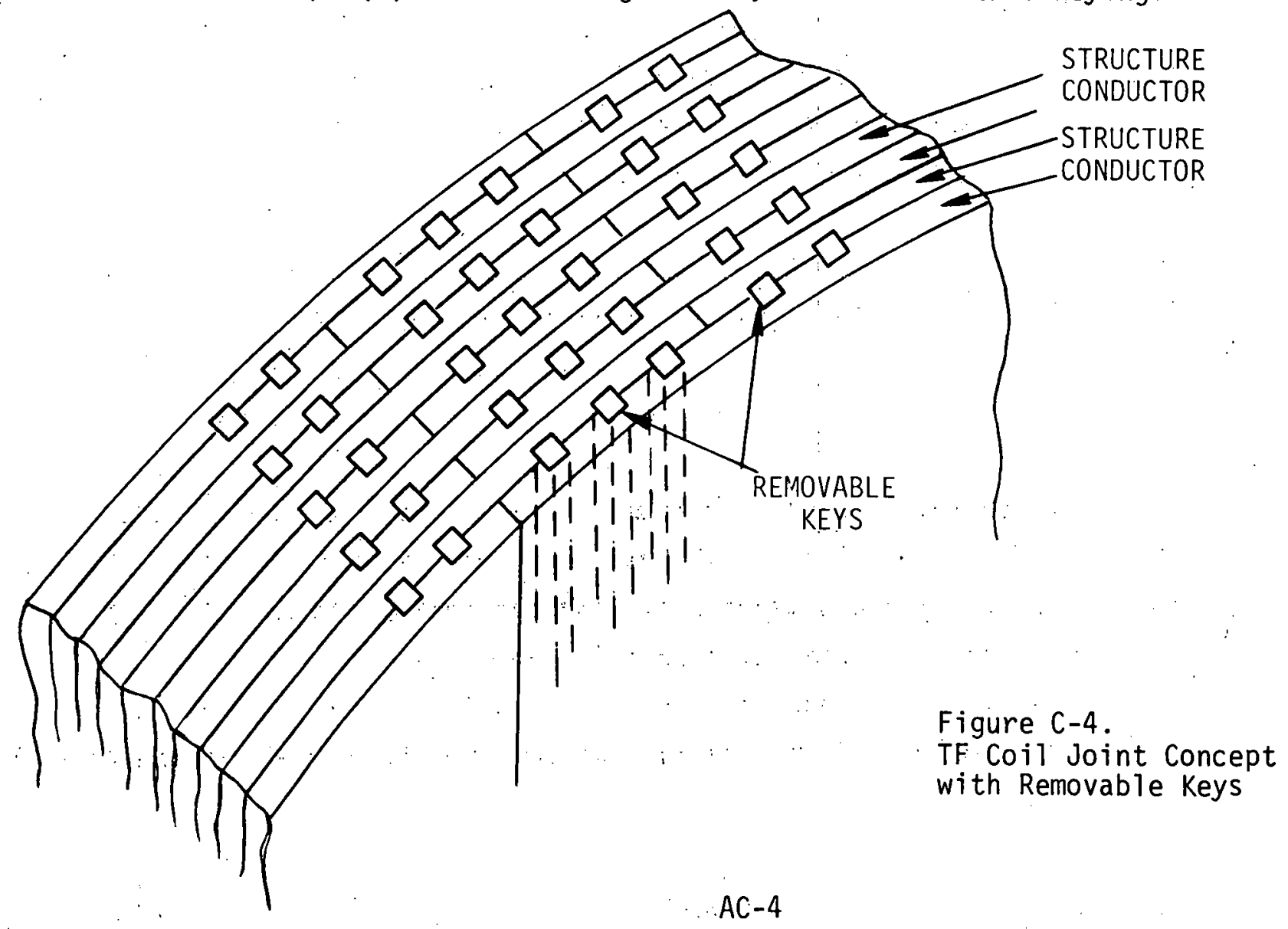


The disadvantage of this concept include: (1) a primary load path cross-sectional reduction by the key slot depth, (2) no tensile load carrying capability at the breaks in the conductor and structure plates and (3) no provisionafor good electrical contact at the breaks in the conductor plates.

Items (3) above can be eliminated, and Item (2) can be partially improved upon by going to concept (d), shown in Figure $\mathrm{C}-5$.

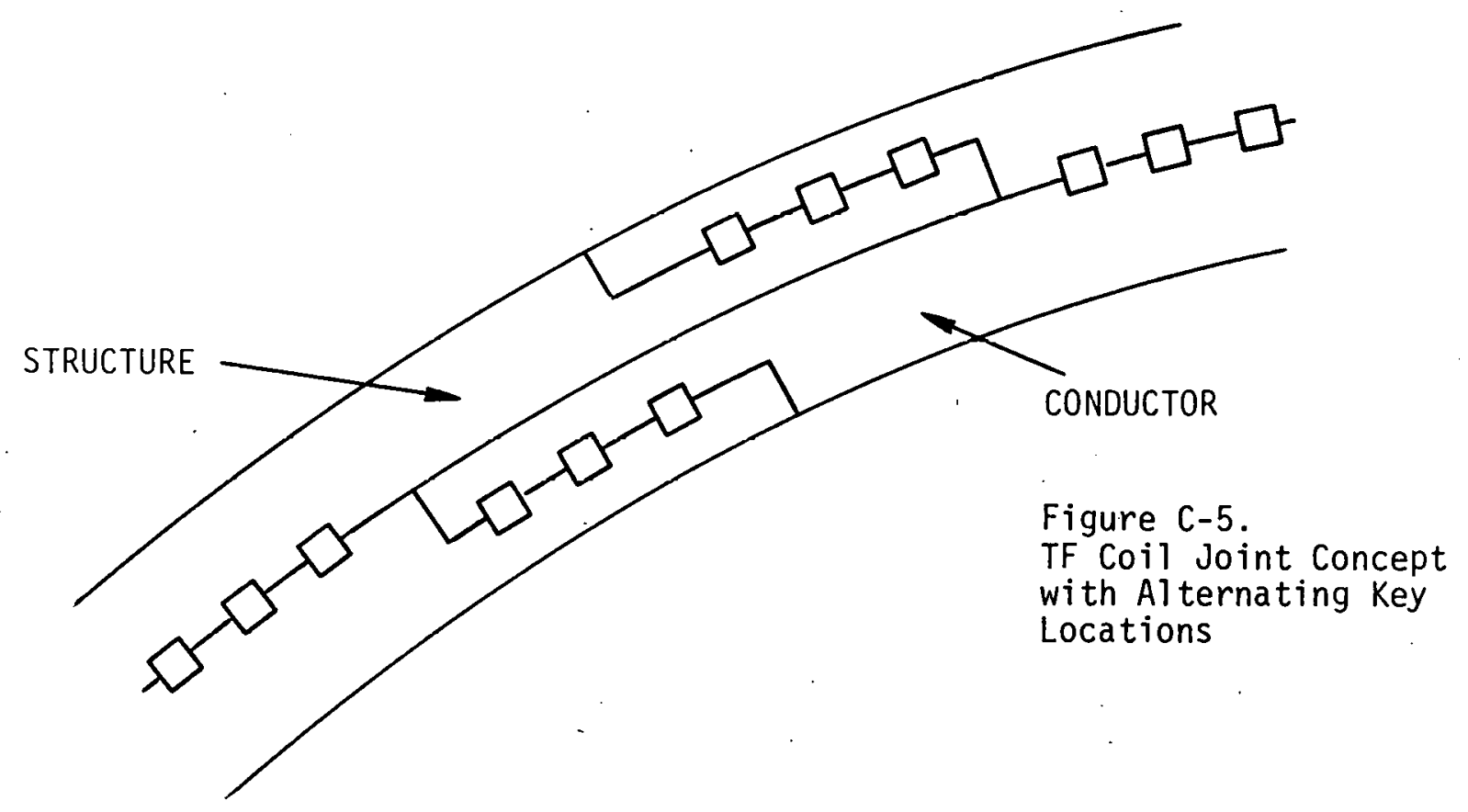

Even with this there are locations where less than half the conductor or less than half of the structure is acting in parallel with its full counterpart.

A major problem with this design would be maintaining the machining alignment tolerances between the mating conductors, the mating structures and the mating conductors to structures to insure both assemblage and effective load transmittal. Actually these two factors will work against each other. If all of the keys are fitted for good sharing of load transmittal, it is unlikely that there would exist sufficient tolerances for inserting the long slender keys into every pair of conductor/structure plates. 
Since a major cost reduction is achieved from placing the PF coils inside the TF coils, the reference configuration is still considered the more desirable approach even though the design of a joint does not appear to be a low risk practical solution to PF coil maintenance.

Other approaches to the maintenance of PF coils should be explored to include the possibilities within the two extreme positions of: (1) joints in the TF coil and (2) no joints in the TF coil.

The approach of no joints in the TF coils would follow the line of reasoning that the PF coil system is constructed with sufficient reliability to preclude the necessi.ty for maintenance and/or repair. In many ways the design would be similar to the PLT machine and the IDR PF coil system should be developed with the full utilization of the experiences that have been gained from PLT operation.

The other approach that has been discussed includes TF coil joints. This approach can be pursued further with the potential for reduced cost and reduced risk with concepts that would include only one or two TF coils with joints. The idea here would be to make a couple of TF coils removable and then rotate the other coils about the device centerline to a position that would allow maintenance or repair of PF coils. Or alternatively, to split the device at the location of two opposite removable TF coils by PF coil connections and by cutting the vacuum vessel.

The alternate IDR II configuration shows the poloidal field coils to be outside the bore of the toroidal field coils, and therefore the TF coil can be constructed without joints.

The primary concern with a TF coil design of this nature would be insuring sufficient structure to conductor cross-sectional area to support the in-plane loads. If a constant-tension shape is pursued a quick estimate of structural requirements could be achieved. For configurations departing from the constant tention shape a more complicated analys is of the coil would be required to adequately account for bending through the coil cross-sections. Since it is anticipated that 
a laminar construction would be used, an improved coil stiffness against lateral loads can be achieved with thru bolts that would provide additional shear restraint against the out-of-plane loads. These bolts should be in accessible locations. They similary should be used for the reference configuration as well. An alternative to through bolts could be exterior bolted clamps which likewise could provide an attachment for torque resisting shear panels.

The most efficient location for the attachment of torque resisting shear panels is on the outer legs of the TF coils at the horizontal midplane. Many tokamak concepts have frequently shown this space to be reserved for neutral beam access. The trade off to be studied here should concern the feasibility and relative cost comparison for locating neutral beam sources such that the beam line is at angles in the range of 30 to $60^{\circ}$ inclined from the horizontal midplane. The apertures at this location are not efficient shear panel locations, and would therefore be better suited for neutral beam usage.

The actual design of other support structures such as a cage type torque frame, : preloading structures and a center bucking column will depend to a large extent: upon the TF coil shape, the plasma and PF coil fields and locations, and the fault loads. The approaches that should be explored for a minimum cost device ": from structural considerations should include: (1) the cost comparison between anticipated repair with a fault and/or improved electrical reliability against the fault condition versus not designing and not implementing structures in anticipation of a shorted coil, (2) a system structural design for overturning magnets that are always in the same direction from the poloidal fields. In other words, the IDR should be designed for unidirectional currents in both the TF coils and the equilibrium field coils with possibly no consideration for anticipation of a fault.

Another approach that can be explored for a minimum cost device should include a study that would establish the consequences of the vertical field component of the toroidal field due to tipping of the TF coils. The goal of such a study should be to define the acceptable limits of TF coil tipping based upon field and plasma physics considerations. Such criteria do not presently exist and certainly would 
represent a valuable contribution, useful for all tokamak designs. It is conceivable that large values of out-of-plane bending of TF coil may be acceptable, thereby precluding or minimizing the need for substantial torque resisting structures such as frames or shear panels. 


\subsection{REFERENCES}

1. Chapin, D. L, "TNS Engineering Trade Study Analyșis," WFPS-TME-069, October, 1977.

2. Varljen, T. C., et al., "Engineering Parameters for Four Ignition TNS Tokamak Reactor Systems," WFPS-TME-058, October, 1977.

3. Flanagan, C. A., ed., "Four Ignition TNS Tokamak Reactor Systems Design Summary," WFPS-TME-071, Westinghouse Fusion Power Systems, October, 1977 .

4. Howland, H. R. and T. C. Varljen, "An Approach to Decision Modeling For An Ignition Test Reactor,: WFPS-TME-066, October, 1977.

5. Cohn, D. R., R. R. Parker, and D. L. Jassby, "Characteristics of High Density Tokamak Ignition Reactors," Nuclear Fusion, 16 (1), 1976, pp. 31-35.

6. Attenberger, S. E., et al., "Dynamics of Tokamak Plasma Experiments and Reactors," ORNL/TM-5509, Oak Ridge National Laboratory, November, 1976.

7. McAlees, D. G., "Alpha Particle Energetic and Neutral Beam Heating in Tokamak Plasmas," ORNL/TM-4661, Oak Ridge National Laboratory, November, 1974.

8. Anderson, 0. A., and H. P. Furth, "Imperfect Axisymmetry in the Tokamak Configuration," Nuclear Fusion, 12, 1972, pp. 207 - 213.

9. Peng, M., private communication, June, 1977.

10. Jassby, D. L., private communication, July, 1977.

11. Sink, D. A. and E. M. Iwinski, "A Computer Code for the Costing and Sizing of TNS Tokamaks," Proceedings of the Seventh Symposium on Engineering Problems of Fusion Research, Knoxville, TN, October $25-28,1977$.

12. Brentari, E. G., and R. V. Smith, "Nucleate and Film Pool Boiling Design Correlations for $\mathrm{O}_{2}, \mathrm{~N}_{2}, \mathrm{H}_{2}$ and He," International Adv. Cry. Eng., Vol. 10, 1965 , p. 325.

13. Schauer, W., "Conductor Materials for Cryomagnets," 5th Int1. Conf. on Magnet Tech. (MT-5) April, 1975.

14. National Bureau of Standards, Technical Note 648, U. S. Dept. of Commerce, 1973.

15. Clark, J. A., "Heat Transfer," in Cryogenic Technology, R, W. Vance, ed, Wiley \& Sons, 1963. 


\section{EXTERNAL DISTRIBUTION}

1. Anderson, J.L., Los Alamos Scientific Laboratory, P.O.Box 1663, Los Alamos NM 87545.

2. Anthony, D.J., General Electric Co., Schenectady NY 12345.

3. Baker, C.C., Argonnë Näfional Tabörátöry, 9700 S. Cass Avive. Aŕgonne IL 60439 .

4. Berry, L.A., Oak Ridge National Laboratory, P.O.Box 4, Oak Ridge TN 37830

5. Bishop, A.A., Nuclear Engineering Programs Director, Chemical Engineering Dept., University of Pittsburgh, Pitrsburgh PA 15261.

6. Bogart, S.L., U.S. Dept. of Energy, Div. of Magnetic Fusion Energy, Mail Stop G-234, Washington DC 20545.

7. Buchsbaum, S.J. , Bell Laboratories, Crawford Corner Road, Hoimdel NJ 07733.

8. Bussard, R.W., Energy Resources Group, Inc., 1500 Wilson Blvd. , Suite 505, Arlington VA 22209.

9. Choo, Yung-An, Nuclear Science and Engineering Div., Carnegie-Mellon University, Schenley Pork, Pitrsburgh PA 15213.

10. Cherdack, R.N., Burns \& Roe, Inc. , 283 Highway 17, Paramus NJ 07652.

11. Clarke, J.F., U.S. Dept. of Energy, Div. of Magnetic Fusion Energy, Woshington DC 20545.

12. Coffman, F.E., U.S. Dept. of Energy, Div. of Magnetic Fusion Energy, Mail Stop G-234, Washington DC 20545.

13. Cohn, D.R., Francis Bitter Laboratory, MIT, 120 Albony St. , Cambridge MA 02139.

14. Conn, R.W., Nuclear Engineering Dept., University of Wisconsin, Madison WI 53706.

15. Geutz, E.C., National Science Foundation, 1800 G Street, N.W., Washington DC 20440.

16. Cullingford, H.S., U.S. Dept. of Energy, Div. of Mognetic Fusion Energy, Mail Stop G-234, Washington DC 20545.

17. Dovidson, R.C., U.S. Dept. of Energy, Div. of Magnetic Fusion Energy, Mail Stop G-234, Washington DC 20545.

18. Davies, N.A., U.S. Dept. of Energy, Div. of Magnetic Fusion Energy, Mail Stop G-234, Washington DC 20545.

19. Dean, S.O., U.S. Dept. of Energy, Div. of Mognetic Fusion Energy, Mail Stop G-234, Washington DC 20545.

20. Favale, A., Grumman Aerospace Corp., Bethpoge NY 11714.

21. Fernbock, S., Lowrence Livermore Laboratory, Livermore CA 94551.

22. von Fischer, E., Bechrel Corp., P. O. Box 3965, San Francisco CA 94119.

23. Forsen, H.K., Exxon Nuclear Co., 777 106th Ave. N.E., Bellevue WA 98004.

24. Fowler, T.K., University of Californio, Lawrence Livermore Lab, $\bar{P} .0 . \bar{B}$. 808 , Livermore CA $9455 \mathrm{i}$.

25. Furth, H.P. , Pinceton Plasma Physies Laboratory, Ainceton University, P. O. Box 451, Pinceton NJ 08540.

26. Gottlieb, M.B., Princeton Plasma Physics Laboratory, Princeton University, P.O. Box 451, Pinceton NJ 08540.

27. Gough, W. C., DOE Office, Electric Power Research Institute, Palo Alto, CA 94304

28. Grace, J. Neison, U.S. Dept. of Energy, Div. of Magnetic Fusion Energy, Mail Stop G-234, Washington DC 20545.

29. Harder, R., General Atomic Co., P.O. Box 81608, San Diego CA 92138.

30. Henning, C.D., University of California, Lawrence Livermore Laboratory, P. O. Box 808 , Livermore CA 94551.

31. Hess, G.K., U.S. Dept. of Energy, Div. of Mognetic Fusion Energy, Washington DC 20545.

32. Hill, A.G., Plasma Fusion Center, Room 4-232, Massochusetts Institute of Technology, 77 Massochusetts Ave., Cambridge MA 20139.

33. Hirsch, R.L., Exxon Research \& Engineering, Box 101, Florham Park NJ 07932.

34. Kammash, T., The University of Michigan, College of Engineering, Dept. of Nucloar Engineering, Ann Arbor Ml 48109.

35. Kintner, E.E., U.S. Dept. of Energy, Div. of Mognetic Fusion Energy, Moil Stop G-234, Washington DC 20545 


\section{EXTERNAL DISTRIBUTION}

36. Kulcinski, G., Nuclear Engineering Dept., University of Wisconsin, Madison W1 53706.

37. Kummer, D., McDonnell Dougias, P. O. Box 516, St. Lovis MO 63166.

38. Maroni, V.A., Argonne National Laboratory, 9700 S. Coss Ave., Argonne IL 60439.

39. Meade, D.M., Ainceton Plasmo Physics Laboratory, Pinceton University, P. O. Box 451, Princeton NJ 08540.

40. Miley, G.H., Nuclear Engineering Program, 214 Nucleor Engineering Loboratory, University of lllinois, Utbana IL 61801 .

41. Mills, R., Princeton Plasmo Laboratory, Princeton University, P. O.Box 451; Princeton NJ 08540.

42. Morgan, O.B., Oak Ridge National Laboratory, P. O. Box 4, Ook Ridge TN 37830

43. Moses, K., U.S. Dept. of Energy, Div. of Magnetic Fusion Energy, Mail Stop G-234, Washington DC 20545.

44. Murphy, M.R., U.S. Dept. of Energy, Div. of Mognetic Fusion Energy, Mail Stop G-234, Washington DC 20545.

45. Noymark, S., Nuclear Services Corp., 1700 Dell Ave., Compbell CA 95008.

46. Neff, J.O., U.S. Dept. of Energy, Div. of Mognetic Fusion Energy, Mail Stop G-234, Washington DC 20545.

47. Ohkawo, T., General Atomic Co., P.O. Box 608, Son Diego CA 92112.

48. Powell, J., Brookhoven National Laborotory, Upton, Long Island NY 11973.

49. Purcell, J.R., General Atomic Co., P.O. Box 608, San Diego CA 92112.

50. Roberts, M., Oak Ridge National Laboratory, P. O. Box 4, Oak Ridge TN 37830. (15 copies)

51. Reardon, P.J., Pinceton Plasma Physics Laborotory, Princeton University, P.O. Box 451, Pinceton NJ 08540.

52. Rose, D.J., Dept. of Nuclear Engineering, Massachusetts Institute of Technol ogy, Cambridge MA 02139.

53. Soger, P., General Atomic Co., P. O. Box 608, San Diego CA 92112.

54. Sowyer, G.A., Los Alamos Scientific Laboratory, P. O. Box 1663, Los Alamos NM 87545.

55. Schmid, L.C., Pacific Northwest Leboratories, Battelle Blvd., P. O. Bbx 999 ; Richiand WA 99352.

56. Schul.tz, M.A., Nuclear Engineering Dept., The Pennsylvania State University, 231 Sackett Building, University Park PA 16802.

57. Stacey, Weston M., Jr., Georgia Institute of Technology, Atlonto GA 30332.

58. Steiner, D., Oak Ridge National Laboratory, P. O. Box 4, Oak Ridge TN 37830.

59. Stickley, C.M., U.S. Dept.of Energy, Div.of Laser Fusion, Weshington DC 20545.

60. Taylor, C.E., Lowrence Livermore Loboratory, Mail Code L-384, P. O. Box 808, Livermore CA 94550.

61. Teofilo, V. . Pacific Northwest Laboratories, Battelle Blvd.,.P. O. Box 999 , Richland WA 99352.

62. Thomassen, K., Lowrence Livermore Laboratory, P. O.Box 808, Livermore CA 94550.

63. Trivelpiece, A.W., Engineering \& Research, Maxwell Laboratories, Inc., 9244 Balboo Ave., San Diego CA 92123.

64. Williams, J.M., U.S. Dept.of Energy, Div. of Magnetic Fusion Energy, Mail Stop. G-234, Woshington DC 20545.

65. Woodson, H.H., Department of Electrical Engineering, University of Texas, Austin TX 78712.

66. Yoshikawa, H., Westinghouse Hanford Co., P.O. Box 1970, Richland WA 99352.

67. Zwilski, K., U.S. Dept. of Energy, Div. of Magnetic Fusion Energy, Moil Stop G-234, Washington DC 20545.

68. U. S. Department of Energy, Technical Information Center, Post Office Box 62, Oak Ridge TE 37830.

69. Mox-Planck-Institut für Plasmaphysiks, 8046 Garching bei München, West Germeny, ATTN: D. L. Johannsen

70. Ribe, F., University of Washington, MS FL-10, Seattle, WA: 98195

71. Amherd, N., Electric Power Research Institute, 3412 Hillview Ave., P. O. Box 10412, Polo Alto, CA 94304

72. Scott, F. R., Electric Power Research Institute, 3412 Hillview Ave., P. O. Box 10412 , Polo Alto, CA 94304

73. French, J. W. Ebosco Services, Ine., TFTR Project, P. O. Box 451, Piniceton, NJ 08540

74. Houbenreich, P. N., Ook Ridge Notional Laboratory, P. O. Box Y, Oak Ridge, TN 37830

75. Shannon, T. E., Oak Ridge National Laboratory, P. O. Box Y., Oak Ridge, TN 37830

76. Peng, Y. M., Oak Ridge National Laboratory, P. O. Box Y, Oak Ridge, TN 37830

77. Jensen, B. K., Public Service Eleetric and Gas Research Corp., 80 Park Ploce.

Newark, NJ 07101 